\title{
Bush Canal Floodgate Study
}

Tate O. McAlpin, Rutherford C. Berger, and Amena M. Henville

July 2009

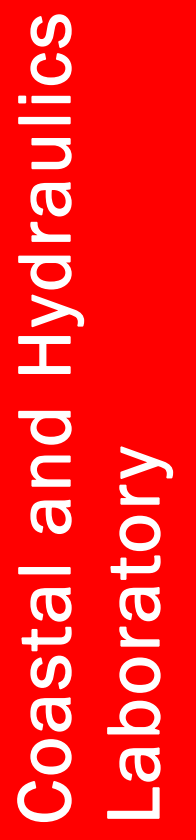





\title{
Bush Canal Floodgate Study
}

\author{
Tate O. McAlpin and Rutherford C. Berger
}

Coastal and Hydraulics Laboratory

U.S. Army Engineer Research and Development Center

3909 Halls Ferry Road

Vicksburg, MS 39180

Amena M. Henville

U.S. Army Engineer District New Orleans

7400 Leake Ave.

New Orleans, LA 70118-3651

Final report

Approved for public release; distribution is unlimited.

Prepared for U.S. Army Engineer District New Orleans 7400 Leake Ave.

New Orleans, LA 70118-3651

Under Military Interdepartmental Purchase Request (MIPR) W42HEM60734548, "H\&H Modeling of Bush Canal/Morganza to the Gulf" 


\begin{abstract}
The ADaptive Hydraulics model, ADH, was used to investigate the circulation tendencies in and around Bush Canal by utilizing its twodimensional shallow-water module. This study characterizes existing water levels and currents in the vicinity of Bush Canal and predicts any potential impacts that may result from the construction of a structure in Bush Canal near its junction with Bayou Terrebonne. Comparing modelgenerated currents and water-surface elevations between pre- and postconstruction conditions provides insight into whether a particular alternative will adversely impact velocity conditions. $\mathrm{ADH}$ was used to develop time series of current fields for the base and plan conditions.
\end{abstract}

DISCLAIMER: The contents of this report are not to be used for advertising, publication, or promotional purposes. Citation of trade names does not constitute an official endorsement or approval of the use of such commercial products. All product names and trademarks cited are the property of their respective owners. The findings of this report are not to be construed as an official Department of the Army position unless so designated by other authorized documents. 


\section{Contents}

Figures and Tables......................................................................................................................

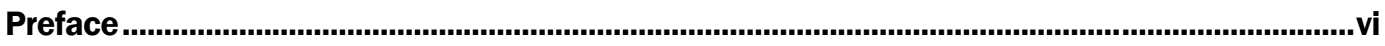

Unit Conversion Factors................................................................................................................ti

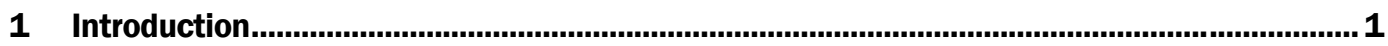

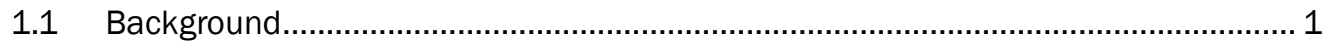

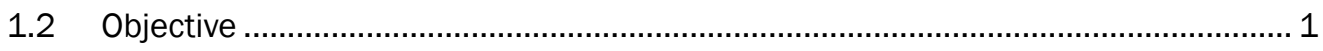

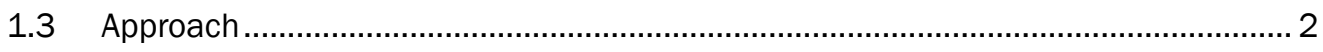

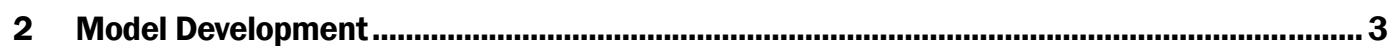

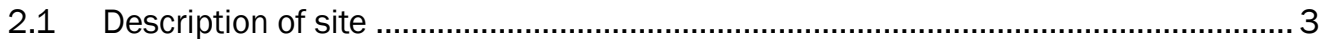

2.2 Field data

2.2.1 Water surface elevation data ............................................................................ 4

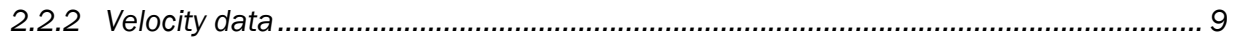

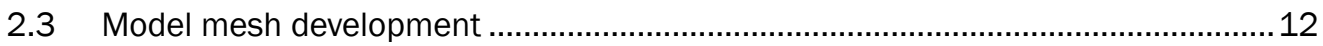

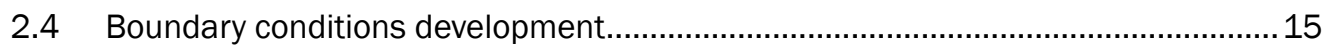

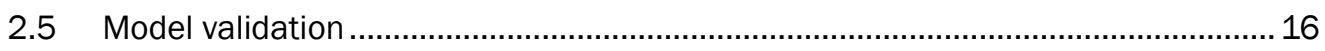

2.5.1 Water surface elevation validation …………………………………………...... 16

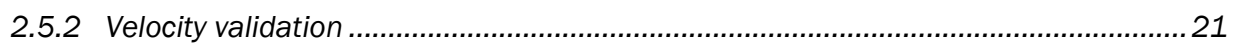

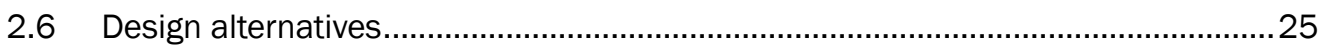

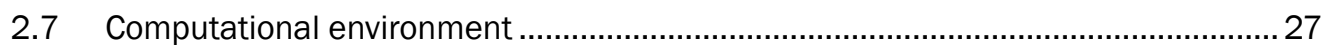

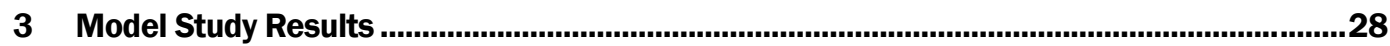

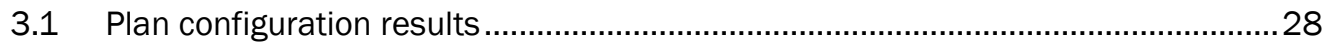

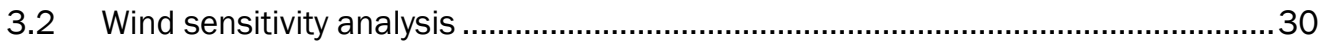

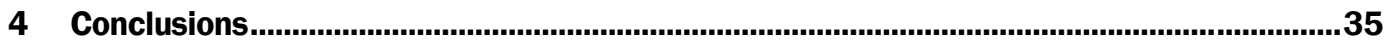

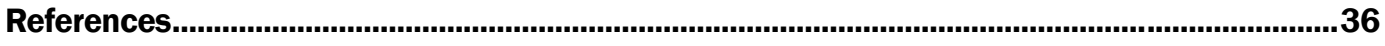

Appendix: Description of the ADaptive Hydraulics (ADH) Model....................................................37

\section{Report Documentation Page}




\section{Figures and Tables}

\section{Figures}

Figure 1. The proposed levee alignment (red line) with the proposed structure locations (yellow circles). Source: Google Maps.

Figure 2. Study area. Source: Google Maps. .................................................................................. 3

Figure 3. Location of the water surface elevation gages Source: Google Maps................................. 4

Figure 4. Graph of the raw and filtered field data from the Cocodrie gage........................................ 5

Figure 5. Graph of the raw and filtered data from the Bush Canal gage............................................ 6

Figure 6. Graph of the raw and filtered data from the Lake Boudreaux gage.................................... 6

Figure 7. Graph of the raw and filtered data from the Bayou Petit Caillou gage.................................. 7

Figure 8. Graph of the raw and filtered data from the Bayou Terrebonne gage. ................................ 7

Figure 9. Graph of the raw and filtered data from the Madison Bay gage. ....................................... 8

Figure 10. Graph of the raw and filtered data from the Humble Canal gage...................................... 8

Figure 11. Locations of the velocity meters. Source: Google Maps. ................................................ 9

Figure 12. Locations of the ADCP transects. Source: Google Maps. ............................................ 10

Figure 13. Plot of adjusted and unadjusted velocity meter measurements for Bush Canal............ 11

Figure 14. Plot of adjusted and unadjusted velocity meter measurements for Bush Canal. ........... 12

Figure 15. Initial RMA2 mesh developed for previous study, with current study area indicated.......................................................................................................................................... 13

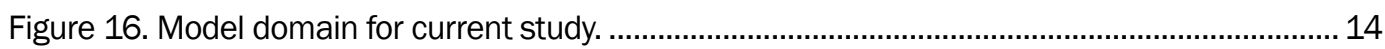

Figure 17. Illustration of increased resolution in the study area.................................................. 14

Figure 18. Mesh showing the tidal boundary ............................................................................ 15

Figure 19. Comparison of model results and predicted tide at Port Fourchon................................. 16

Figure 20. Unadjusted filtered data and the model data for Cocodrie........................................... 17

Figure 21. Adjusted filtered data and the model data for Cocodrie............................................... 18

Figure 22. Filtered data and the model data for Bush Canal. ........................................................ 18

Figure 23. Filtered data and the model data for Lake Boudreaux................................................ 19

Figure 24. Filtered data and the model data for Bayou Petit Caillou. .............................................. 19

Figure 25. Filtered data and the model data for Bayou Terrebonne...............................................20

Figure 26. Filtered data and the model data for Madison Bay.......................................................2 20

Figure 27. Filtered data and the model data for Humble Canal. ...................................................... 21

Figure 28. Model velocity results and the ADCP measurements for Bayou Terrebonne. .................. 22

Figure 29. Model velocity results and the ADCP measurements for Bush Canal...............................2 22

Figure 30. Model velocity results and the ADCP measurements for Bayou Petit Caillou south of Bush Canal.

Figure 31. Model velocity results and the ADCP measurements for Bayou Petit Caillou North of Boudreaux Canal. 
Figure 32. Model velocity results and the velocity meter measurements for lower Bayou Petit Caillou.

Figure 33. Model velocity results and the adjusted velocity meter measurements for Bush Canal.

Figure 34. Model velocity results and the adjusted velocity meter measurements for Bayou Terrebonne. 25

Figure 35. Efficient sail-through structure with efficient sluice gates.............................................26

Figure 36. Less-efficient sail-through structure with efficient sluice gates. ..................................... 26

Figure 37. Maximum velocities in the sail-through structure; positive is flood direction.....................28

Figure 38. Maximum model velocities in the sail-through structure............................................... 29

Figure 39. Velocity Vectors and Contours for Alternative 5 ............................................................30

Figure 40. Location of USGS gage for wind data. ..................................................................... 31

Figure 41. Wind data for the Bayou Petit Caillou USGS gage (USGS 07381343) for 2006............ 31

Figure 42. Maximum velocities for Alternative 5, with wind..........................................................32

Figure 43. Maximum velocities for Alternative 5, without wind.....................................................32

Figure $44.90^{\text {th }}$ percentile velocities for Alternative 5, with wind..................................................33

Figure $45.90^{\text {th }}$ percentile velocities for Alternative 5, without wind. ..............................................33

Figure 46. Wind data during maximum velocity model results. ..........................................................34

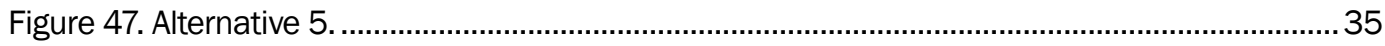

\section{Tables}

Table 1. Plan Alternatives. 


\section{Preface}

This study was conducted for the U.S. Army Engineer District, New Orleans (CEMVN) under Military Interdepartmental Purchase Request (MIPR) W42HEM60734548, "H\&H Modeling of Bush Canal/Morganza to the Gulf," dated 15 March 2006. Project coordination at New Orleans District was provided by Ms. Amena M. Henville (CEMVN-ED-H).

The work described herein and the preparation of this report were performed from May 2006 through December 2008 by the U.S. Army Engineer Research and Development Center Coastal and Hydraulics Laboratory (ERDC-CHL), Vicksburg, MS. The work was performed under the general supervision of Mr. Thomas Richardson, Director, ERDC-CHL, and Dr. William Martin, Deputy Directory, ERDC-CHL. Direct supervision was provided by Mr. Bruce Ebersole, Chief, Flood and Storm Protection Division, CEERD-HF; and Dr. Robert McAdory, Chief of the Estuarine Engineering Branch, CEERD-HF-E. Mr. Tate O. McAlpin, CEERD-HF-E, and Dr. Rutherford C. Berger, CEERD-HF-E, conducted this study and prepared the report.

At the time of publication of this report, COL Gary E. J ohnston, USA, was Commander and Executive Director of ERDC, and Dr. J ames R. Houston was the Director. 


\section{Unit Conversion Factors}

\begin{tabular}{|l|c|l|}
\hline Multiply & By & To Obtain \\
\hline cubic feet & 0.02831685 & cubic meters \\
\hline cubic inches & $1.6387064 \mathrm{E}-05$ & cubic meters \\
\hline cubic yards & 0.7645549 & cubic meters \\
\hline degrees (angle) & 0.01745329 & Radians \\
\hline Feet & 0.3048 & Meters \\
\hline foot-pounds force & 1.355818 & Joules \\
\hline Inches & 0.0254 & Meters \\
\hline inch-pounds (force) & 0.1129848 & newton meters \\
\hline Knots & 0.5144444 & meters per second \\
\hline miles (nautical) & 1,852 & Meters \\
\hline miles (U.S. statute) & $1,609.347$ & Meters \\
\hline miles per hour & 0.44704 & meters per second \\
\hline Slugs & 14.59390 & Kilograms \\
\hline square feet & 0.09290304 & square meters \\
\hline square inches & $6.4516 \mathrm{E}-04$ & square meters \\
\hline square miles & $0.589998 \mathrm{E}+06$ & square meters \\
\hline square yards & & square meters \\
\hline Yards & 0.9144 & Meters \\
\hline
\end{tabular}




\section{Introduction}

\subsection{Background}

The U.S. Army Engineer District, New Orleans (MVN) is in the process of determining the correct sizing for sail-through structures to be constructed along the new proposed Morganza to the Gulf levee system in Louisiana. In the aftermath of Hurricane Katrina, numerous new levees are being constructed to reduce the risk of storm surge flooding. To provide the best protection, waterways north of the new levee system will be shut off from the Gulf of Mexico during storm events. In order to accomplish this protection with minimum impact on the natural environment and waterborne transportation, numerous sail-through structures - each capable of being closed as necessary - are being constructed to allow for continued waterborne transportation between the Gulf of Mexico and areas north of the new levee system. These structures will also allow for the continued movement of water to and from the Gulf of Mexico, thereby minimizing the impact of the new levees on natural habitat along the Louisiana coast.

At the request of New Orleans District, the U.S. Army Engineer Research and Development Center (ERDC) performed a number of engineering studies in support of efforts to determine the proper size of one of these proposed structures, to be located on the eastern end of Bush Canal near Bayou Terrebonne. Four additional structures (Humble Canal, Bayou Terrebonne, Lapeyrouse Canal, and Bayou Petit Caillou) are also to be constructed in the same vicinity. The Bush Canal structure will consist of a sector gate structure, with additional sluice gates being added if needed. The proposed levee alignment with all five proposed structure locations is shown in Figure 1.

\subsection{Objective}

The primary objective of this study was to determine the smallest structure that will provide reasonable velocity fields. The modeling approach applied to size the Bush Canal structure will subsequently be used to size the other sail-through structures. 


\subsection{Approach}

Data sources and acquisition, and model development methods using ADaptive Hydraulics numerical model code (ADH), are described in detail in Chapter 2. Several design alternatives were simulated using the validated numerical model.

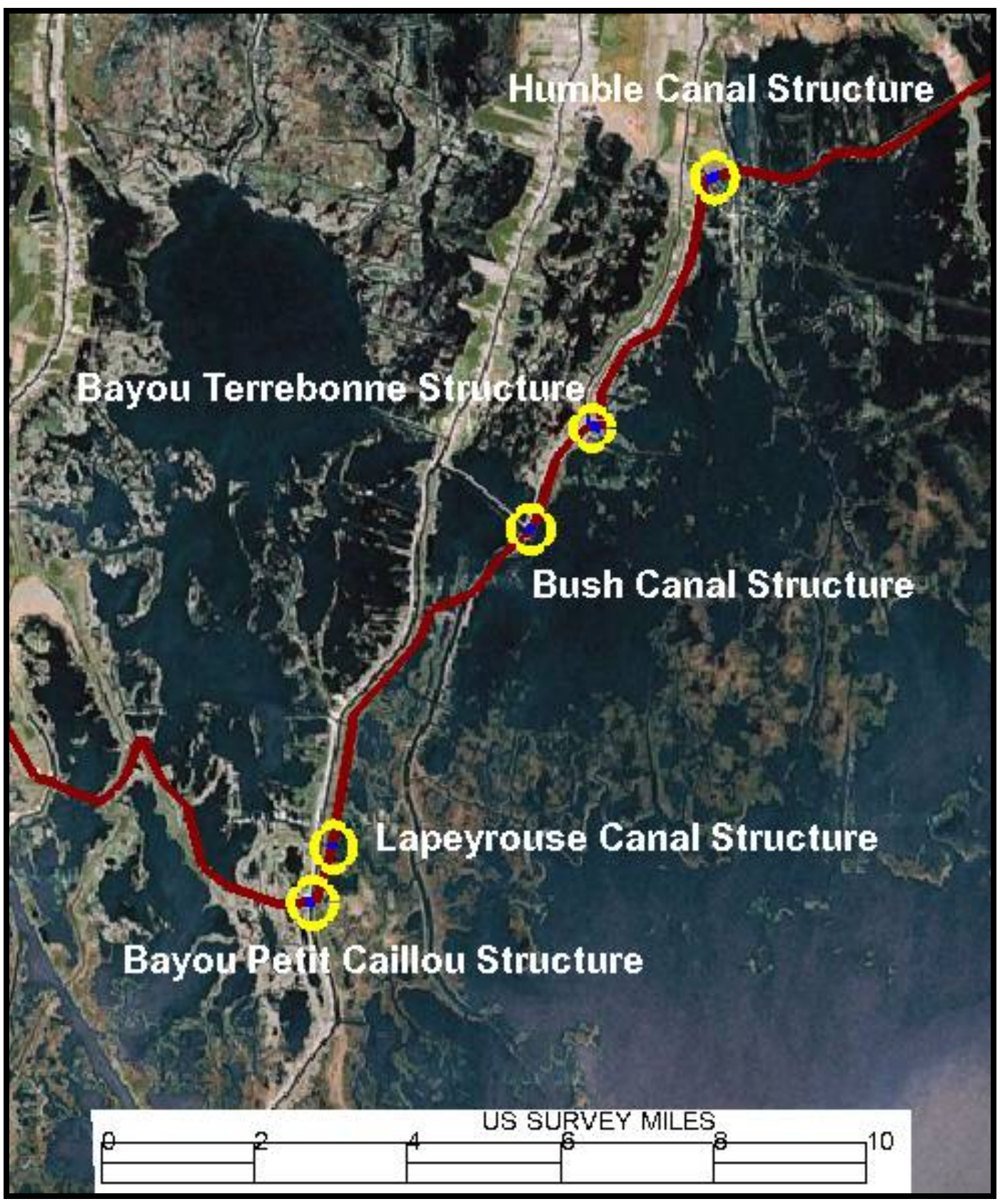

Figure 1. The proposed levee alignment (red line) with the proposed structure locations (yellow circles). Source: Google Maps. 


\section{Model Development}

\subsection{Description of site}

The project is located south of Houma, LA, on the southern coast of Louisiana. The primary waterways of interest are Bayou Petit Caillou, Bayou Terrebonne, and Bush Canal. Bayou Petit Caillou and Bayou Terrebonne lie almost parallel to each other, with approximate north-south orientations. The primary means of waterborne transportation connecting Bayou Petit Caillou and Bayou Terrebonne is Bush Canal. Bayou Petit Caillou extends south to Cocodrie, where it joins the Houma Navigational Canal. It also has connections to the west to Lake Boudreaux and Lake Quitman. Bayou Terrebonne extends south to Lake Barre and has connections to the east to Madison Bay. Bayou Petit Caillou and Bayou Terrebonne join north of the study area and extend northward to join the Gulf Intracoastal Waterway (GIWW) in Houma, LA. The study area is shown in Figure 2.

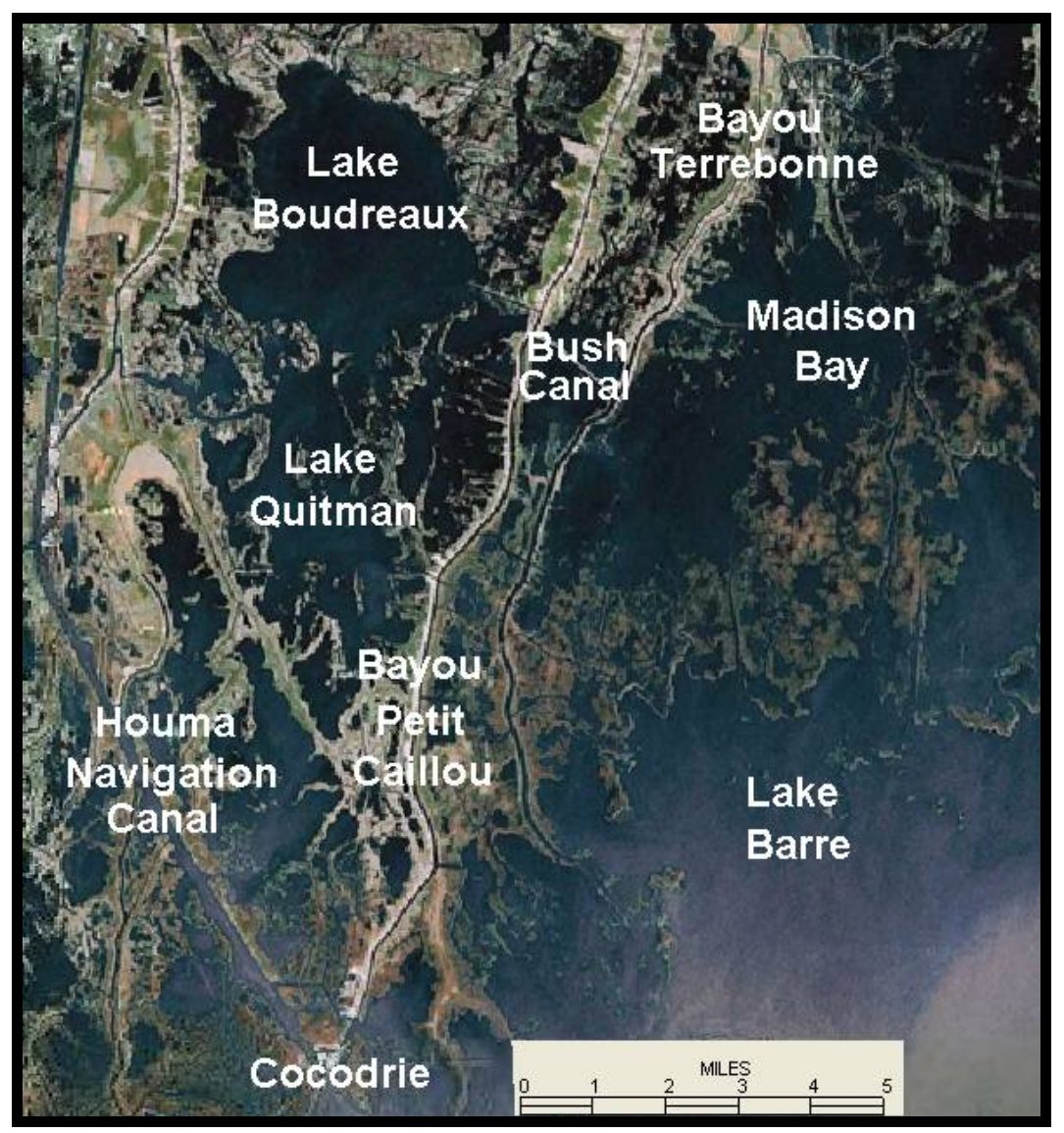

Figure 2. Study area. Source: Google Maps. 


\subsection{Field data}

\subsubsection{Water surface elevation data}

The first field data collection goal for this study was to obtain enough water surface elevation gage data to adequately validate the model water surface elevation results. The validation period for the model was 1 May 2006 to $22 \mathrm{~J}$ uly 2006. MVN maintained several water surface elevation gages located in and around the study area, and varying amounts of data were available for different gages during this validation time period (i.e., some gages recorded data for the entire time period and some recorded data for a shorter duration during this period). These water surface elevation gages were essential to the validation of the model. The gage locations are shown in Figure 3.

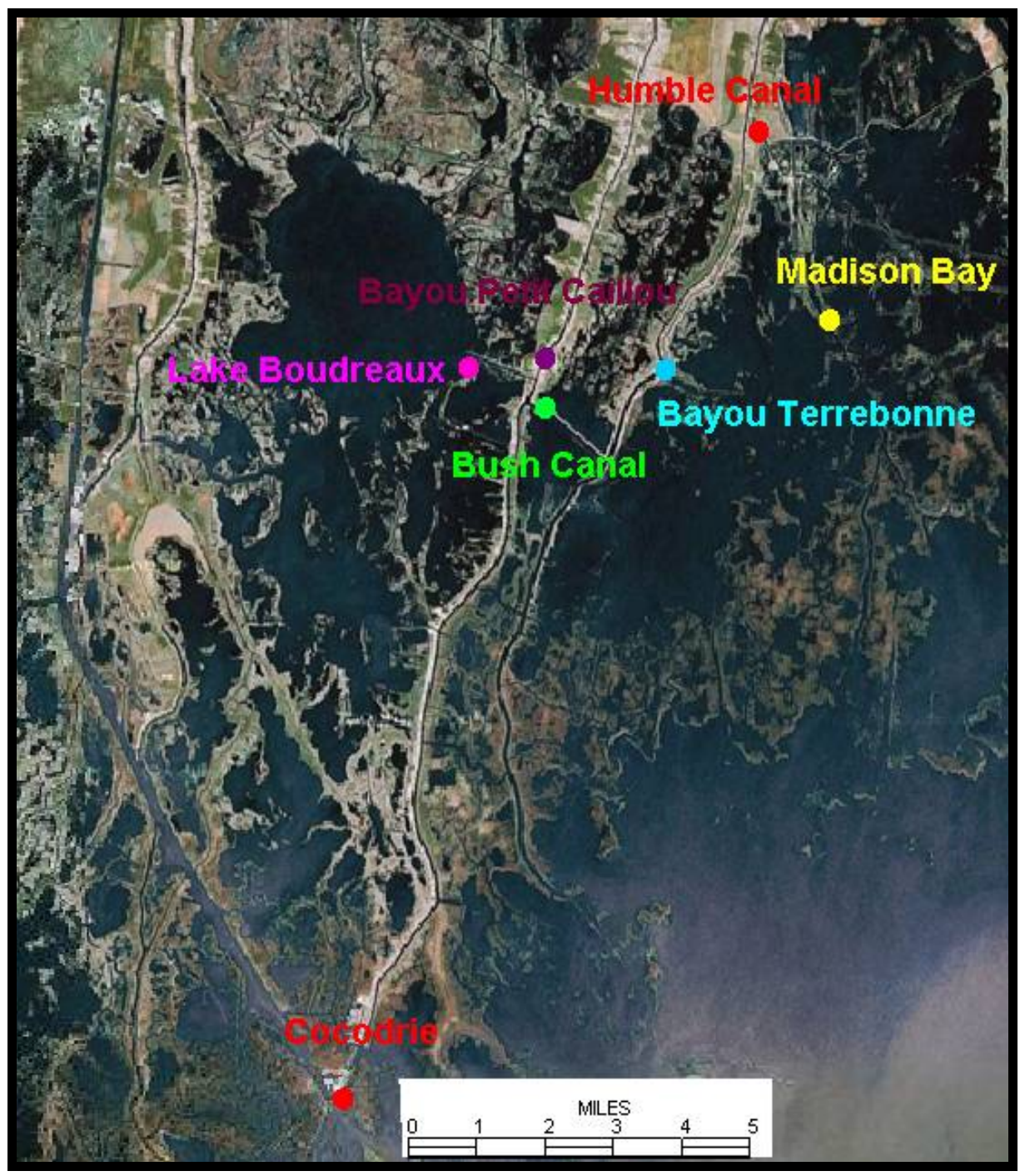

Figure 3. Location of the water surface elevation gages Source: Google Maps. 
From inspection of the water surface elevation data it was determined that the wind had a significant effect on the water surface elevations. To remove this effect, the raw field data were filtered to eliminate any signals that had a period longer than 30 hours. Thus, the longer-period signals (primarily the wind signal) were removed, leaving only the shorter-period signals (primarily the tidal signal). Comparisons of the raw data versus filtered data for each of the gages are shown in Figures 4 - 10.

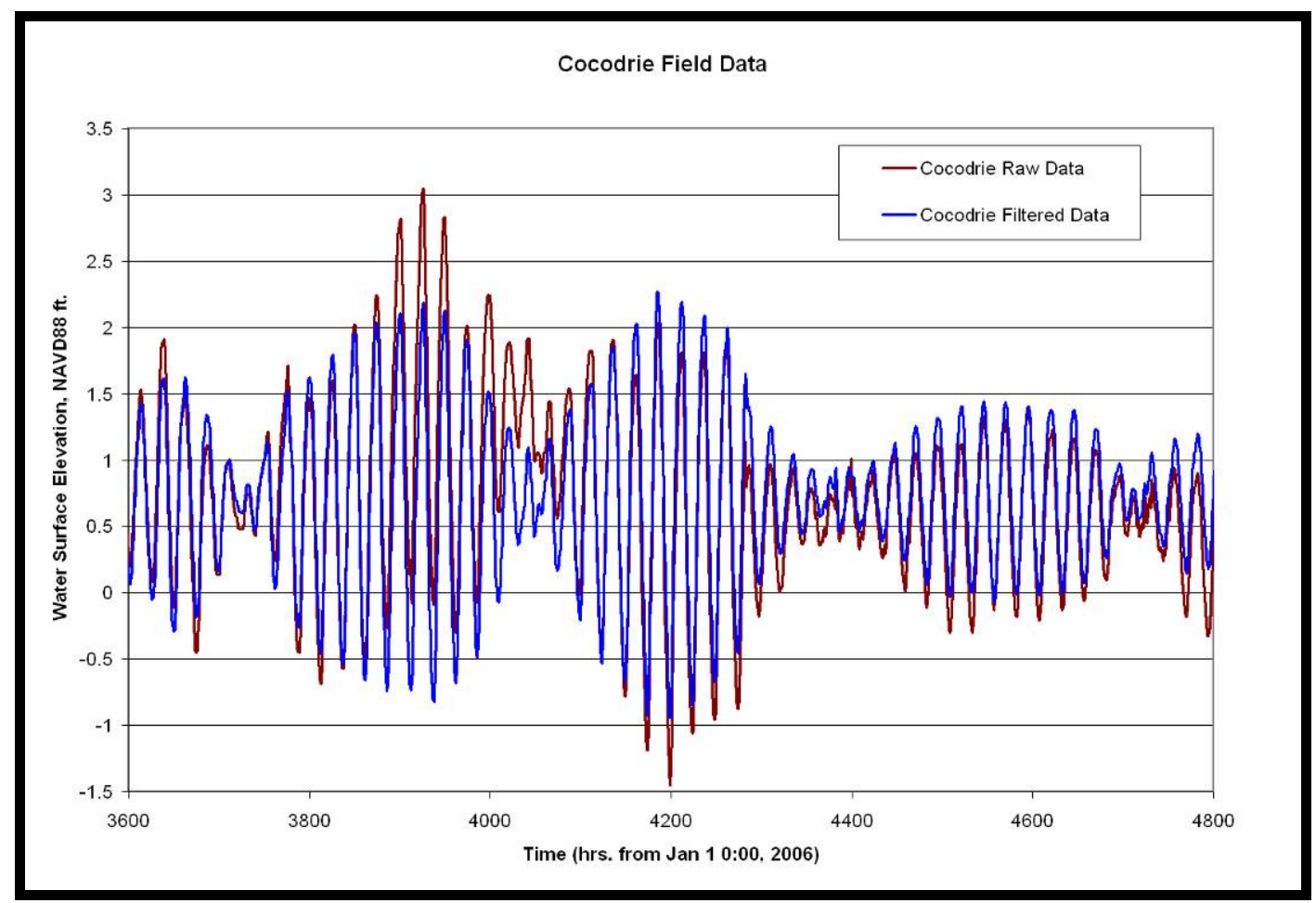

Figure 4. Graph of the raw and filtered field data from the Cocodrie gage. 


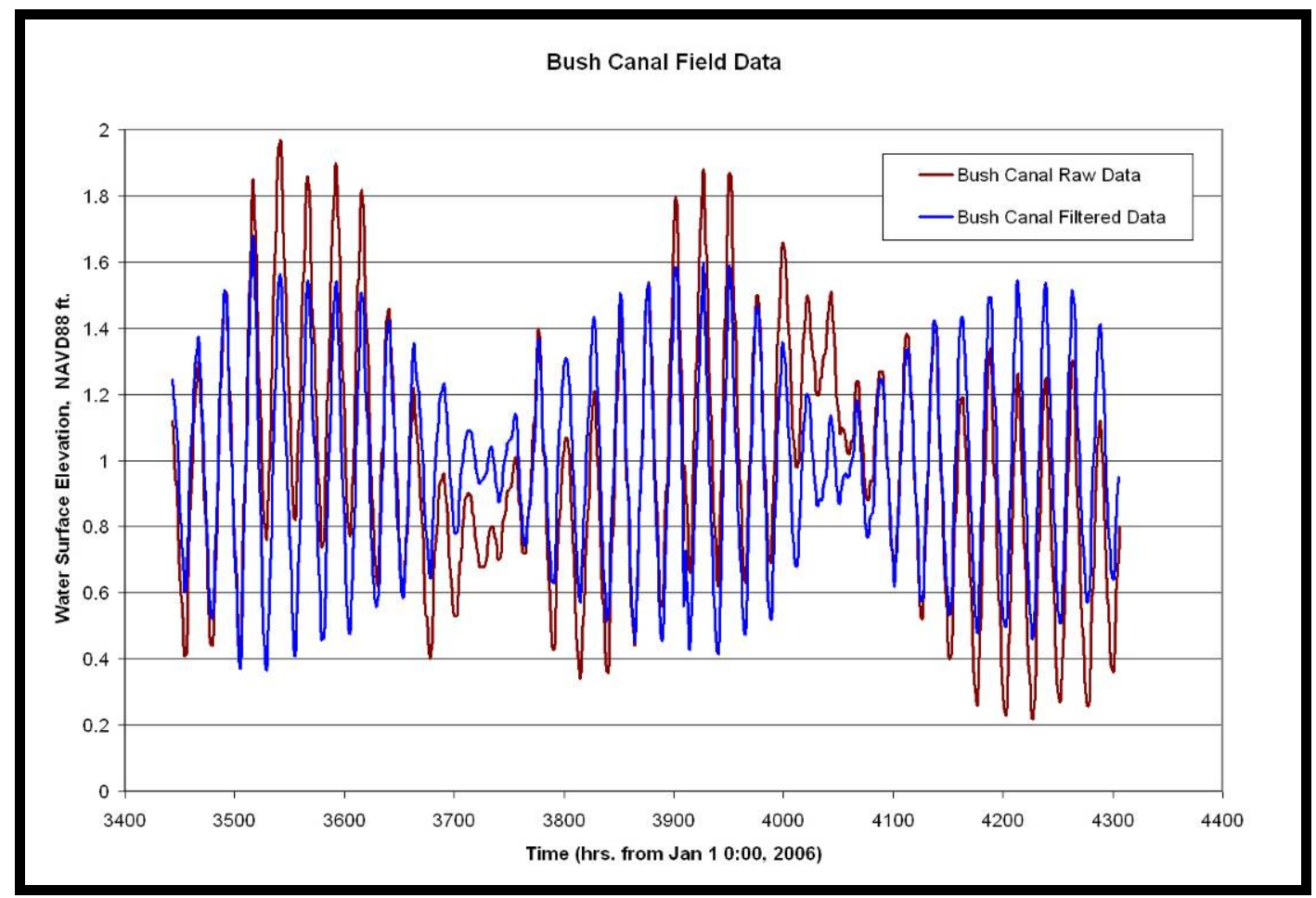

Figure 5. Graph of the raw and filtered data from the Bush Canal gage.

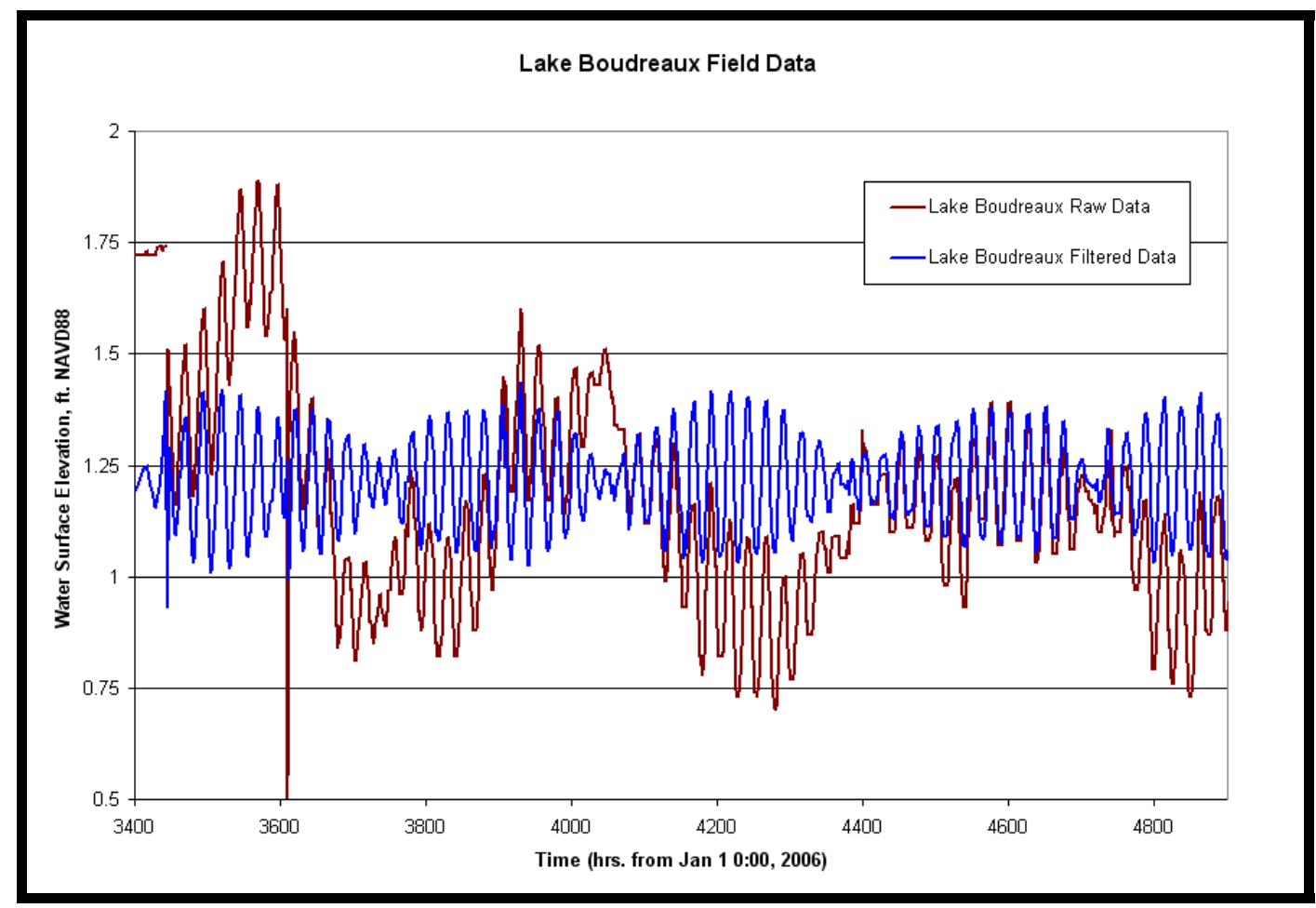

Figure 6. Graph of the raw and filtered data from the Lake Boudreaux gage. 


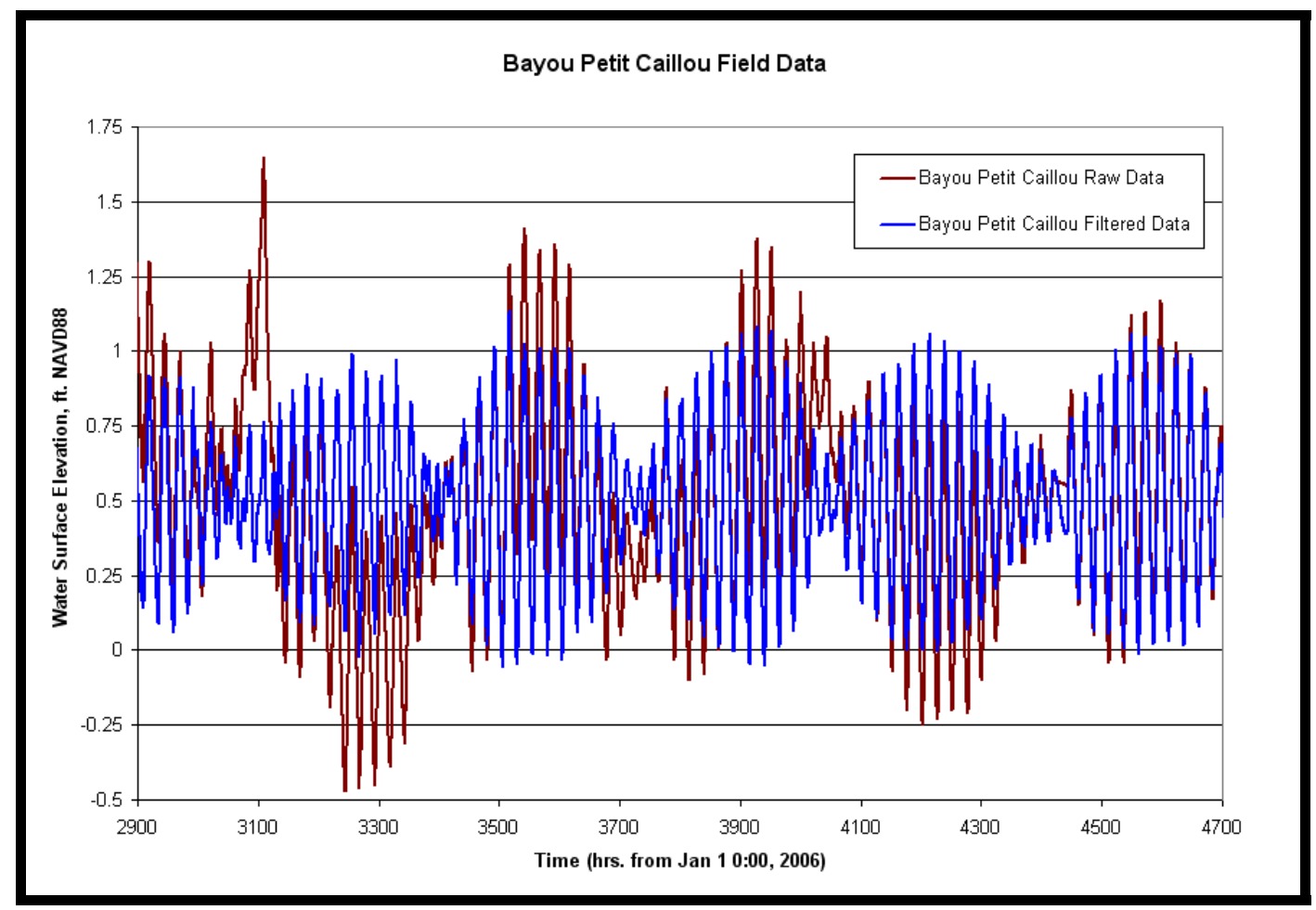

Figure 7. Graph of the raw and filtered data from the Bayou Petit Caillou gage.

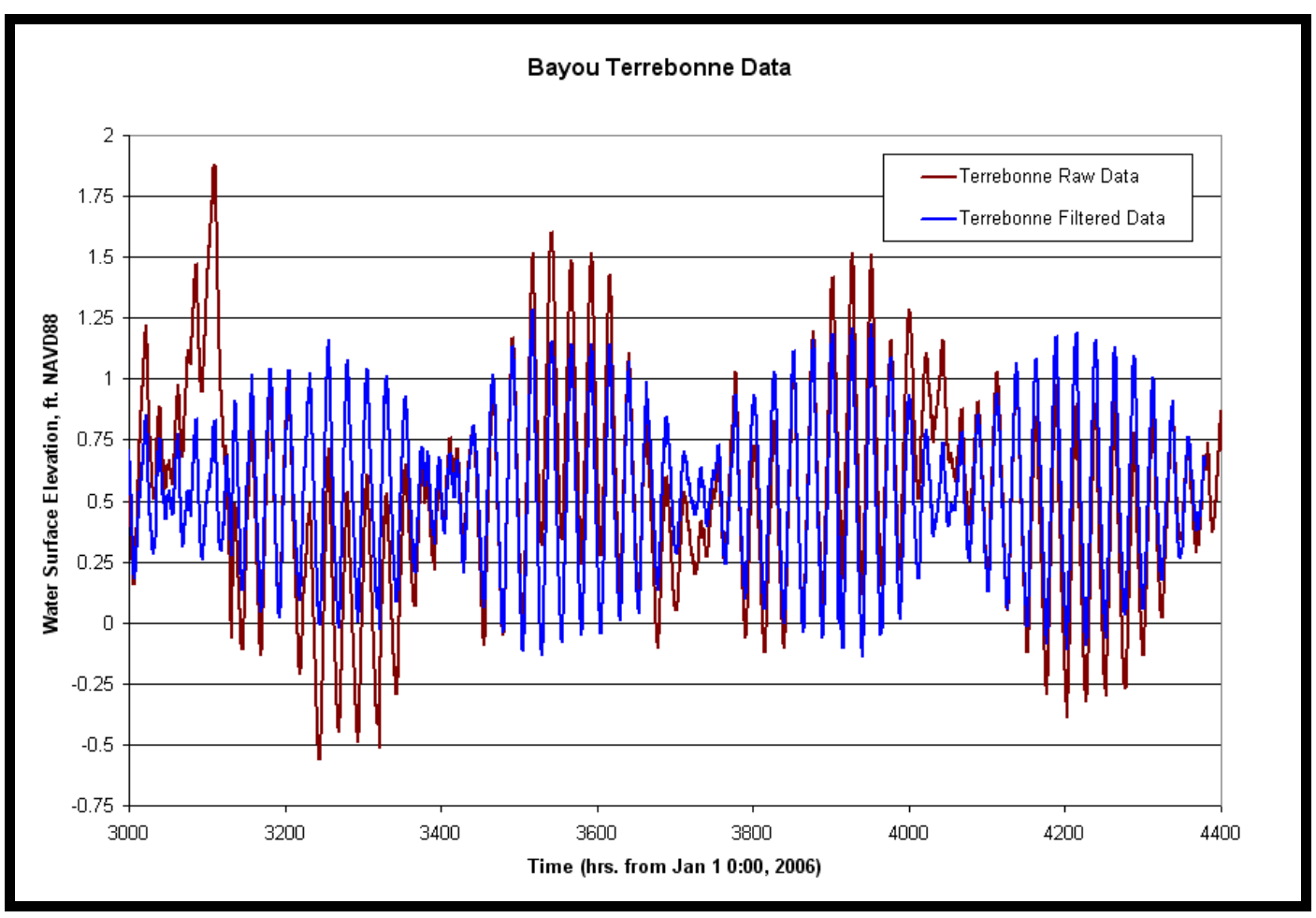

Figure 8. Graph of the raw and filtered data from the Bayou Terrebonne gage. 


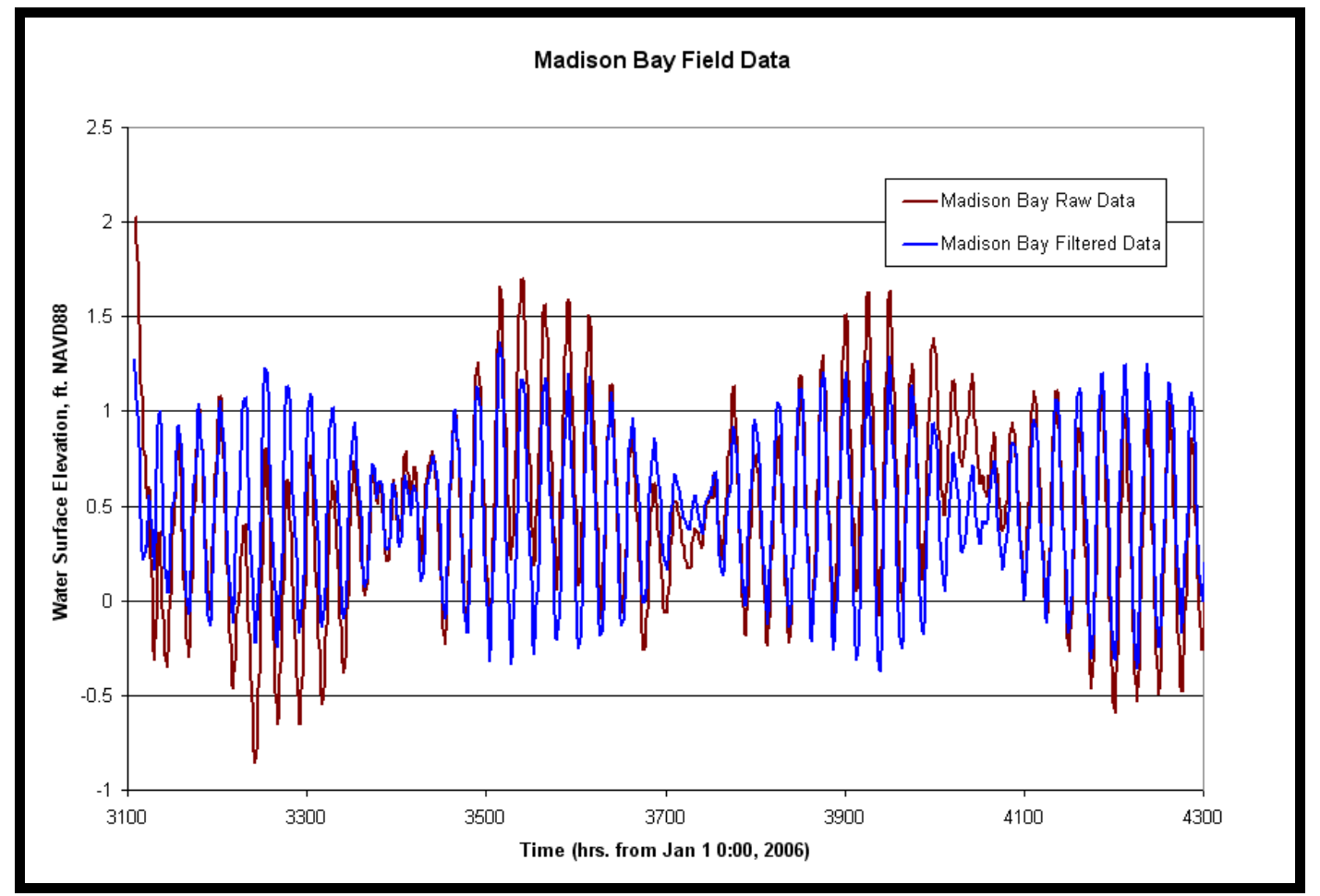

Figure 9. Graph of the raw and filtered data from the Madison Bay gage.

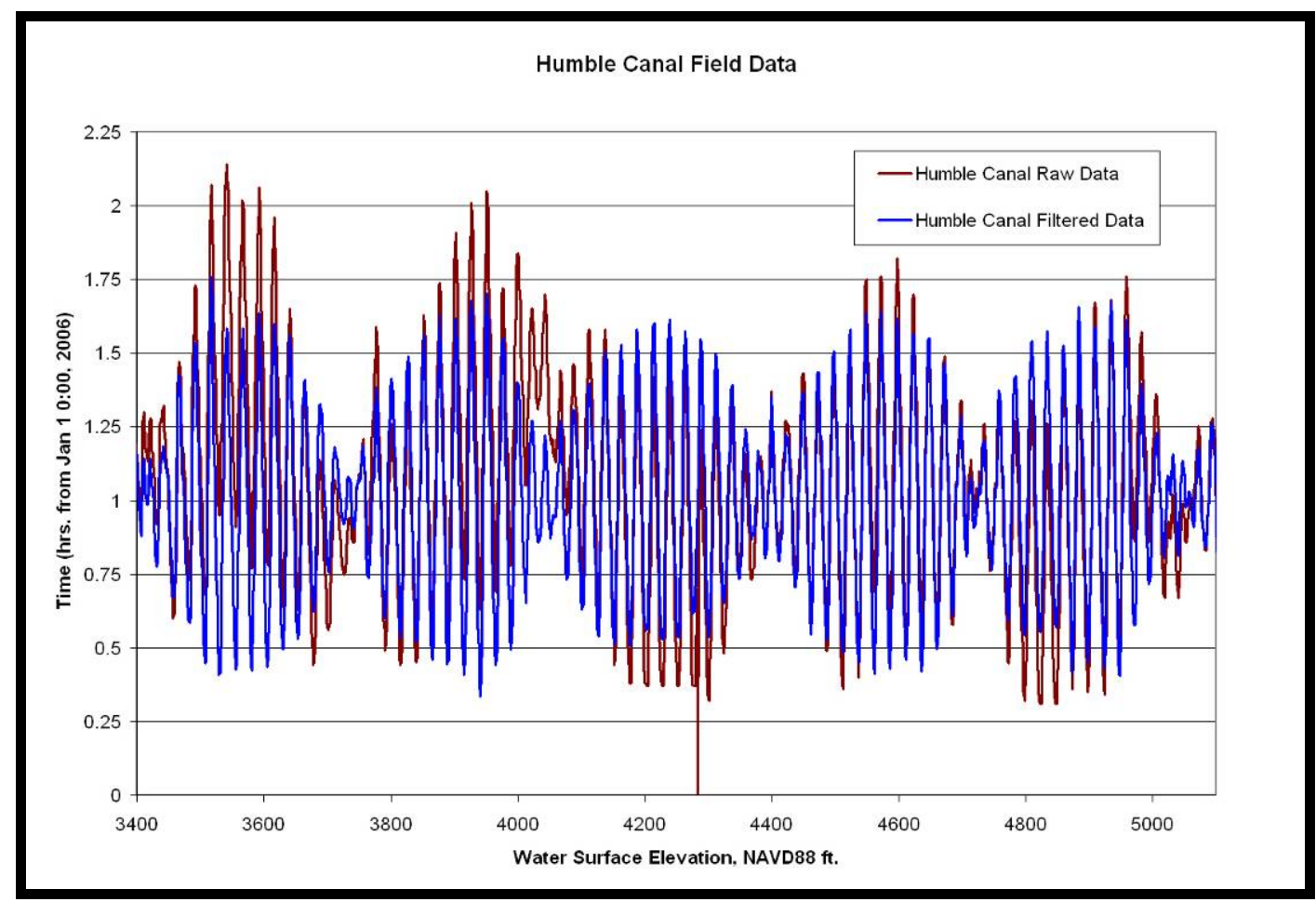

Figure 10. Graph of the raw and filtered data from the Humble Canal gage. 


\subsubsection{Velocity data}

The second data collection goal of this study was met by installing five velocity meters to operate over the same time period that the surface elevation data were collected. The purpose of the velocity meters, located as shown in Figure 11, was to get a better understanding of the flow split along these waterways and provide current velocity data for model validation. The two meters located to the far north on the two bayous (Upper Bayou Terrebonne and Upper Bayou Petit Caillou) were needed to verify that the tide was in fact reaching these locations and that no unknown inflows were affecting the study area. These velocity meter data are plotted in the model validation section (section 2.5, Figures 32 to 34).

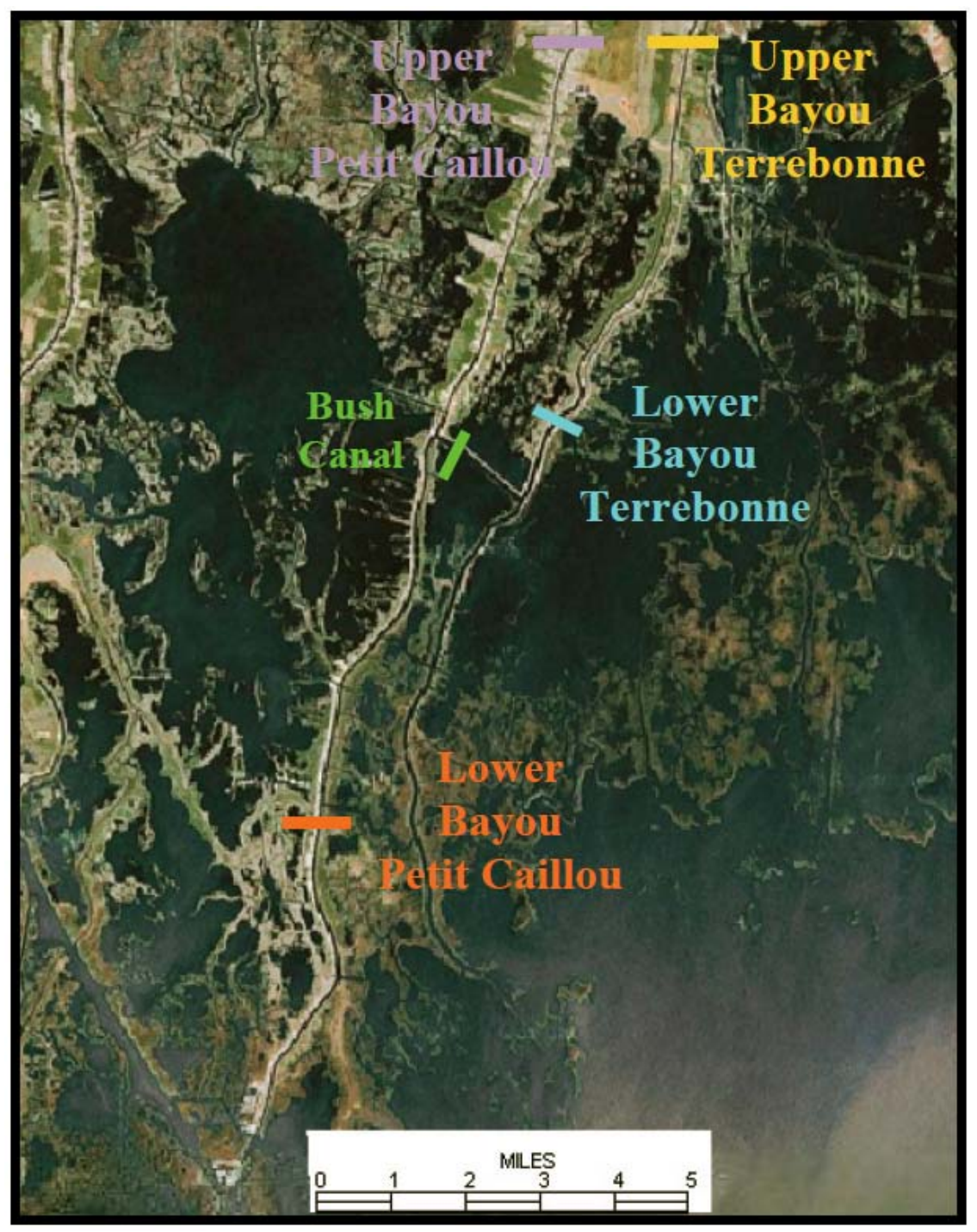

Figure 11. Locations of the velocity meters. Source: Google Maps. 
In addition to the velocity measurements, Acoustic Doppler Current Profile (ADCP) transect measurements were taken on $13 \mathrm{~J}$ uly 2006. The ADCP measurements were taken at least once an hour for eight consecutive hours. The locations for these transects were chosen to allow for a good understanding of the flow splits occurring in and around Bush Canal. These ADCP measurements were used as the primary validation tool for comparison with the model velocities. The ADCP measurements were also used to correlate the velocity meter measurements from Bush Canal and Bayou Terrebonne to an average cross-sectional velocity. The locations of the ADCP transects are shown in Figure 12, and the model data are shown in the model validation section (section 2.5, Figures 28 to 31 ).

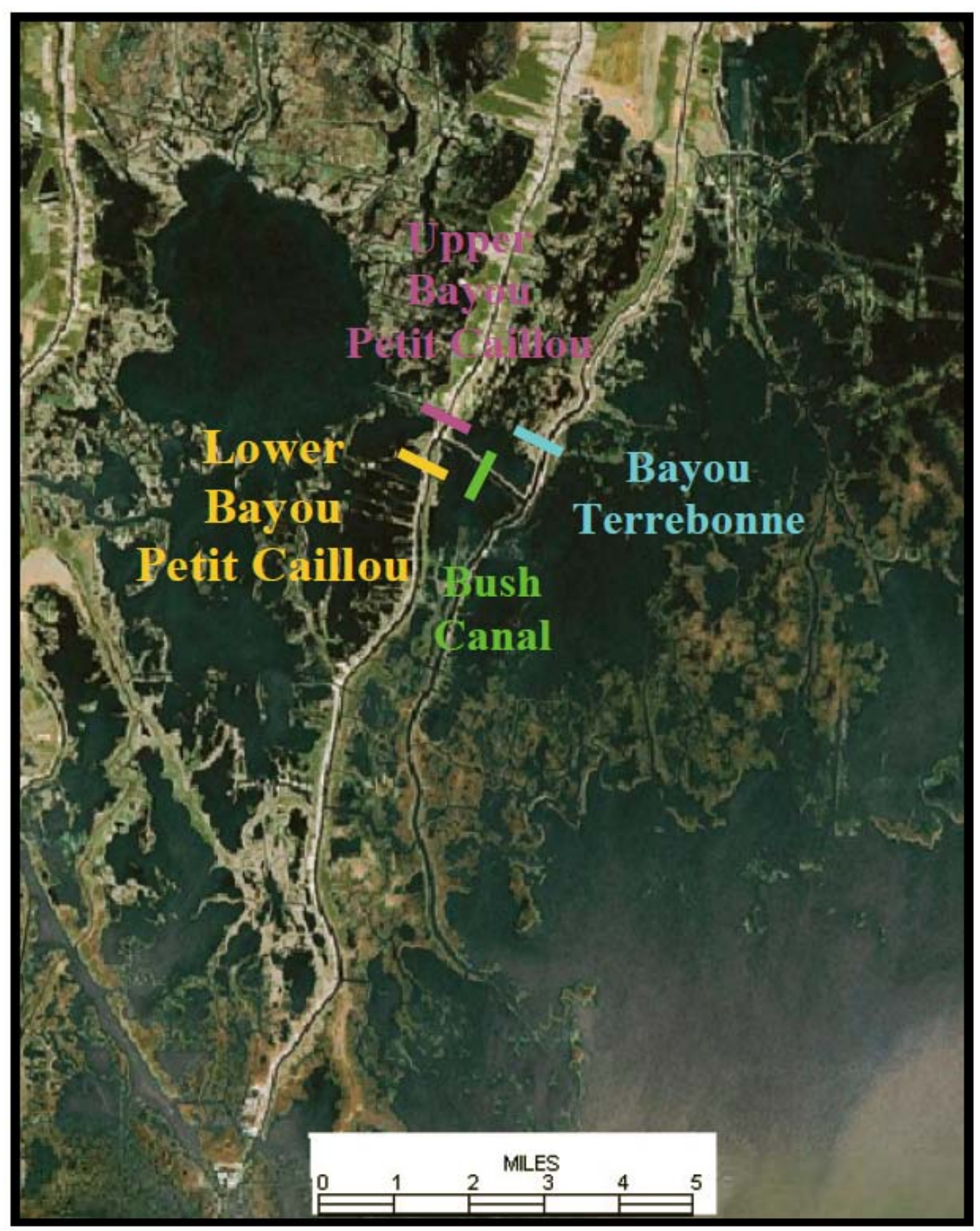

Figure 12. Locations of the ADCP transects. Source: Google Maps. 
The adjustments made to the velocities at Bush Canal and Bayou Terrebonne are shown in Figures 13 and 14. The velocity meter measurements at Bush Canal were increased by a factor of 2.2 while the velocity meter measurements at Bayou Terrebonne were increased by a factor of 3 . These factors were determined by correlating the velocity meter measurements with the cross-sectionally averaged ADCP velocities. By scaling the velocity meter measurements in this way, a larger data set is available for modeldata comparison. The ADCP measurements were relied upon in this way because they are more representative of the overall flow in the canal.

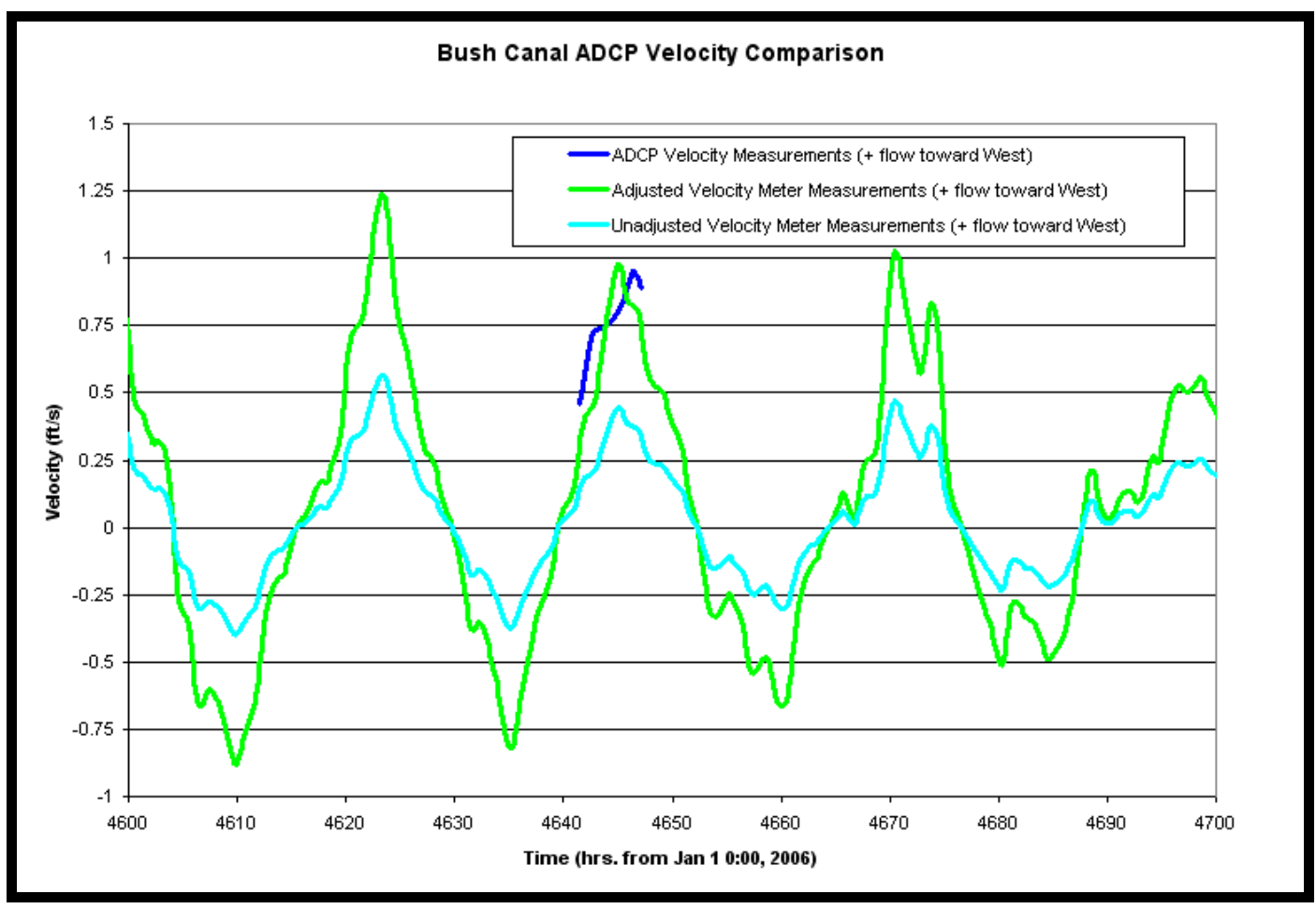

Figure 13. Plot of adjusted and unadjusted velocity meter measurements for Bush Canal. 


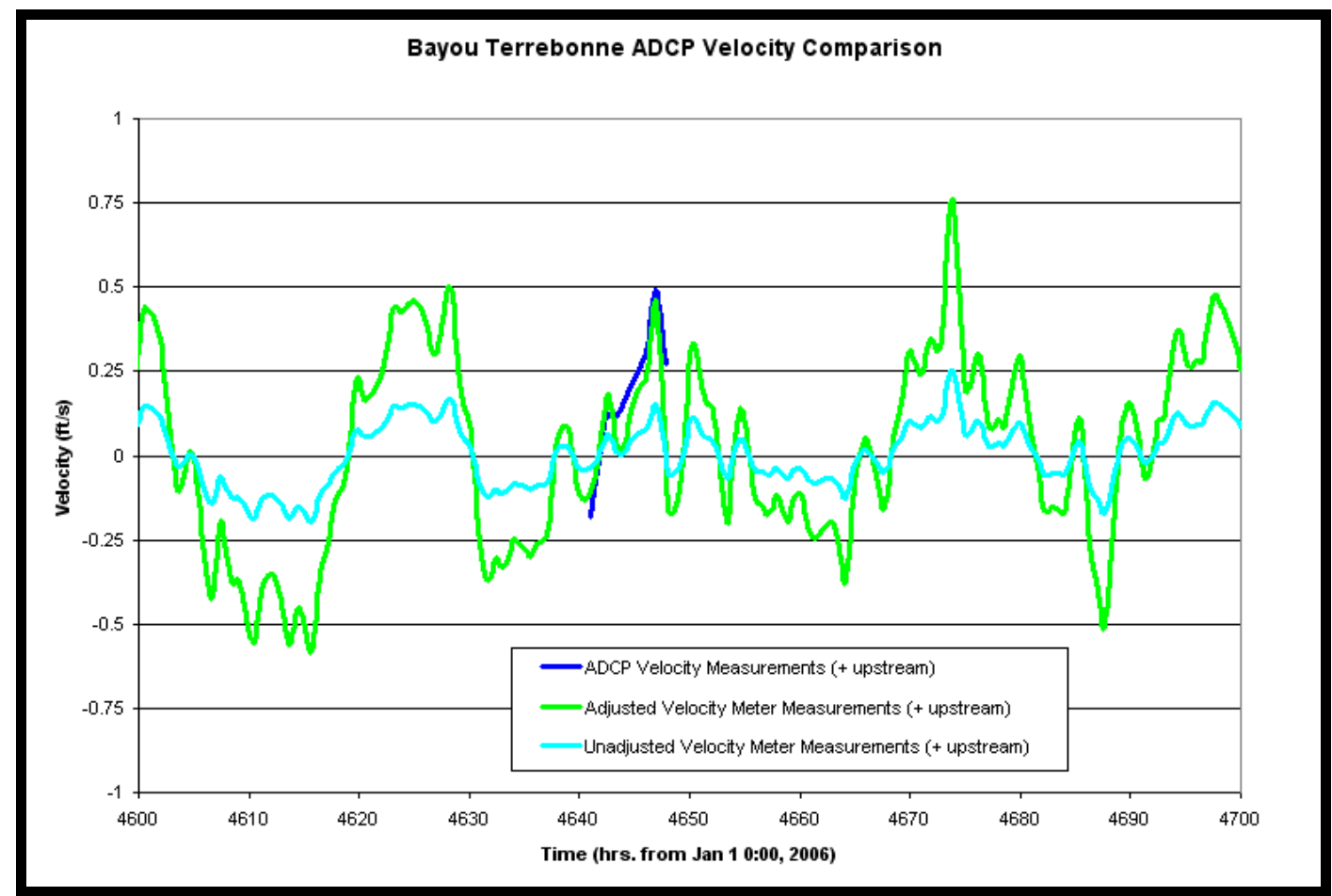

Figure 14. Plot of adjusted and unadjusted velocity meter measurements for Bush Canal.

\subsection{Model mesh development}

The ADaptive Hydraulics numerical model code (ADH) was chosen to model the Bush Canal system (see Appendix). An existing RMA2 mesh of the central southern Louisiana coast was provided by New Orleans District. This initial mesh was created by Mr. J oseph V. Letter, J r., for an Atchafalaya Bay study using RMA2 (Donnell, Letter, and Teeter 1991). It was later modified by Mr. David Elmore and again by Amena Henville (both of New Orleans District) for the Morganza to the Gulf of Mexico project, also using RMA2. This initial mesh, shown in Figure 15, extends from the Atchafalaya Bay to the west to Port Fourchon to the east. It contains a large area to the west of the study area that was not necessary for conducting the current study. 


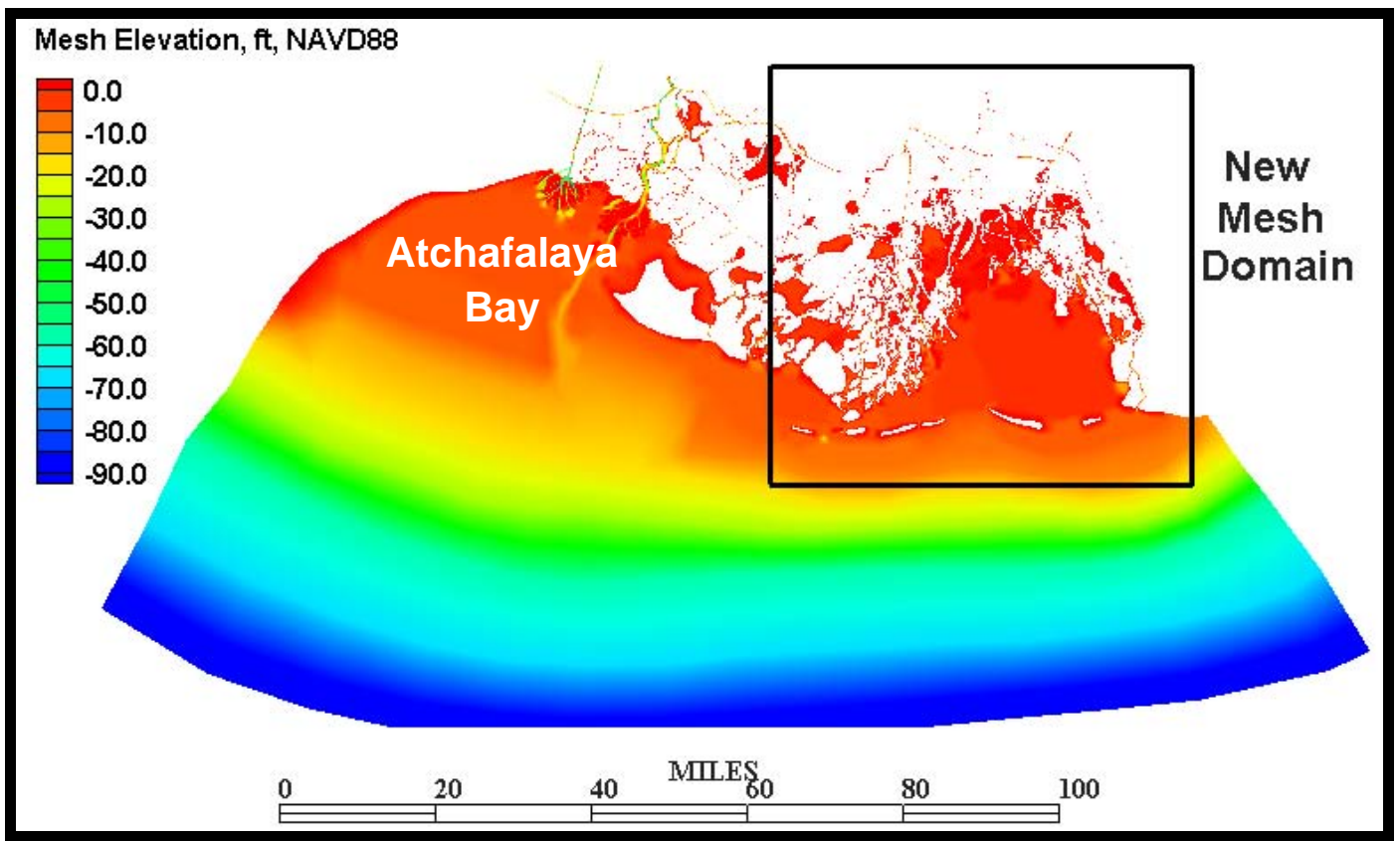

Figure 15. Initial RMA2 mesh developed for previous study, with current study area indicated.

To create the Bush Canal mesh for the current project, the western area outside the greater study location was removed. The mesh was also converted to an $\mathrm{ADH}$-compatible format, which involved converting from quadratic elements used in RMA2 to linear elements for ADH. Because $\mathrm{ADH}$ accepts only triangles, all quadrilaterals in the mesh were converted to triangles. The resolution in the study area was significantly increased. These mesh modifications were performed in the Surface-water Modeling System (SMS) (Brigham Young University 2002), a graphical user interface developed by ERDC for use in setting up and running numerical models. The final model domain used in this study is shown in Figure 16, with Figure 17 showing the increased resolution in the study area. 


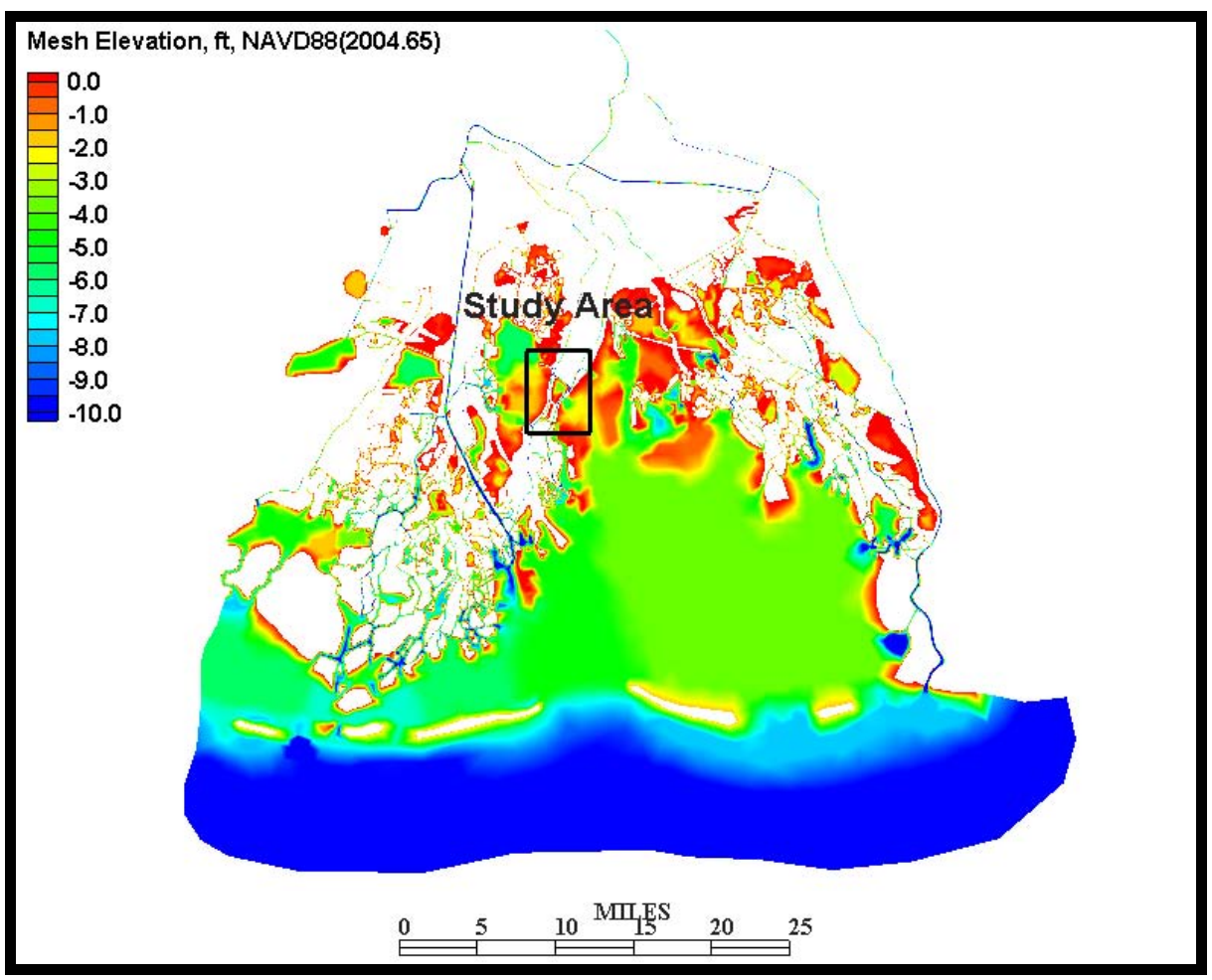

Figure 16. Model domain for current study.

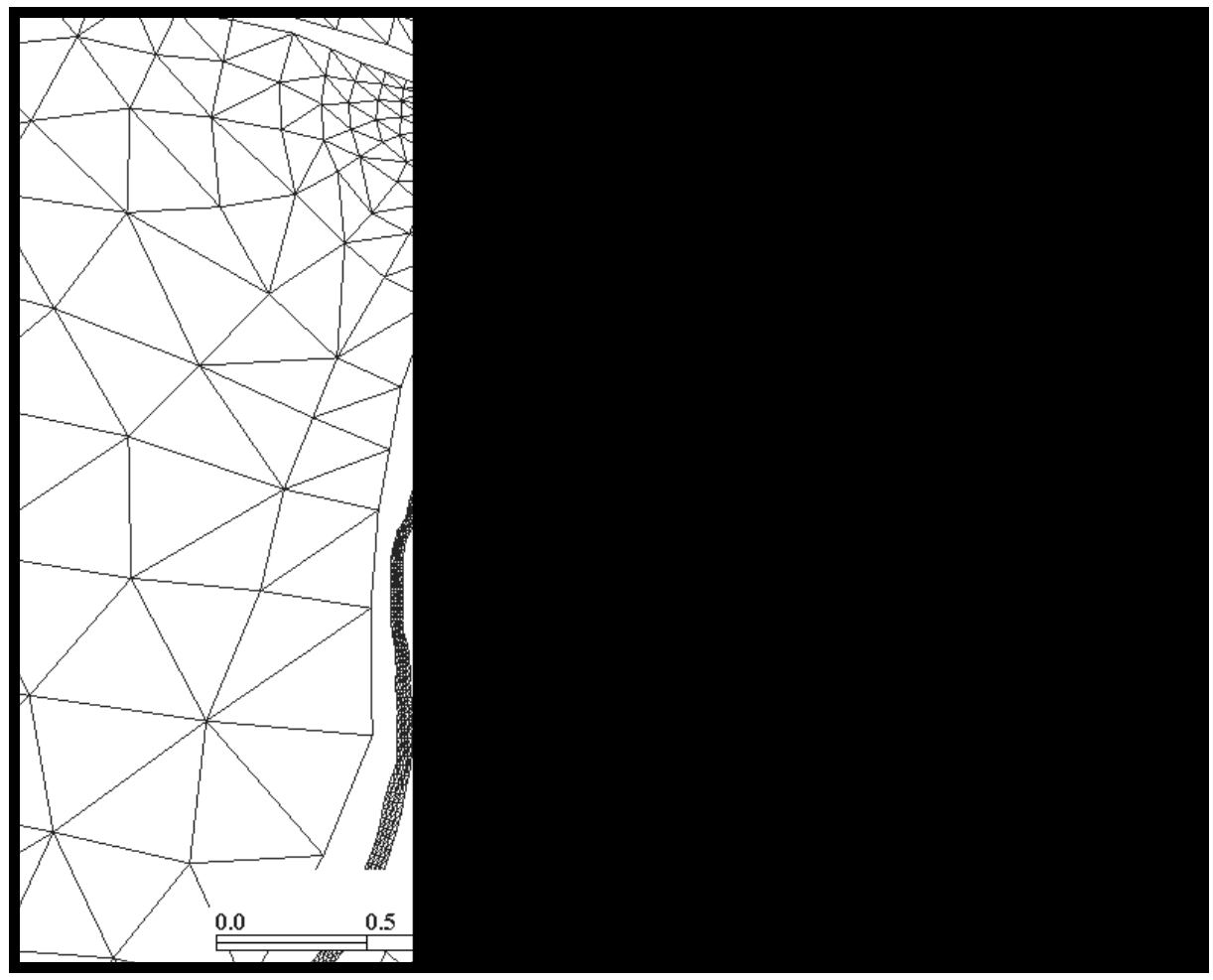

Figure 17. Illustration of increased resolution in the study area. 


\subsection{Boundary conditions development}

Because there were no river inflows, the development of boundary conditions consisted only of the tidal boundary. The predicted tide for Port Fourchon was applied along the southern boundary of the model shown in Figure 18. Wind and rain were not considered in this study, and therefore were not included in the boundary conditions file. The black circle in the lower-right side of Figure 18 shows the location of the Port Fourchon gage.

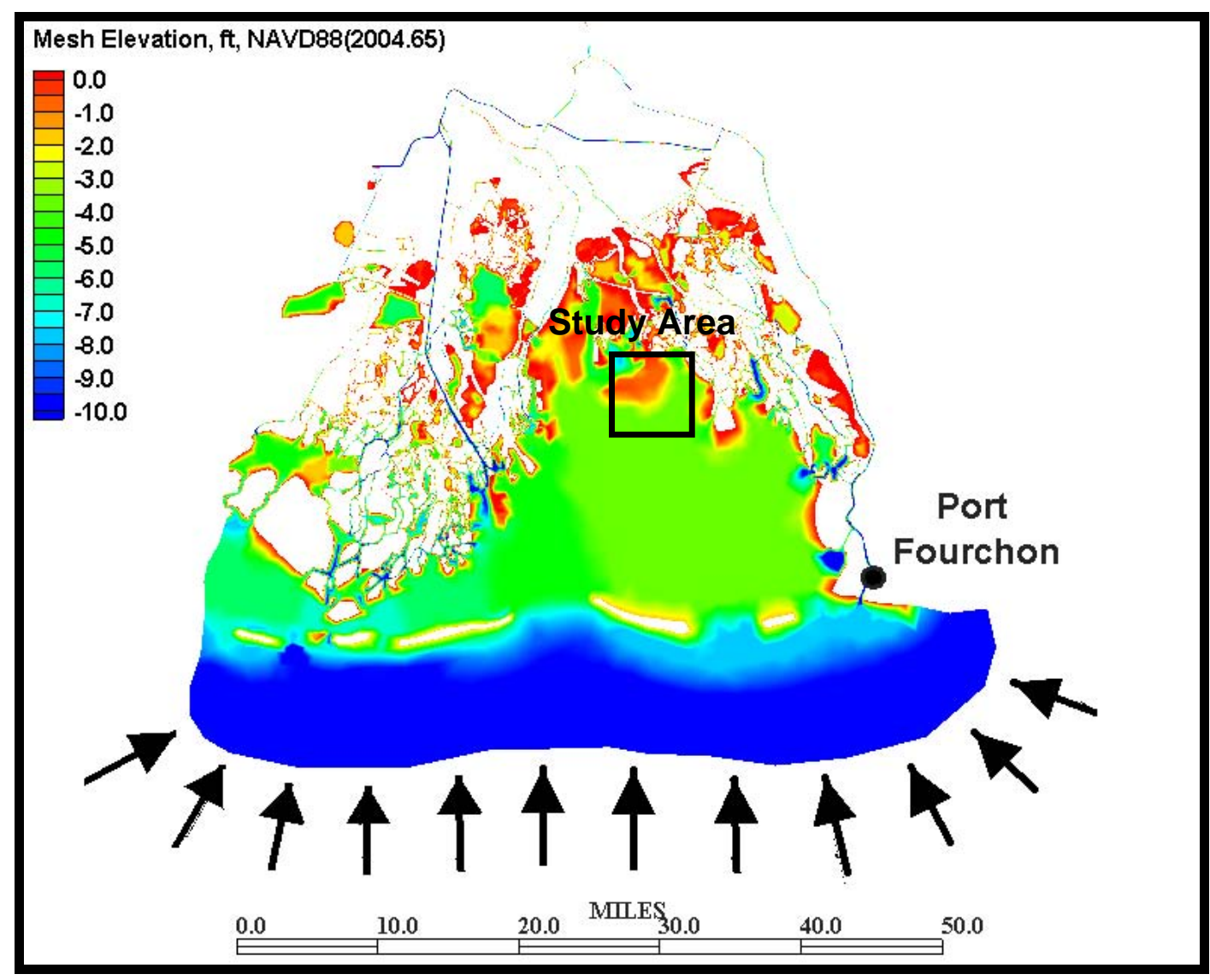

Figure 18. Mesh showing the tidal boundary.

To ensure the validity of applying the Port Fourchon tide along the boundary farther to the south, comparisons were made between the model data at the Port Fourchon gage location and the Port Fourchon predicted tide. This was done to ensure no amplification or phase shift was occurring due to the movement of this tide south to the model boundary location. A graphical comparison (Figure 19) of the model results at Port Fourchon and the predicted tide at Port Fourchon showed no significant difference. Therefore, no significant amplification or phase shift occurs by applying the Port Fourchon predicted tide along the southern boundary of the 
model. This is the expected result since the boundary and the gage are in such close proximity to each other. The predicted Port Fourchon tide was used for the tidal boundary in the base and plan condition model runs.

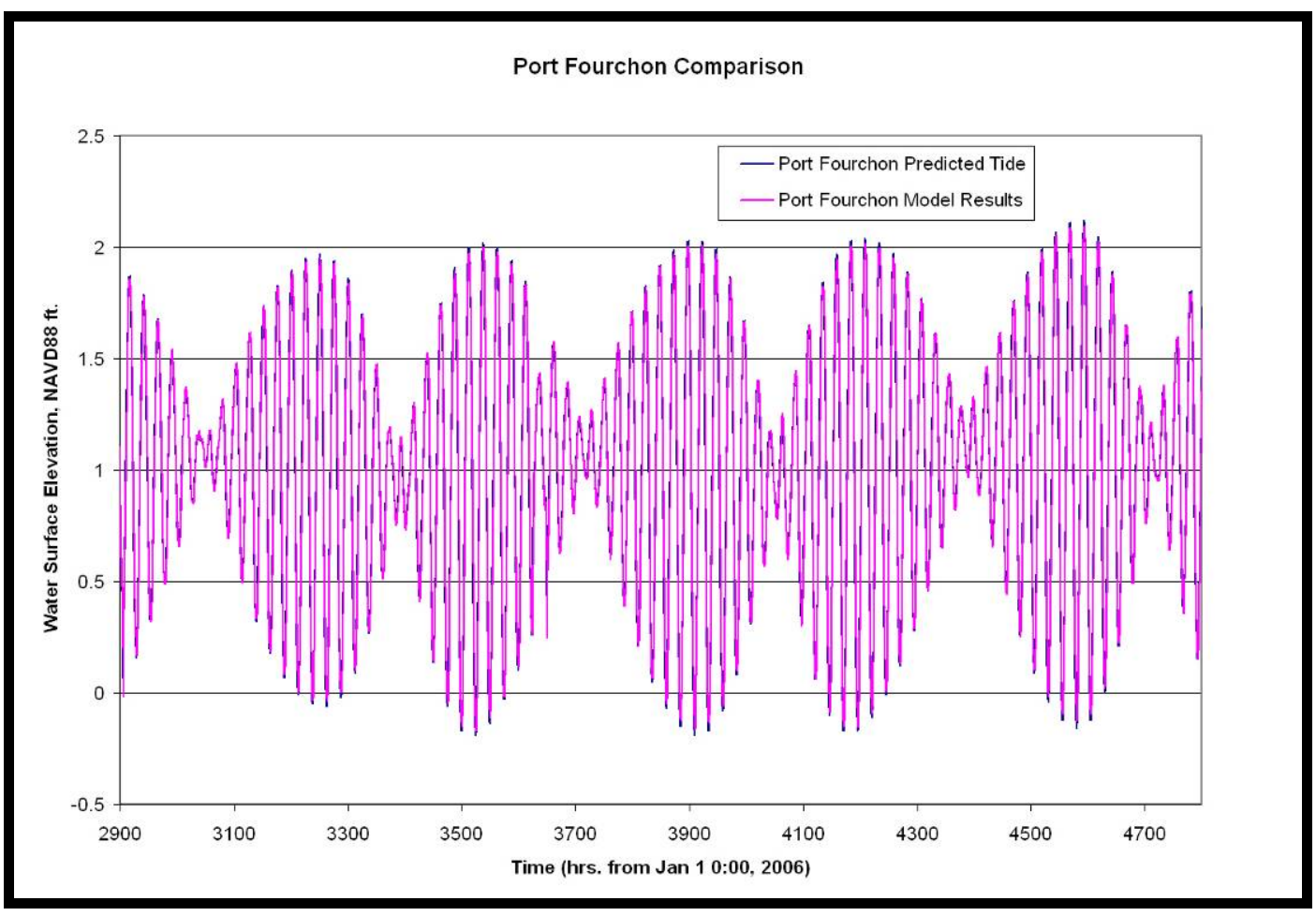

Figure 19. Comparison of model results and predicted tide at Port Fourchon.

\subsection{Model validation}

\subsubsection{Water surface elevation validation}

The hydrodynamic model was validated by comparison of the modelcomputed water surface elevations with filtered observed water surface elevations. New Orleans District had placed water surface elevation gages in and around the study area, as previously shown in Figure 3. These gages were of vital importance in the validation process. Comparisons of the filtered observed water surface elevations with the model water surface elevations are shown in Figures 20 - 27. 


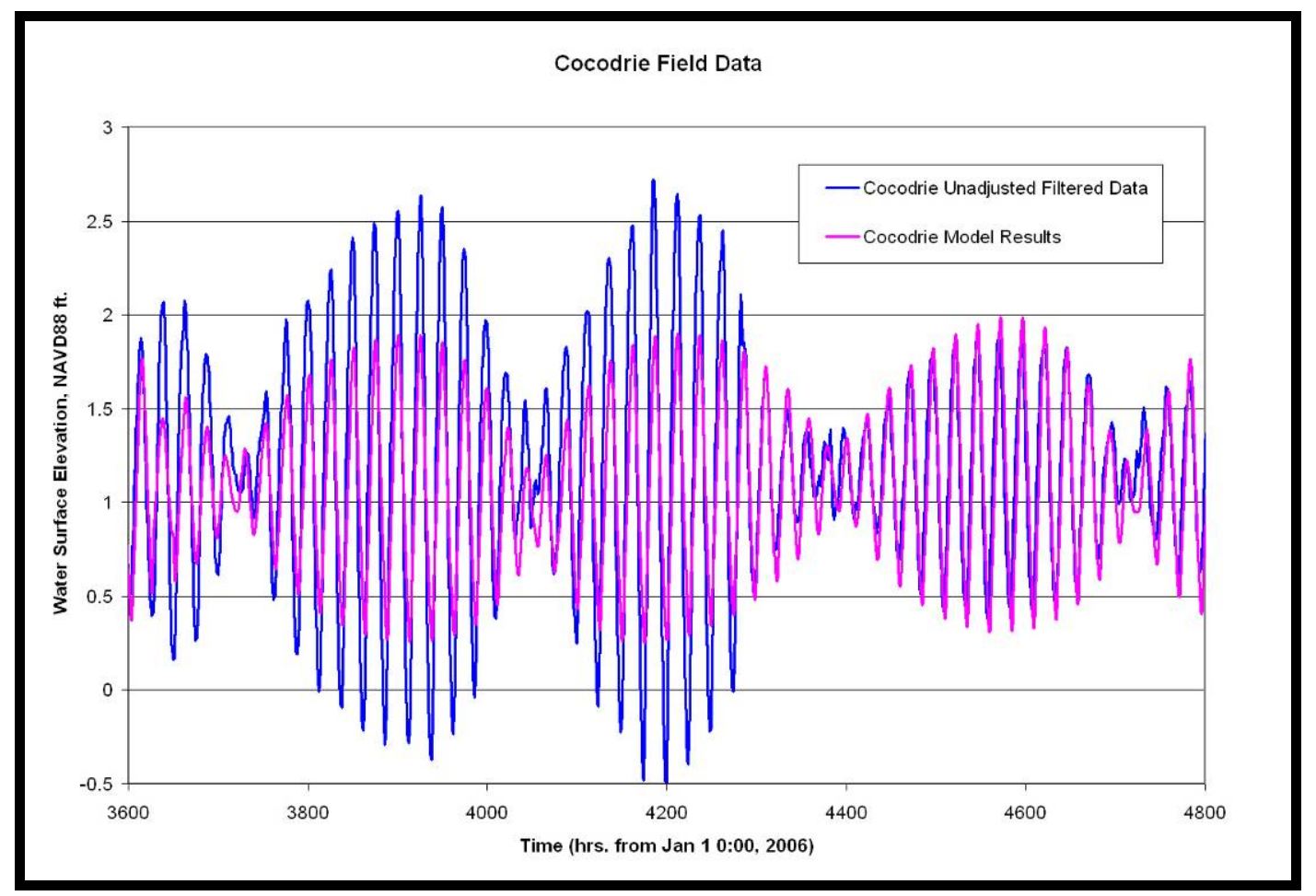

Figure 20. Unadjusted filtered data and the model data for Cocodrie.

From observing the filtered Cocodrie data in Figure 20, it was noticed that the range of the tide changed dramatically around hour 4380. Upon further investigation, it was discovered that the Cocodrie gage was downloaded at hour 4382. After comparing model results and the tides at other locations, it was determined that the data prior to hour 4382 was amplified by some amount. The amplified data were then proportioned until approximately the same spring tide range was present for the data before and after the gage reading. This proportioning resulted in a reduction in the tide range (before hour 4380) by a factor of 2 . By halving the range about the mean, the tide ranges prior to hour 4382 approximately matched the tide ranges present after hour 4382 for the spring tide events. A plot of the adjusted Cocodrie filtered data as compared with the model results is shown in Figure 21. 


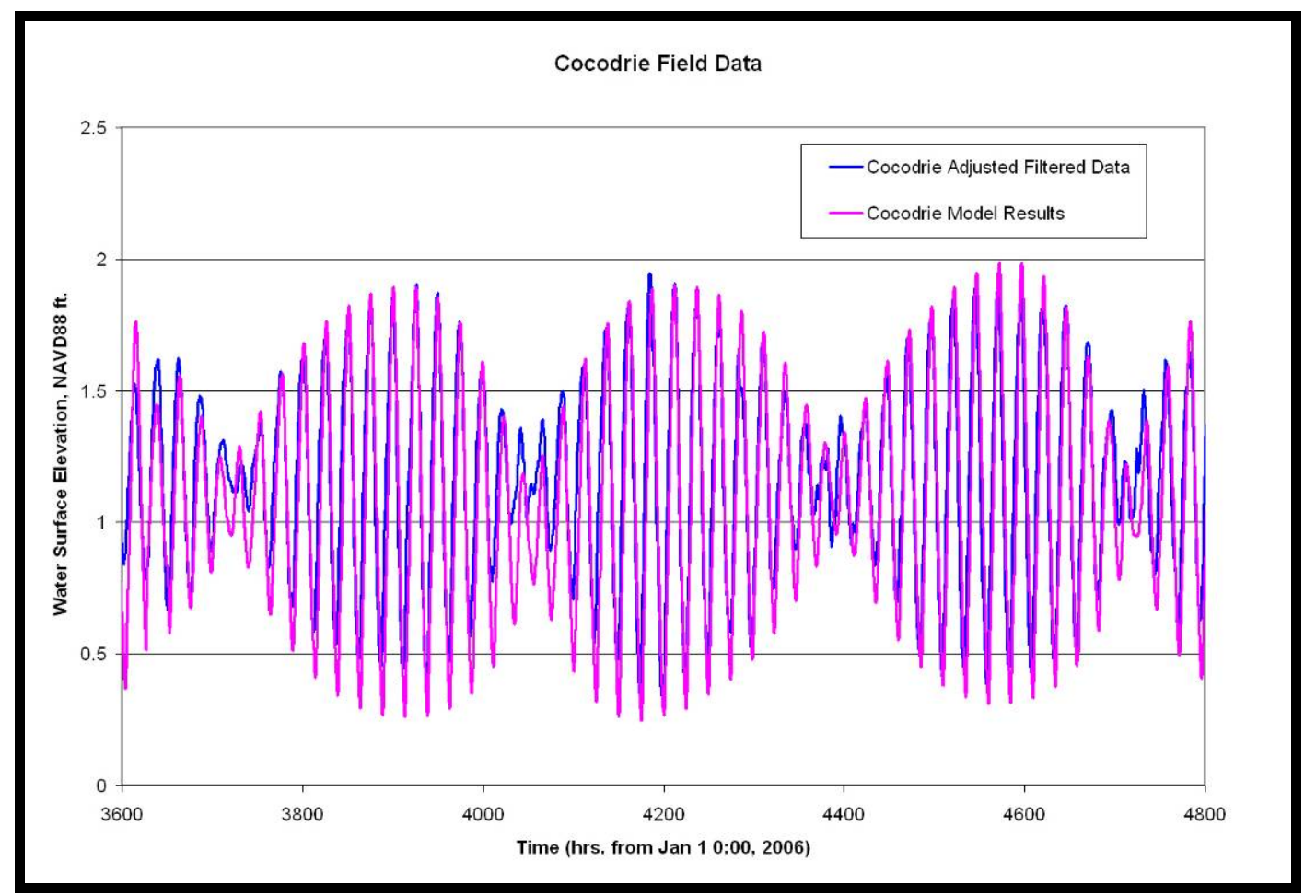

Figure 21. Adjusted filtered data and the model data for Cocodrie.

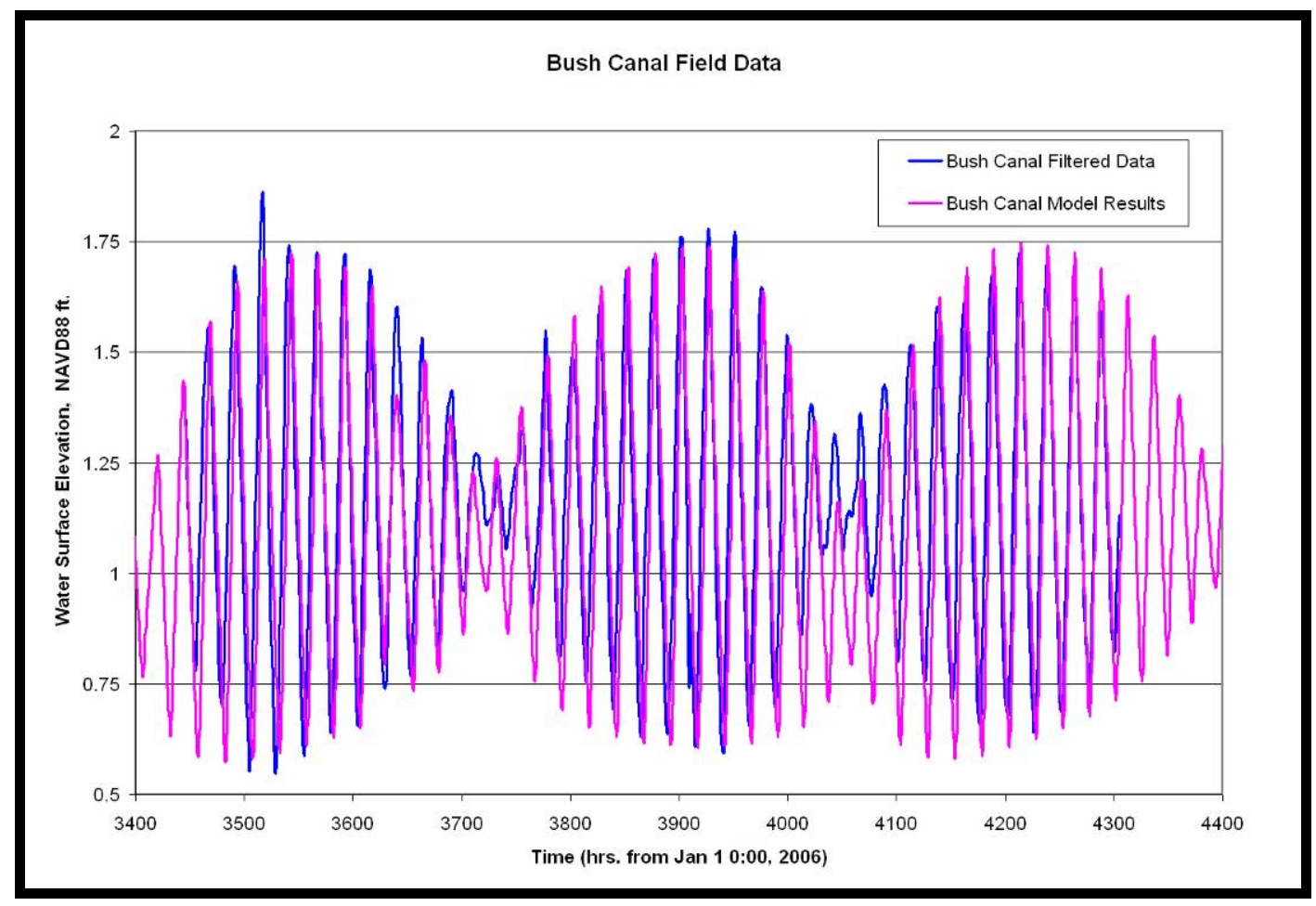

Figure 22. Filtered data and the model data for Bush Canal. 


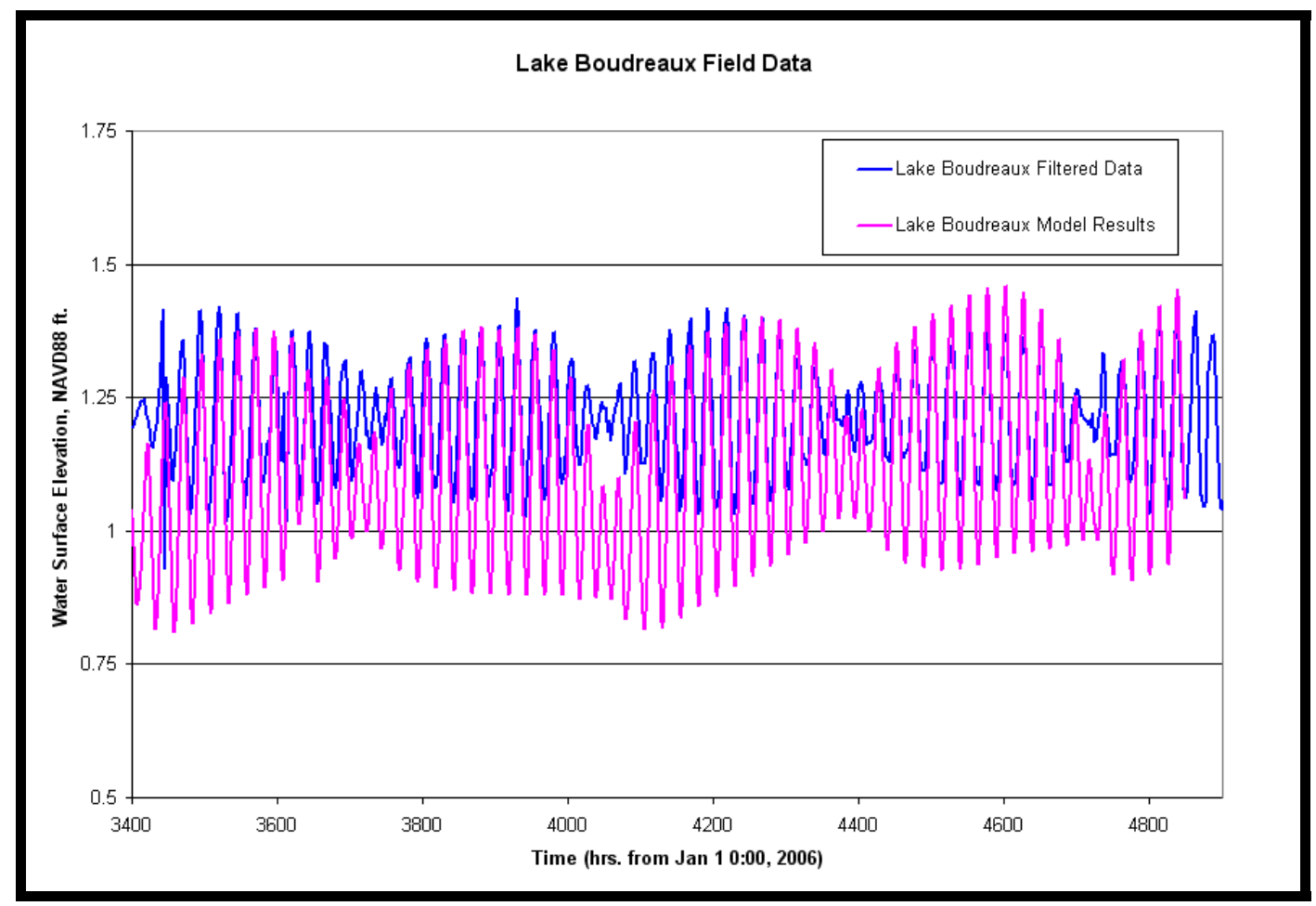

Figure 23. Filtered data and the model data for Lake Boudreaux.

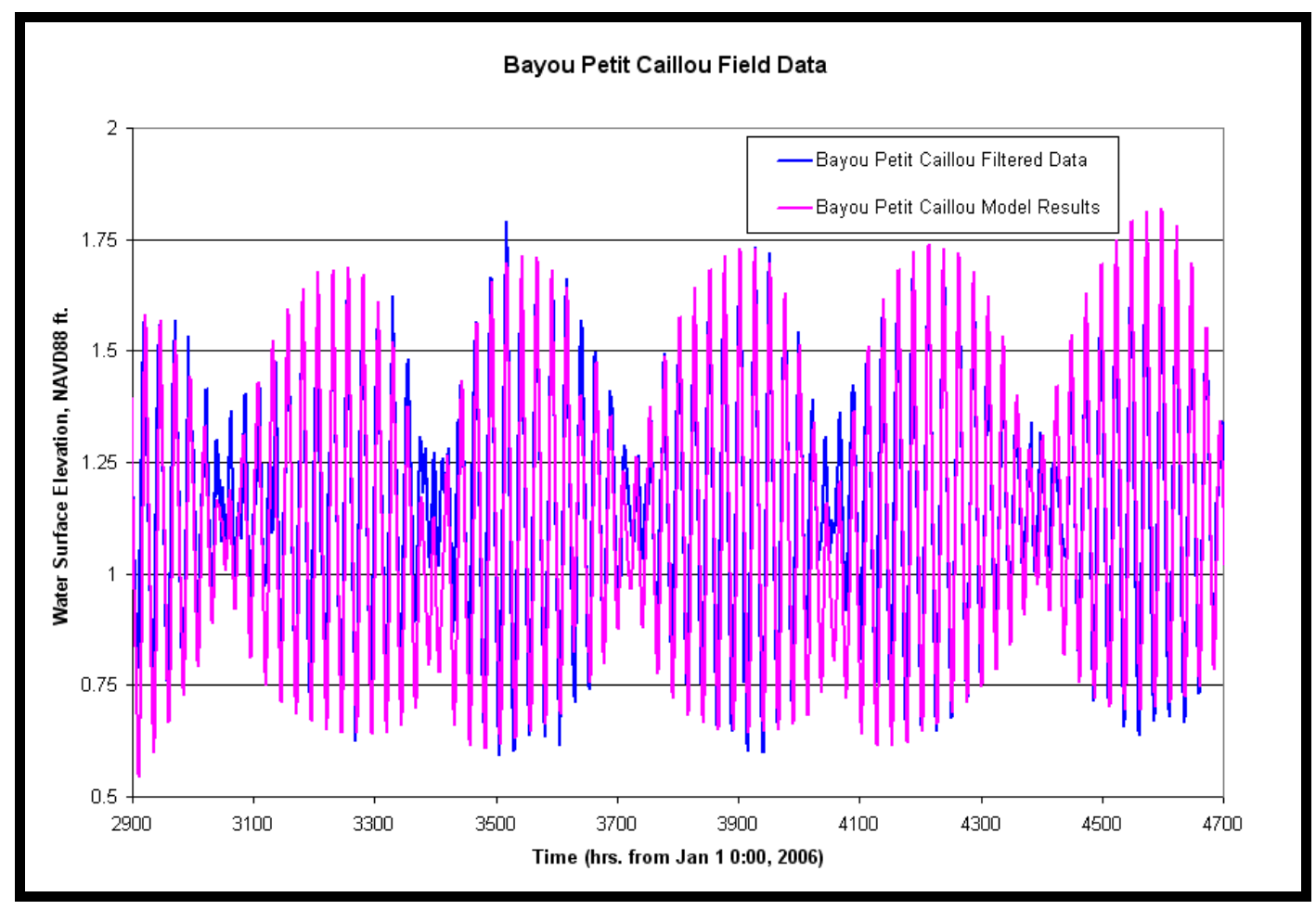

Figure 24. Filtered data and the model data for Bayou Petit Caillou. 


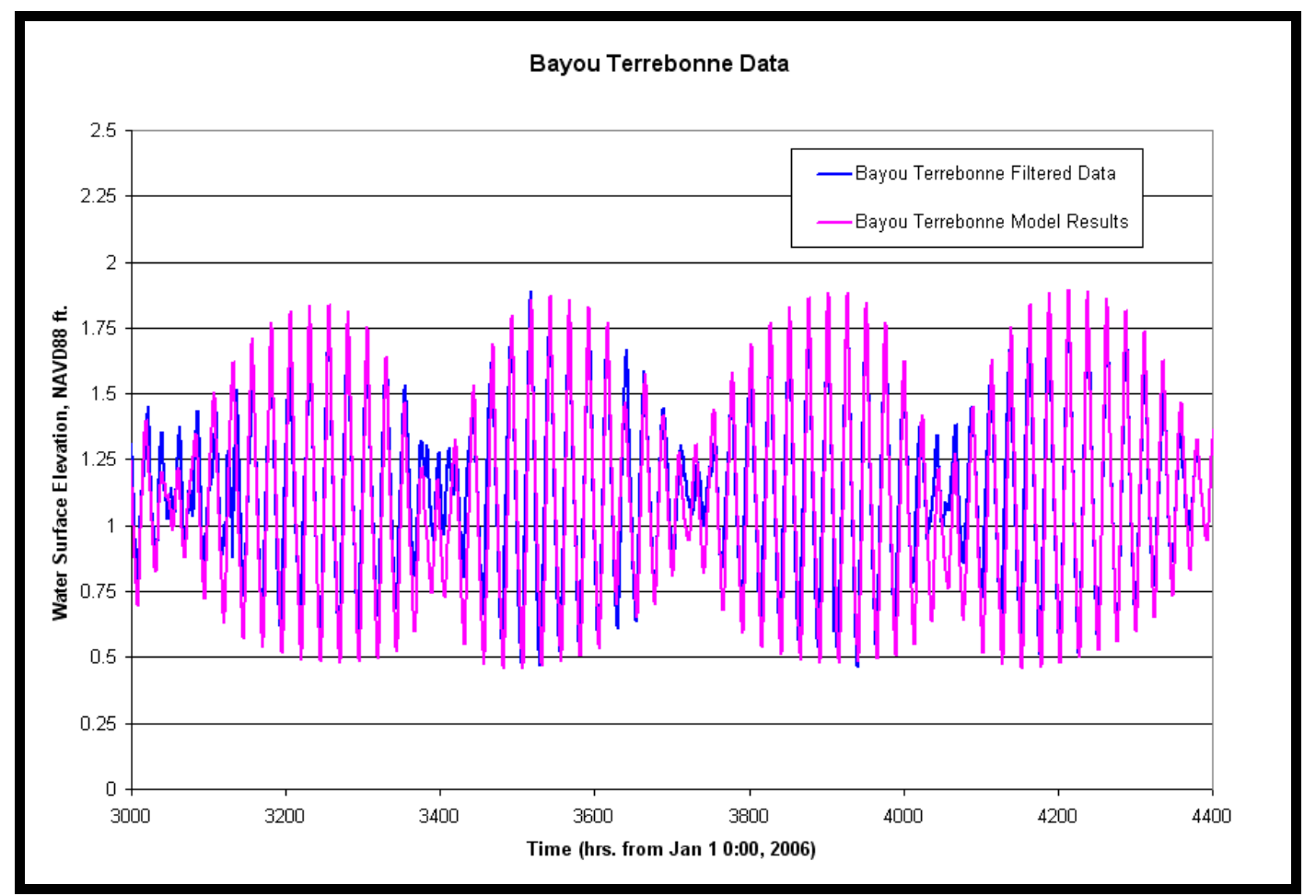

Figure 25. Filtered data and the model data for Bayou Terrebonne.

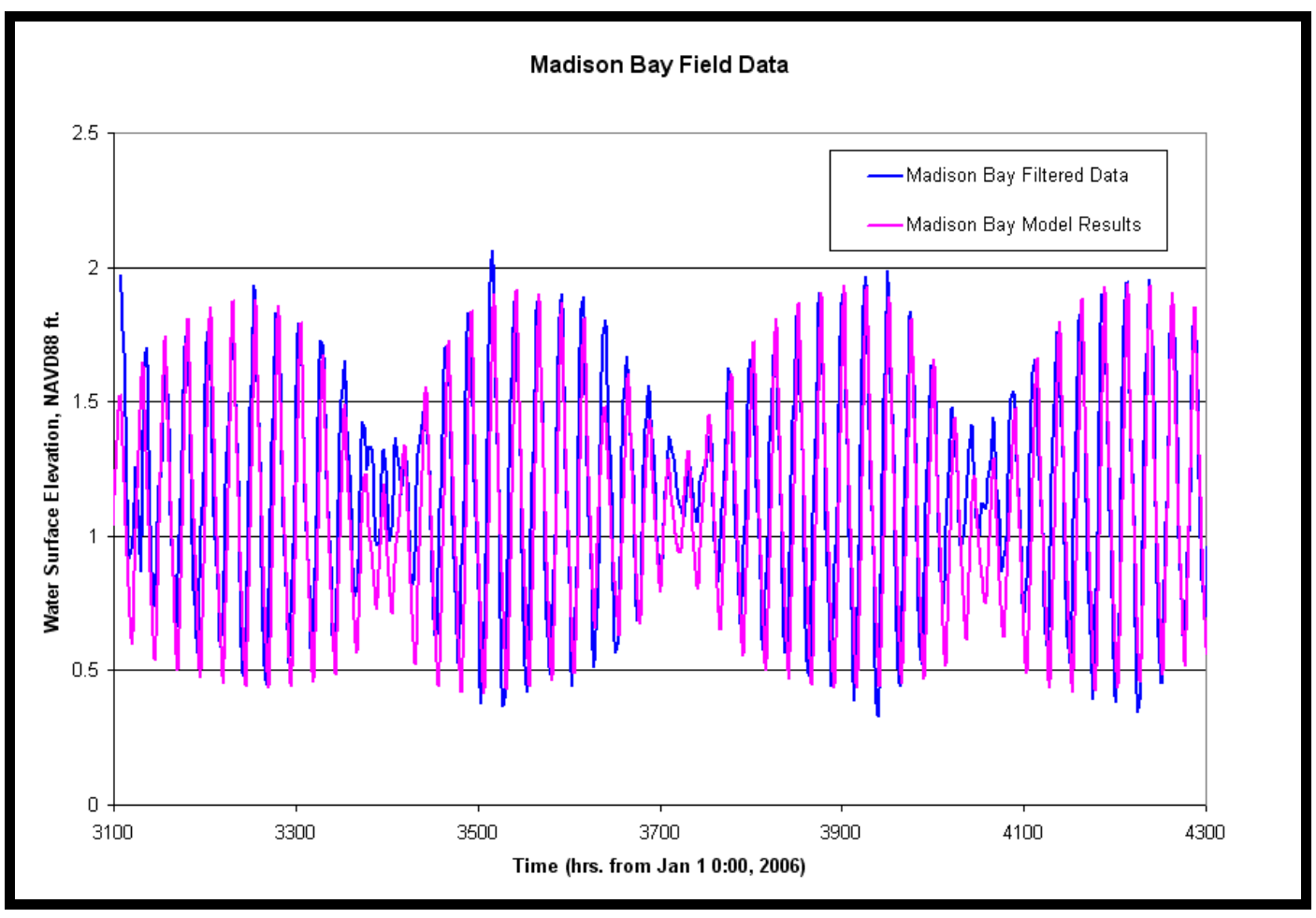

Figure 26. Filtered data and the model data for Madison Bay. 


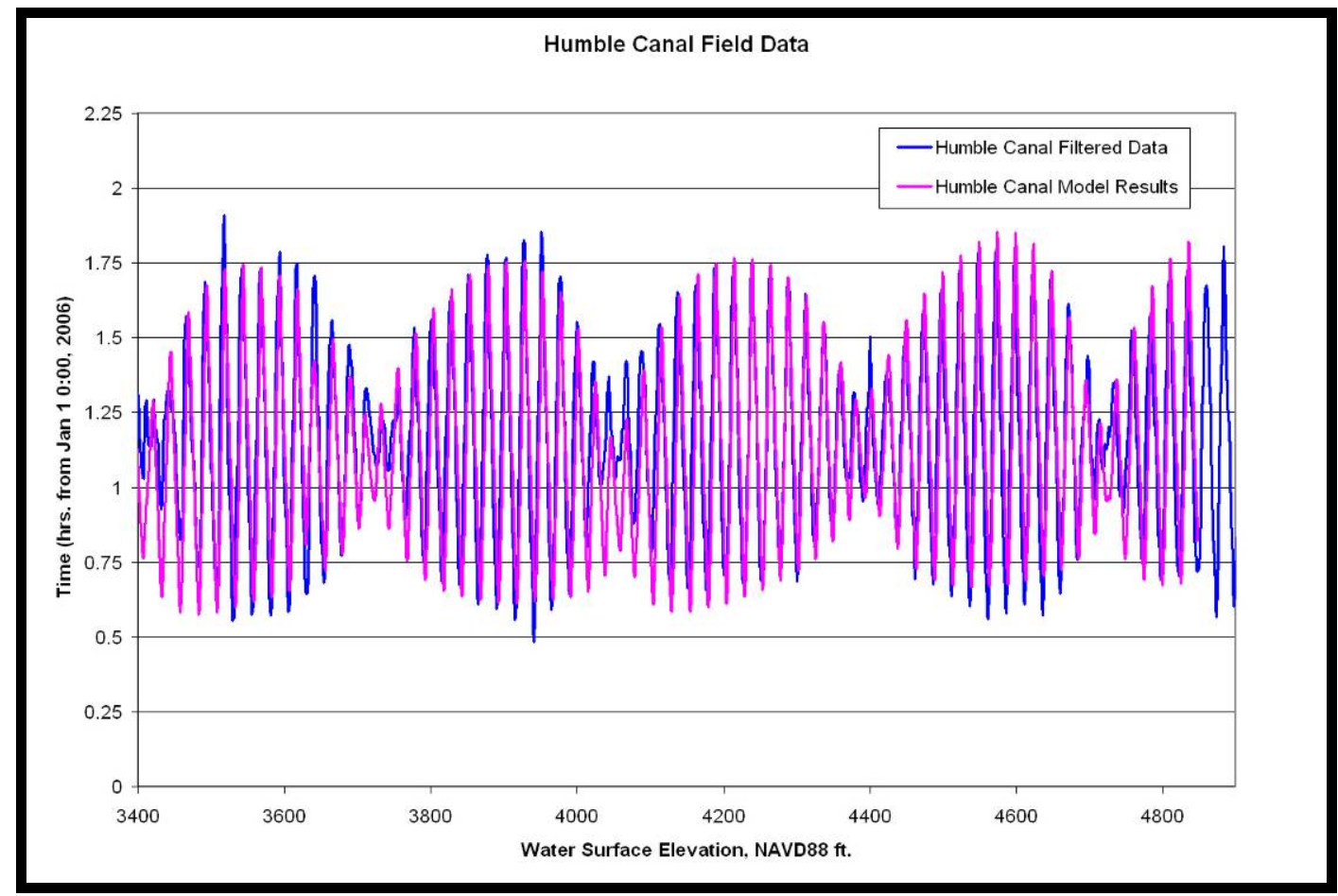

Figure 27. Filtered data and the model data for Humble Canal.

With the exception of the Lake Boudreaux gage, the remaining gage comparisons are good. The Lake Boudreaux gage is located in Lake Boudreaux near a connection to Bayou Petit Caillou (see Figure 3). Upon completion of the hydrodynamic modeling it was discovered that a weir, not included in the $\mathrm{ADH}$ model, was located along the Boudreaux Canal connecting Bayou Petit Caillou to Lake Boudreaux. This missing weir would greatly affect the model water surface elevations at the Lake Boudreaux gage. It is believed, however, that this missing weir will have a minimum affect on the remainder of the system because the Bayou Petit Caillou observed water surface elevation and velocity data (Figures 24, 30, 31, and 32) matched the model results well.

\subsubsection{Velocity validation}

Validation of the model velocity results consisted of comparisons with the measured ADCP data taken on 13 J uly 2006. The cross-sectional averaged velocity in the channel measured by the $\mathrm{ADCP}$ was compared to the crosssectional averaged velocity in the channel from the 2D ADH model results. The locations of the ADCP transects are shown in Figure 12. The ADCP comparison results are shown in Figures 28 - 31. The velocity meter locations are shown in Figure 11, and their comparison plots are shown in Figures $32-34$. 


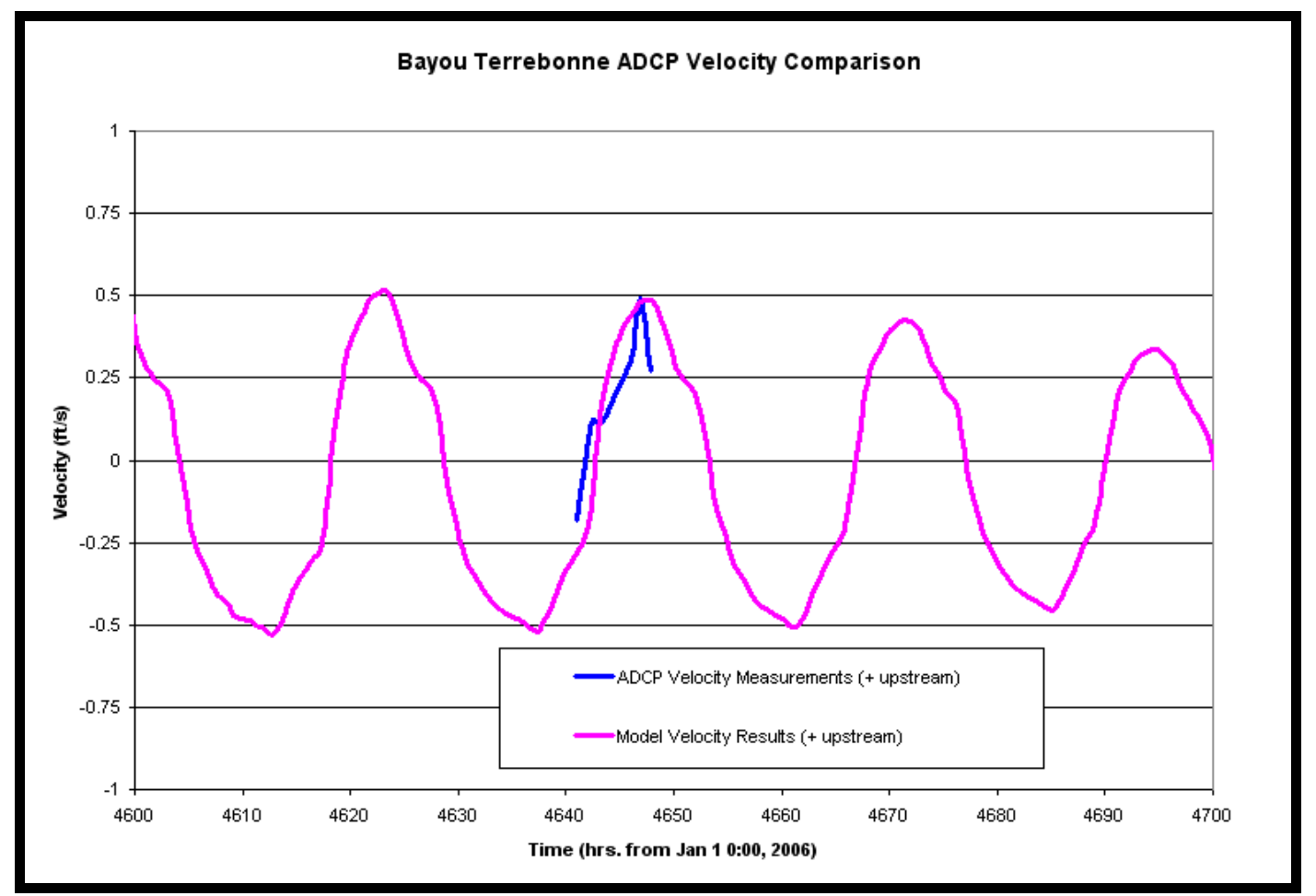

Figure 28. Model velocity results and the ADCP measurements for Bayou Terrebonne.

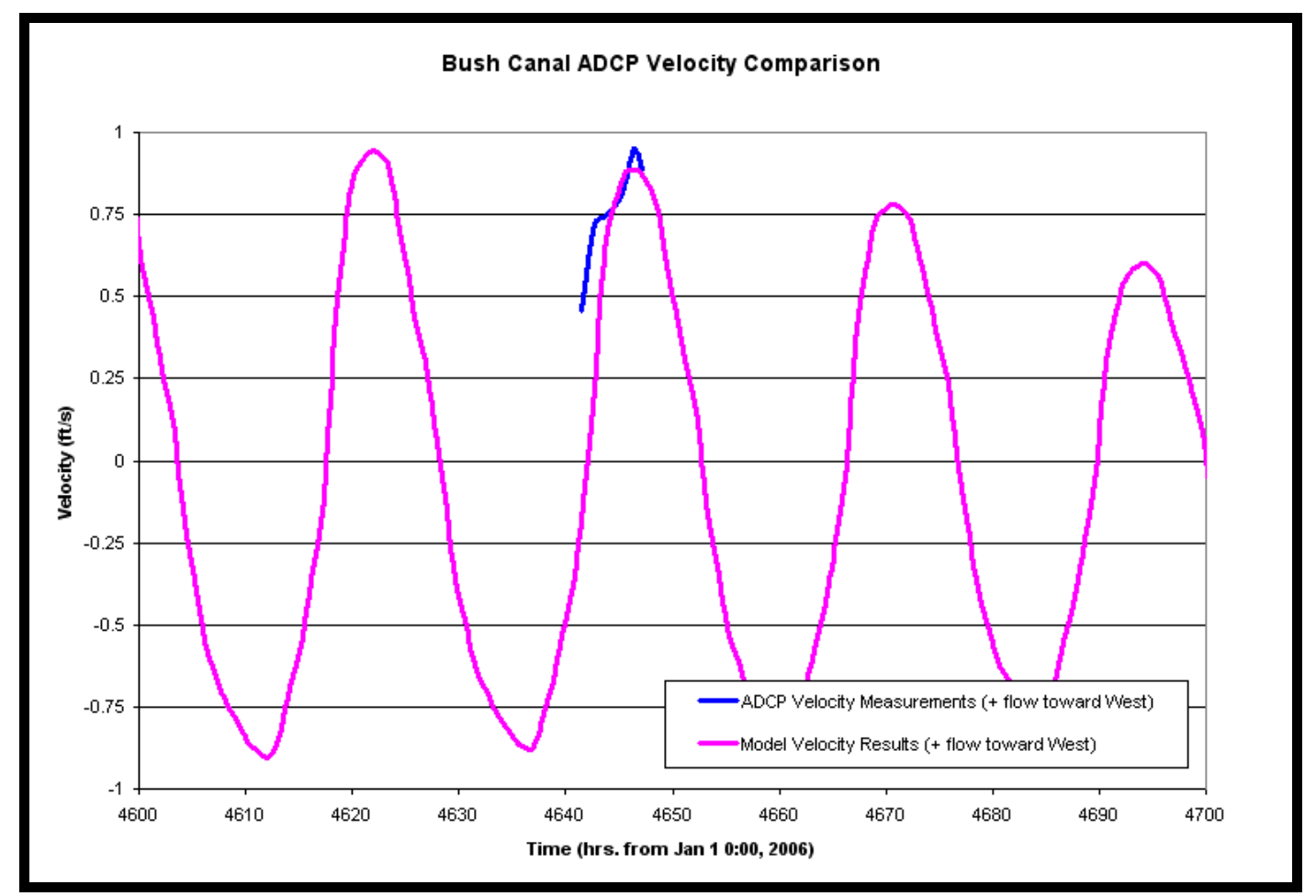

Figure 29. Model velocity results and the ADCP measurements for Bush Canal. 


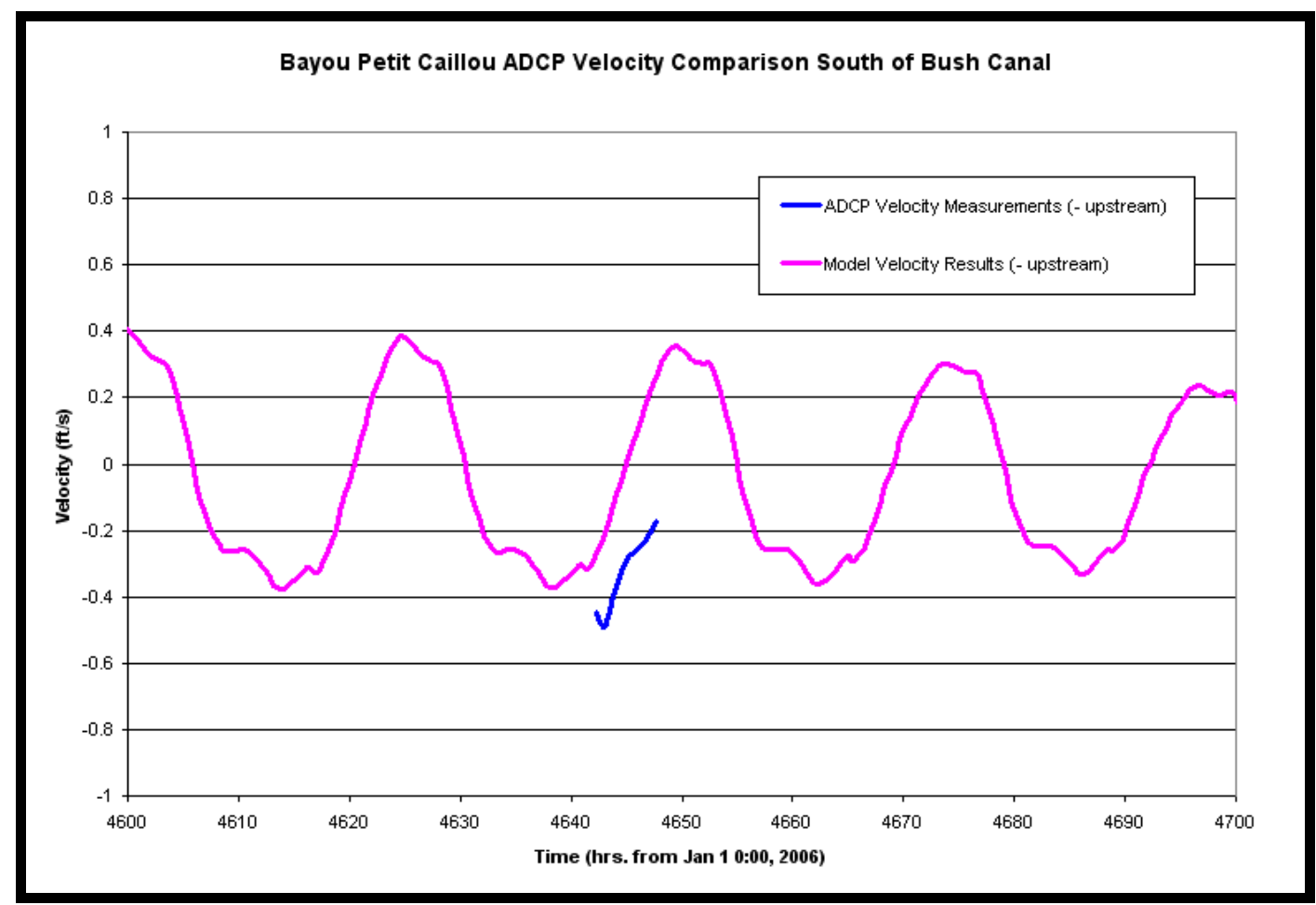

Figure 30. Model velocity results and the ADCP measurements for Bayou Petit Caillou south of Bush Canal.

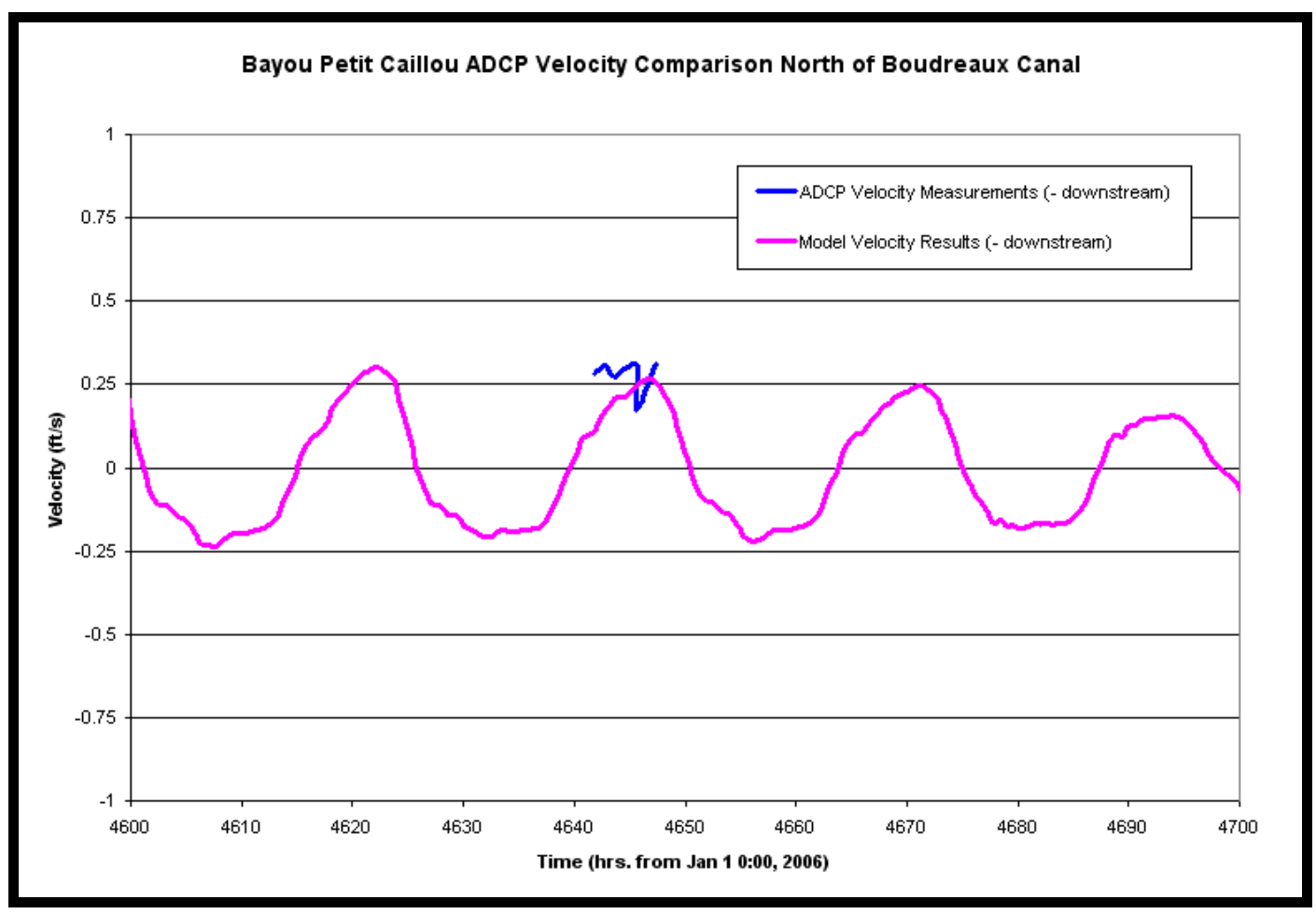

Figure 31. Model velocity results and the ADCP measurements for Bayou Petit Caillou North of Boudreaux Canal. 


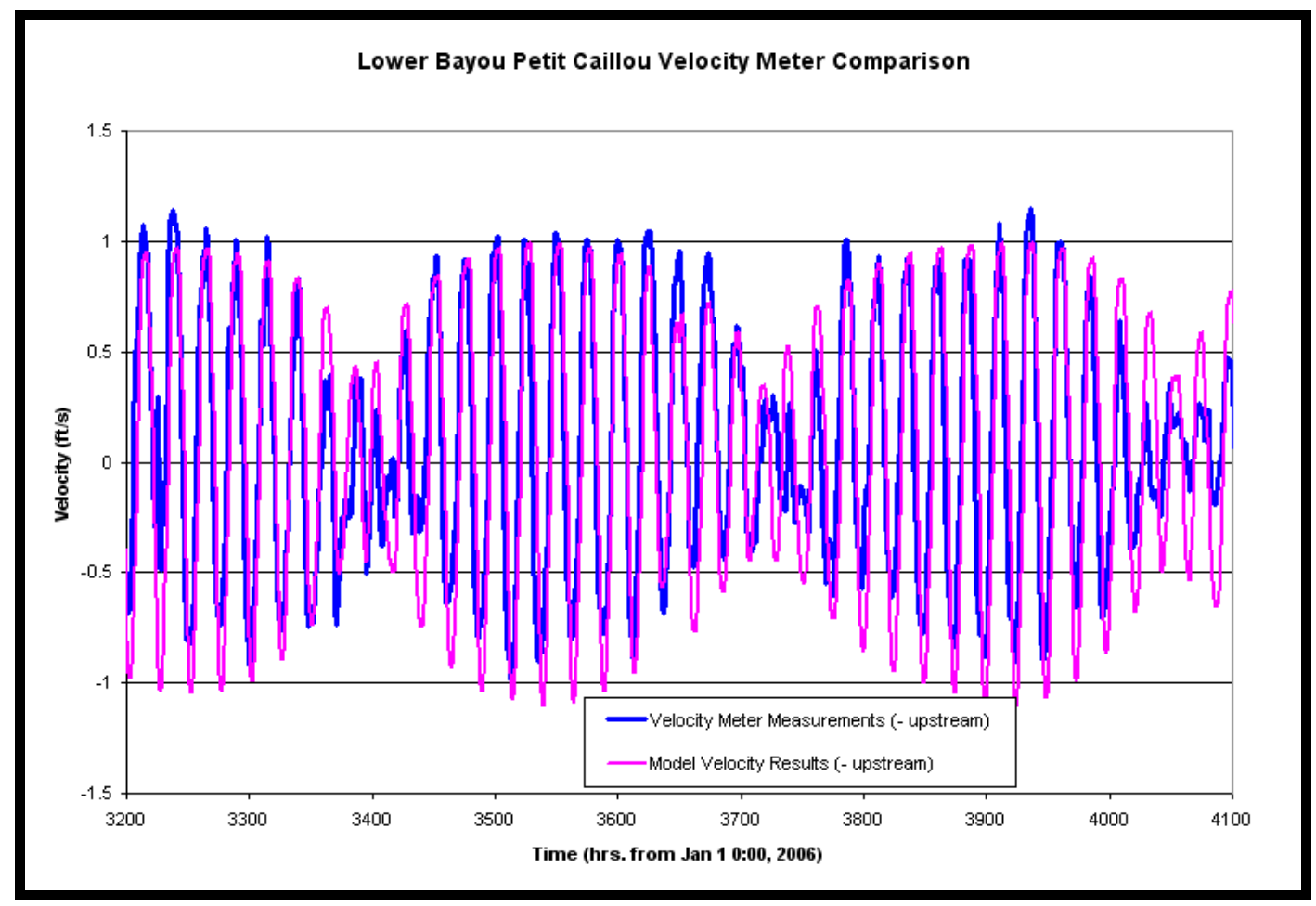

Figure 32. Model velocity results and the velocity meter measurements for lower Bayou Petit Caillou.

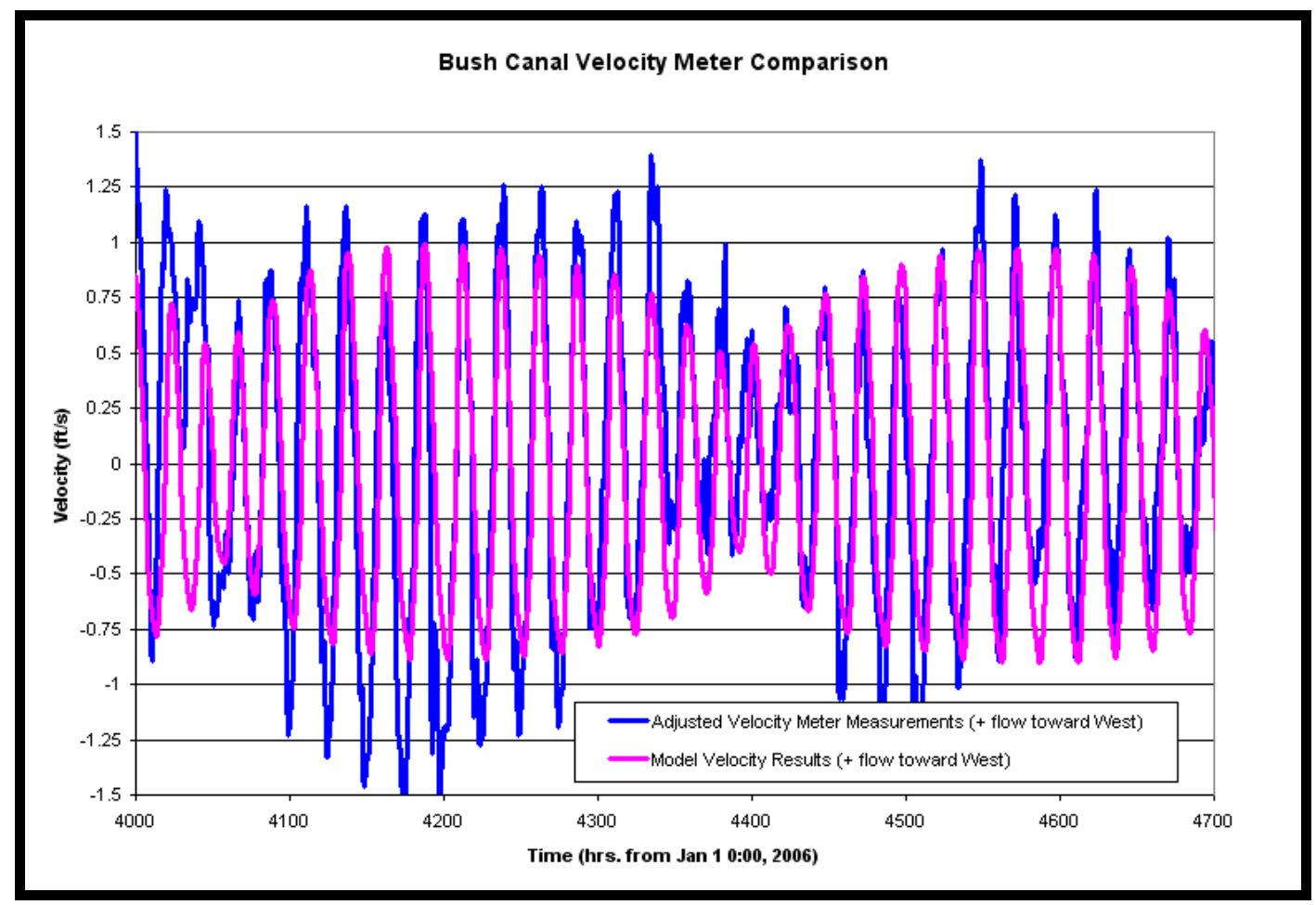

Figure 33. Model velocity results and the adjusted velocity meter measurements for Bush Canal. 


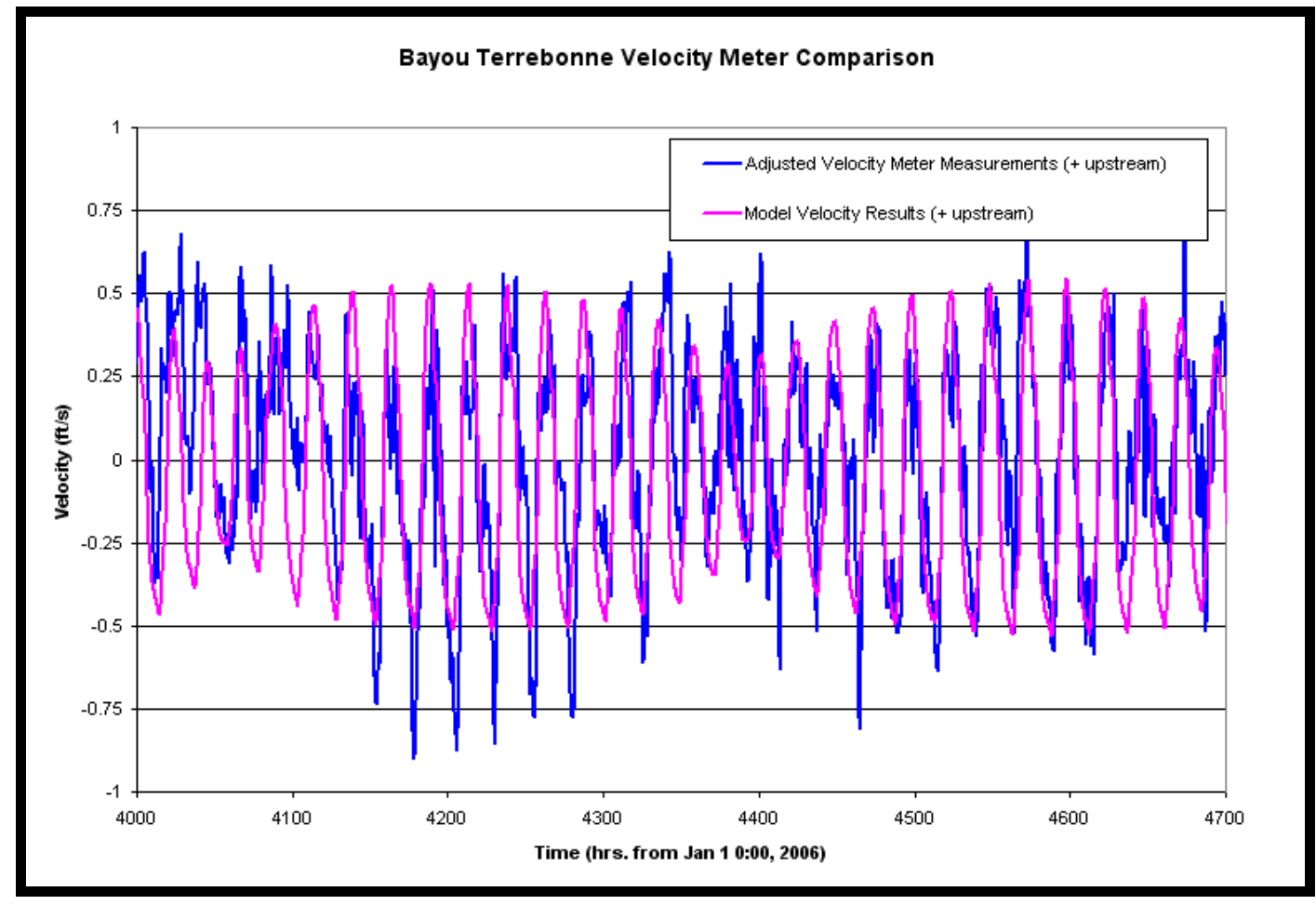

Figure 34. Model velocity results and the adjusted velocity meter measurements for Bayou Terrebonne.

\subsection{Design alternatives}

The aim of the design alternatives was to determine an appropriate structure that would produce reasonable velocity fields. Testing included the use of multiple structure sizes in conjunction with the possible installation of sluice gates of varying sizes. It was determined during initial testing that the design of the structure and sluice gate entrances and exits had a critical impact the velocities reported by the model. By making the sail-through structure more rounded at the entrance and exit, the structure became more efficient and passed more water. A negative consequence of this design, however was that it also increased velocities within the structure. It was decided that the sluice gates should be made more efficient by using both rounded entrances and exits, but the sail-through structure should be made less efficient by incorporating less-rounded entrances. This design alternative allows a significant portion of the water to circumvent the lessefficient structure and flow instead through the more-efficient sluice gates. This results in increased velocities through the sluice gates and reduced velocities within the sail-through structure. An example of the hydraulically efficient structure and the inefficient structure are shown in Figures 35 and 36, respectively. 


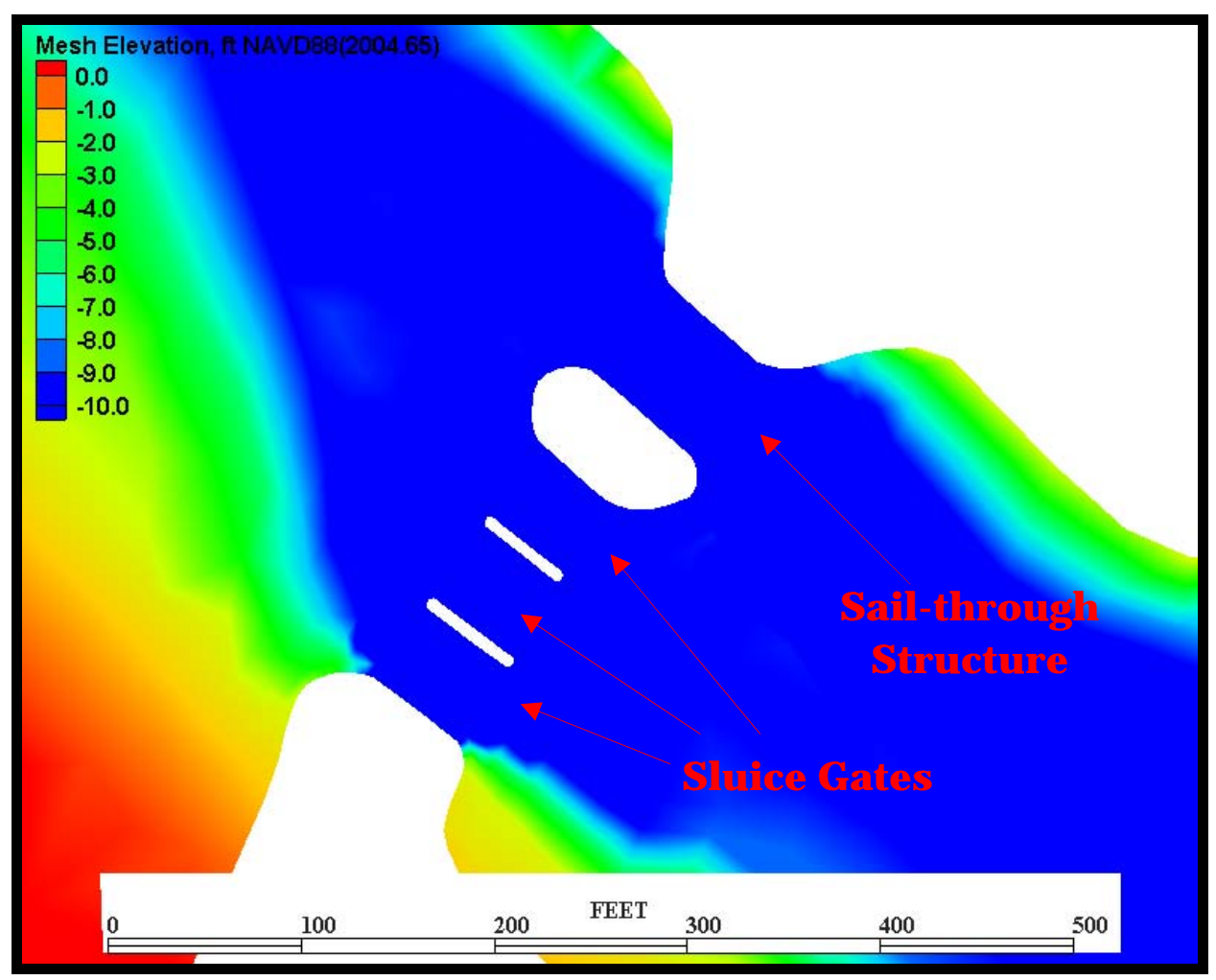

Figure 35. Efficient sail-through structure with efficient sluice gates.

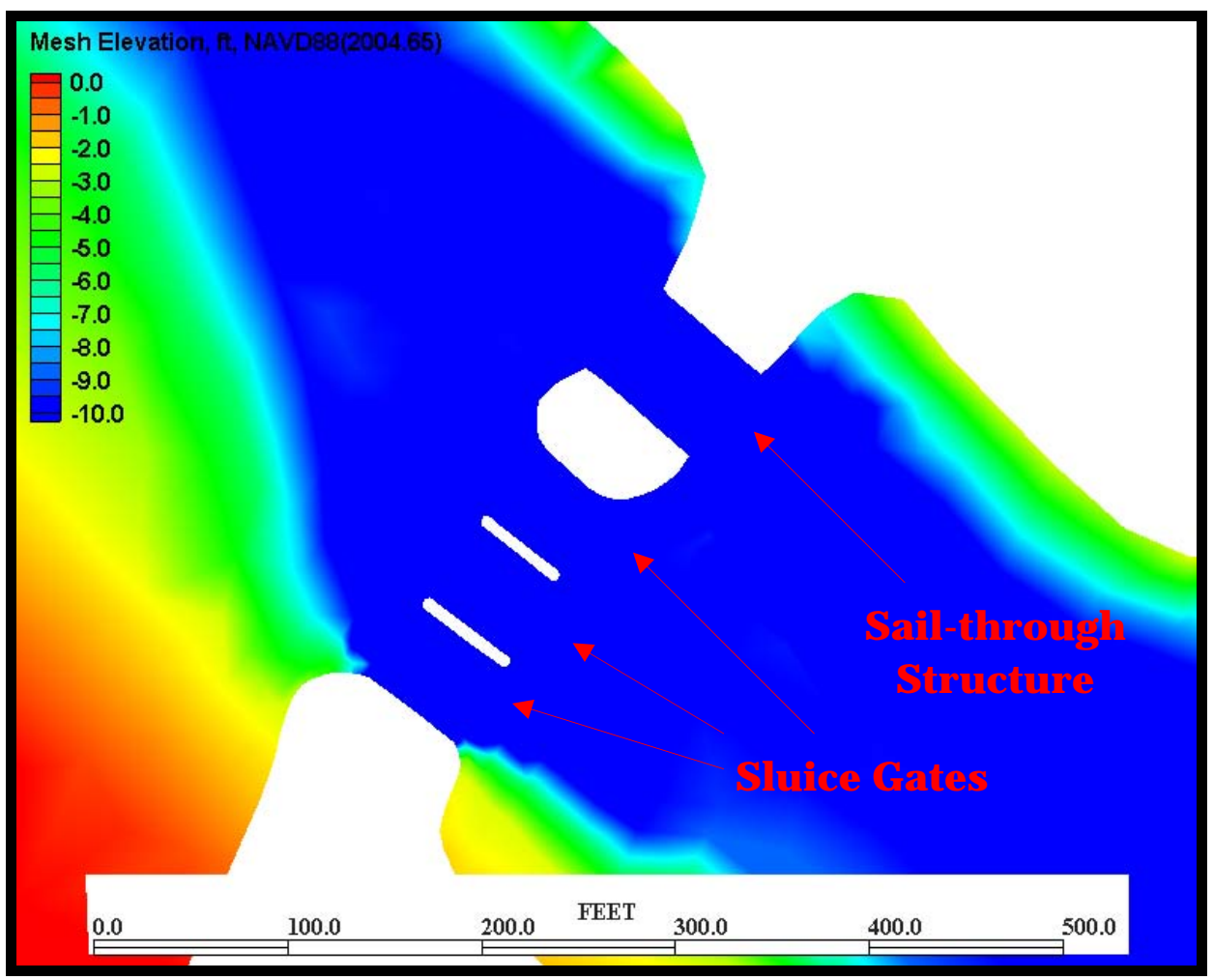

Figure 36. Less-efficient sail-through structure with efficient sluice gates. 
The initial testing phase was primarily intended to obtain the size of the structure and the necessary number and sizes of the sluice gates. Because the exact design was not known at the time of this study, a general design was used in the mesh. A list of the alternatives tested in the initial testing phase is given in Table 1.

Table 1. Plan Alternatives.

\begin{tabular}{|l|l|l|l|l|l|l|l|l|}
\hline \multicolumn{2}{|l|}{ Structure } & \multicolumn{3}{l}{ Sluice Gates } \\
\hline Alternative Number & $\begin{array}{l}\text { Depth } \\
(\mathrm{ft})\end{array}$ & $\begin{array}{l}\text { Width } \\
(\mathrm{ft})\end{array}$ & $\begin{array}{l}\text { Depth of } \\
\text { Sluice Gate } \\
1(\mathrm{ft})\end{array}$ & $\begin{array}{l}\text { Width of } \\
\text { Sluice Gate } \\
1(\mathrm{ft})\end{array}$ & $\begin{array}{l}\text { Depth of } \\
\text { Sluice Gate } \\
2(\mathrm{ft})\end{array}$ & $\begin{array}{l}\text { Width of } \\
\text { Sluice Gate } \\
\text { 2 (ft) }\end{array}$ & $\begin{array}{l}\text { Depth of } \\
\text { Sluice Gate } \\
\text { 3 (ft) }\end{array}$ & $\begin{array}{l}\text { Width of } \\
\text { Sluice Gate } \\
\text { 3 (ft) }\end{array}$ \\
\hline $\begin{array}{l}\text { Existing } \\
\text { Conditions }\end{array}$ & N/A & N/A & N/A & N/A & N/A & N/A & N/A & N/A \\
\hline $\begin{array}{l}\text { Existing } \\
\text { Conditions with } \\
\text { new levee }\end{array}$ & N/A & N/A & N/A & N/A & N/A & N/A & N/A & N/A \\
\hline 1 & 12 & 56 & N/A & N/A & N/A & N/A & N/A & N/A \\
\hline 2 & 12 & 56 & 12 & 46 & N/A & N/A & N/A & N/A \\
\hline 3 & 10 & 56 & 12 & 46 & 12 & 46 & N/A & N/A \\
\hline 4 & 12 & 56 & 12 & 46 & 12 & 46 & N/A & N/A \\
\hline 5 & 10 & 56 & 10 & 46 & 10 & 46 & 10 & 46 \\
\hline 6 & 10 & 56 & 12 & 46 & 12 & 46 & 12 & 46 \\
\hline 7 & 12 & 56 & 12 & 46 & 12 & 46 & 12 & 46 \\
\hline 8 & 12 & 56 & 12 & 60 & 12 & 60 & 12 & 30 \\
\hline 9 & 12 & 71 & 12 & 46 & 12 & 46 & 12 & 46 \\
\hline 10 & 12 & 200 & N/A & N/A & N/A & N/A & N/A & N/A \\
\hline
\end{tabular}

\subsection{Computational environment}

The hydrodynamic modeling was executed on the ERDC High Performance Computing (HPC) SGI Origin 3000 (Ruby) parallel processing supercomputer. The initial model mesh contains 57,834 nodes and 84,790 elements, with the mesh adapting the number of nodes to as many as 140,000 when needed. The model was executed on 16 parallel processors and required approximately 20 hours of computational time (54.6 CPU hours) to run for 14 model days. The model used a time step of 360 seconds, with the ability to adapt to smaller time steps when needed. 


\section{Model Study Results}

\subsection{Plan configuration results}

The maximum flood and ebb velocities in the sail-through structure are plotted as a time series in Figure 37. The flow through Bush Canal is driven by the water level differences between Bayou Terrebonne and Bayou Petit Caillou. The smallest velocities are for the existing conditions, which offer the best connections between the two bayous and allow the water levels to equilibrate most quickly. When the proposed levee is built, many additional connections will be cut off, making the remaining ones pass more water at higher velocities. This effect is exemplified in a model run using the existing conditions with only the new levee represented in the mesh (i.e., no structure in Bush Canal). The removal of the small side channels connecting Bayou Petit Caillou and Bayou Terrebonne (see Figure 17) resulted in an increase of $0.7 \mathrm{ft} / \mathrm{s}$ in the maximum flood velocity and a $0.4 \mathrm{ft} / \mathrm{s}$ increase in the maximum ebb velocity. When this result is paired with a major constriction in the channel (proposed alternatives), a significant increase in velocity occurs. Figure 38 is a bar graph of the maximum model velocities in the structure for the different alternatives.

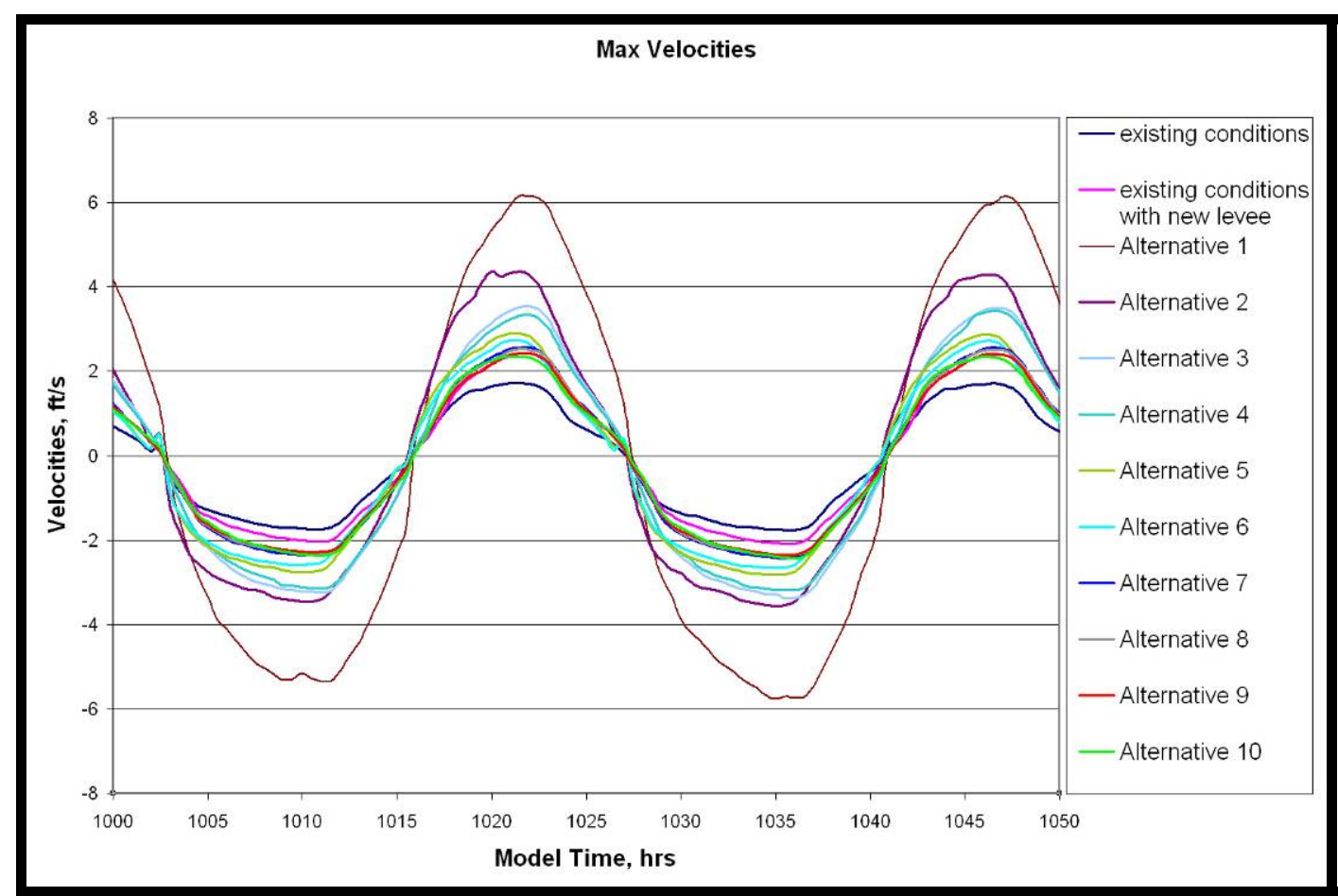

Figure 37. Maximum velocities in the sail-through structure; positive is flood direction. 


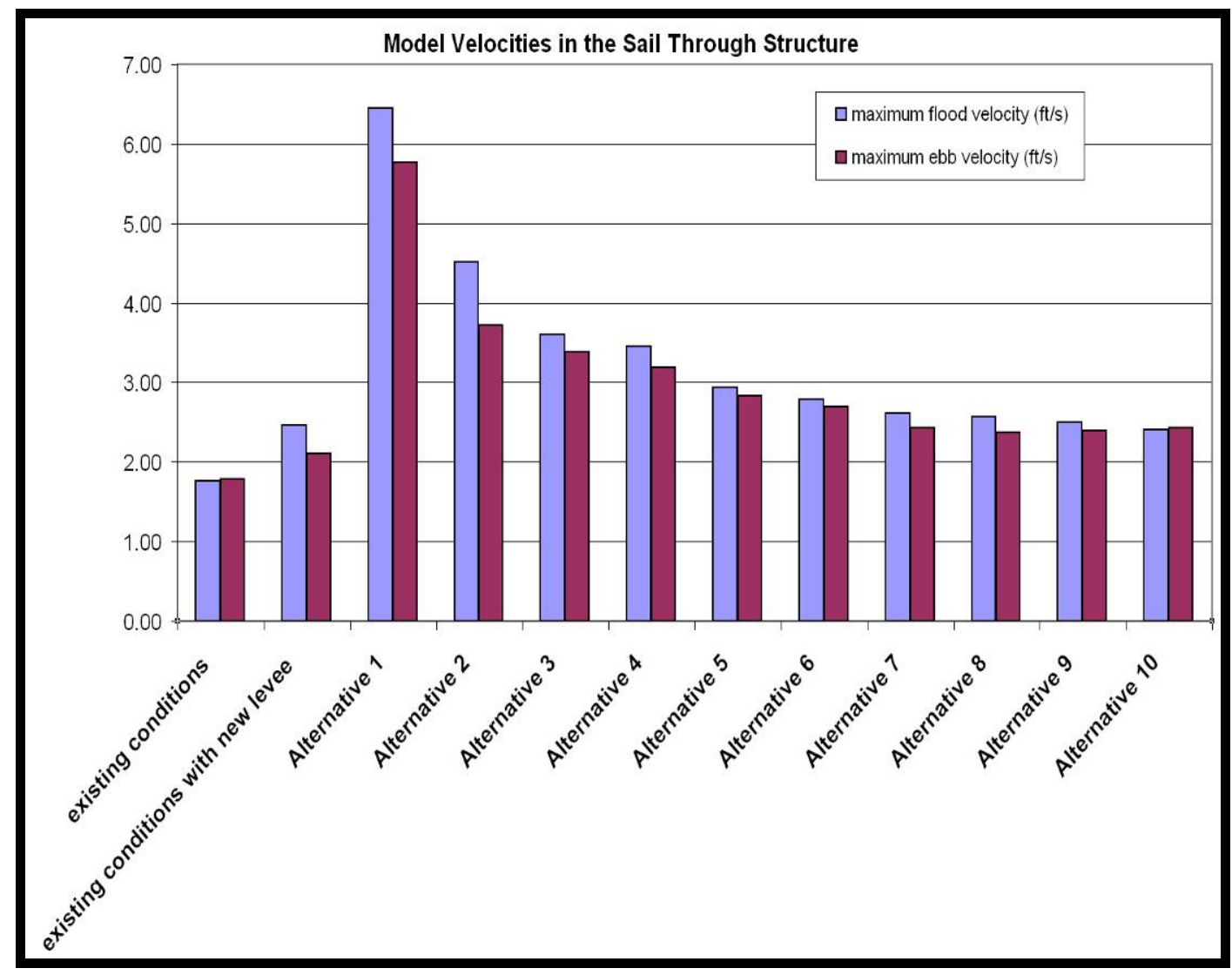

Figure 38. Maximum model velocities in the sail-through structure.

From the initial model results, it was determined that a maximum of three sluice gates should be used. As the number of sluice gates increased, the effectiveness of the additional gates was reduced. The additional sluice gates were farther from the natural channel, thereby reducing their effectiveness. Shown in Figure 39 is a contour velocity plot of the maximum flood conditions for alternative 5 ( $56 \mathrm{ft}$ sail-through structure with three $46 \mathrm{ft}$ sluice gates). The velocities in the third sluice gate are significantly lower than the velocities in the first and second sluice gates. From the bar plot in Figure 38, the increase from adding the third sluice gate is lower than the increase gained from adding the second gate. Based on this trend, it may reasonably be concluded that the addition of a fourth sluice gate would provide only minimal improvement in the velocity magnitudes. 


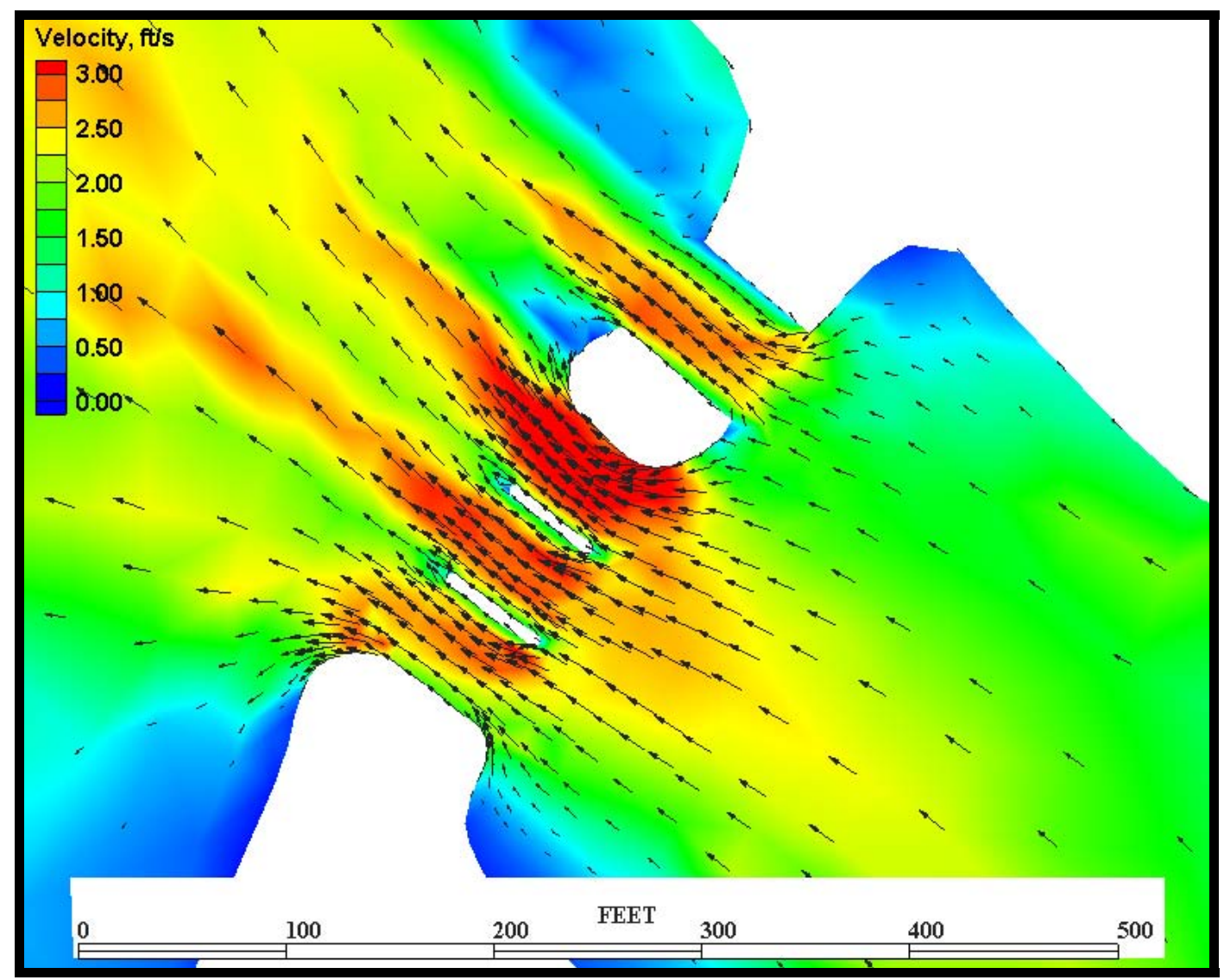

Figure 39. Velocity vectors and contours for alternative 5.

\subsection{Wind sensitivity analysis}

Because this model describes a shallow system, wind effects may be important. A sensitivity analysis was performed to determine an approximate effect on the velocities due to wind. Wind measurements for the Bayou Petit Caillou U.S. Geological Service (USGS) gage, shown in Figure 40, were applied to the numerical model to determine an approximate magnitude of wind effects on the currents through the structure. Because alternative 5 was judged to be the best alternative, it was used for this analysis. A percentile analysis was performed on the model-outputted velocity results, without and with wind, for a 3 month test period from May to J uly 2006. Wind data are plotted in Figure 41. It was observed that the maximum values increased with wind by approximately $15 \%$, from $\sim 3 \mathrm{ft} / \mathrm{s}$ to $\sim 3.5 \mathrm{ft} / \mathrm{s}$ (Figure 42 versus Figure 43). While that increase is significant, the 90th percentile velocities (i.e., velocities at or below these values $90 \%$ of the time) produced very few differences (Figure 44 versus Figure 45 ). There appears to be a steady northwestern wind blowing during this time period (see Figure 46). Because wind fields are rarely this constant, it is believed that the data captured a rare event that is unlikely to occur very 
often. Therefore, wind effects can have a significant impact on the velocities within the sail-through structure during rare events, but they do not appear to produce a consistent, significant increase in the velocity fields.

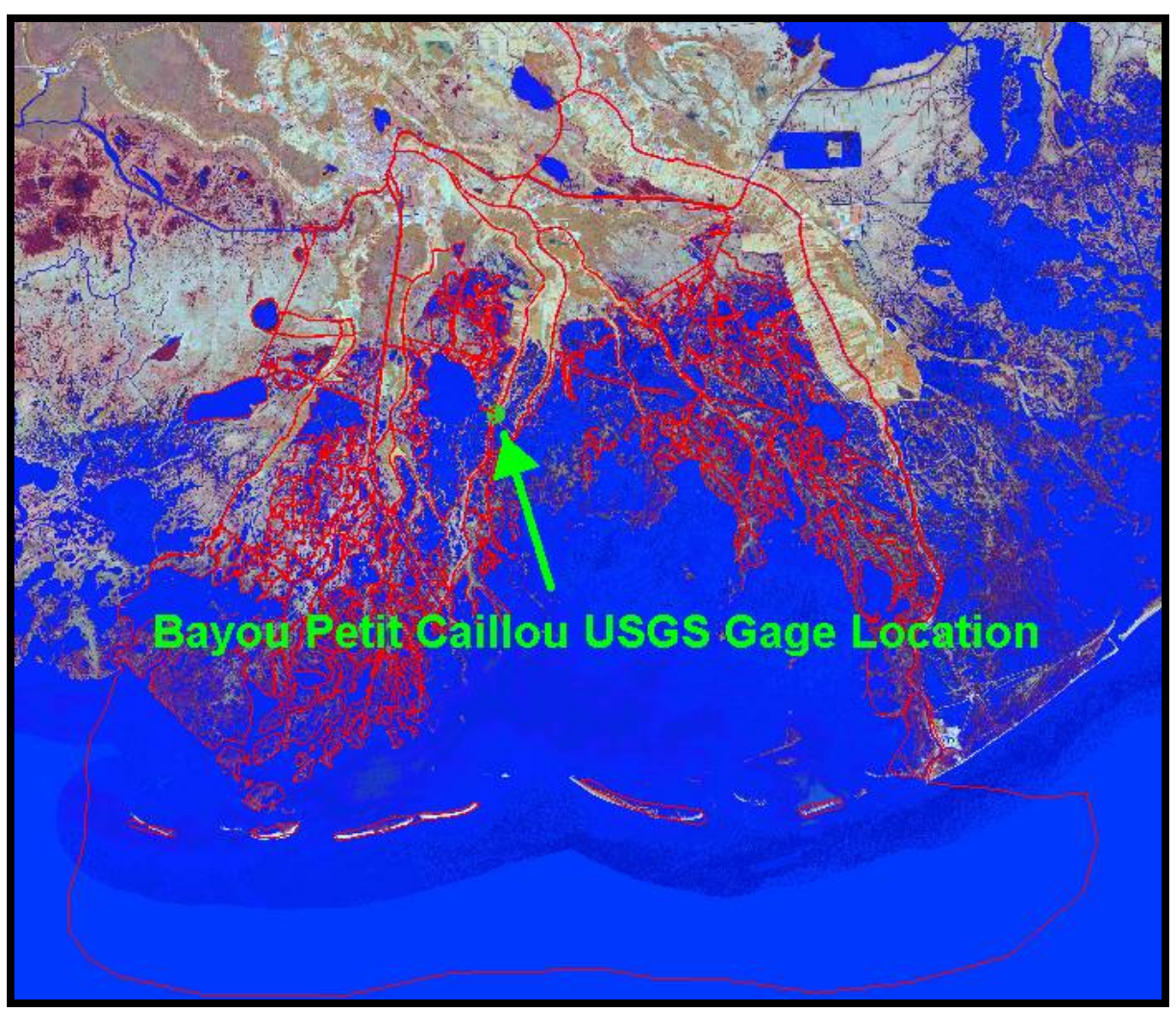

Figure 40. Location of USGS gage for wind data.

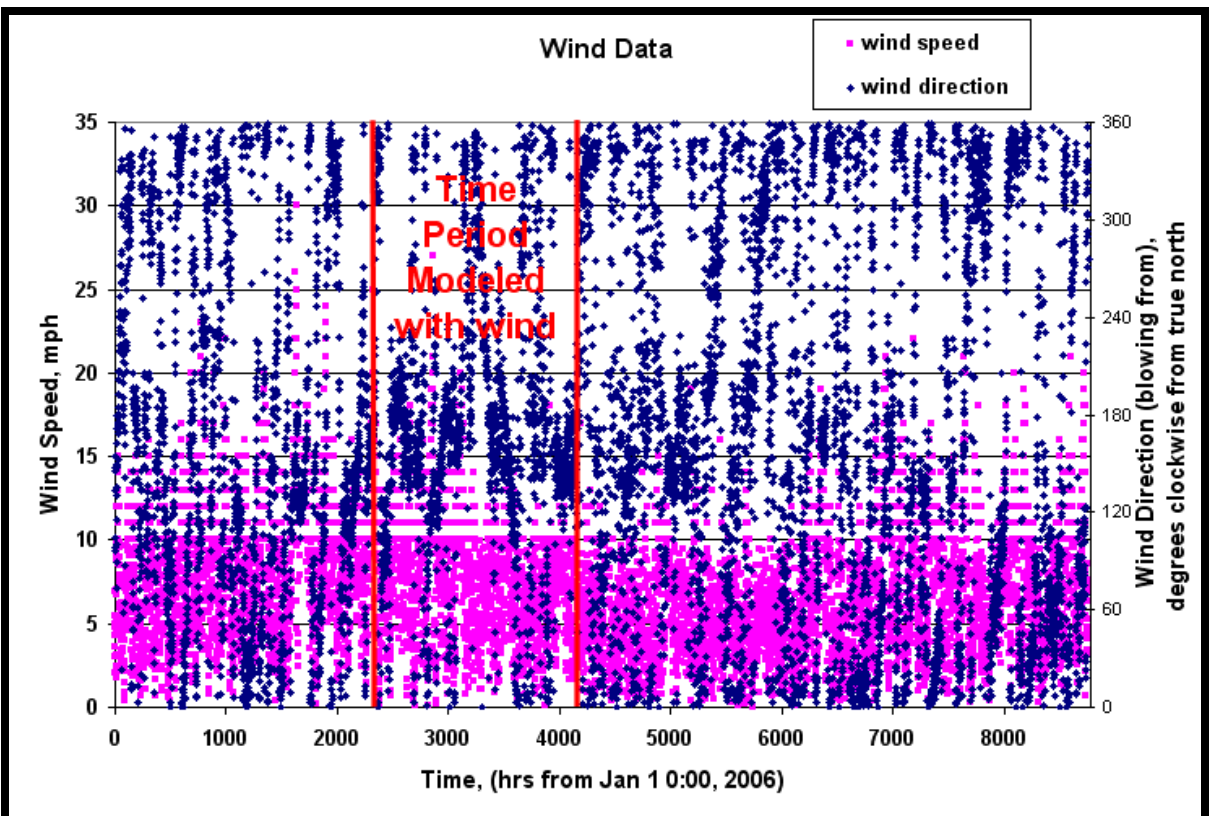

Figure 41. Wind data for the Bayou Petit Caillou USGS gage (USGS 07381343) for 2006. 


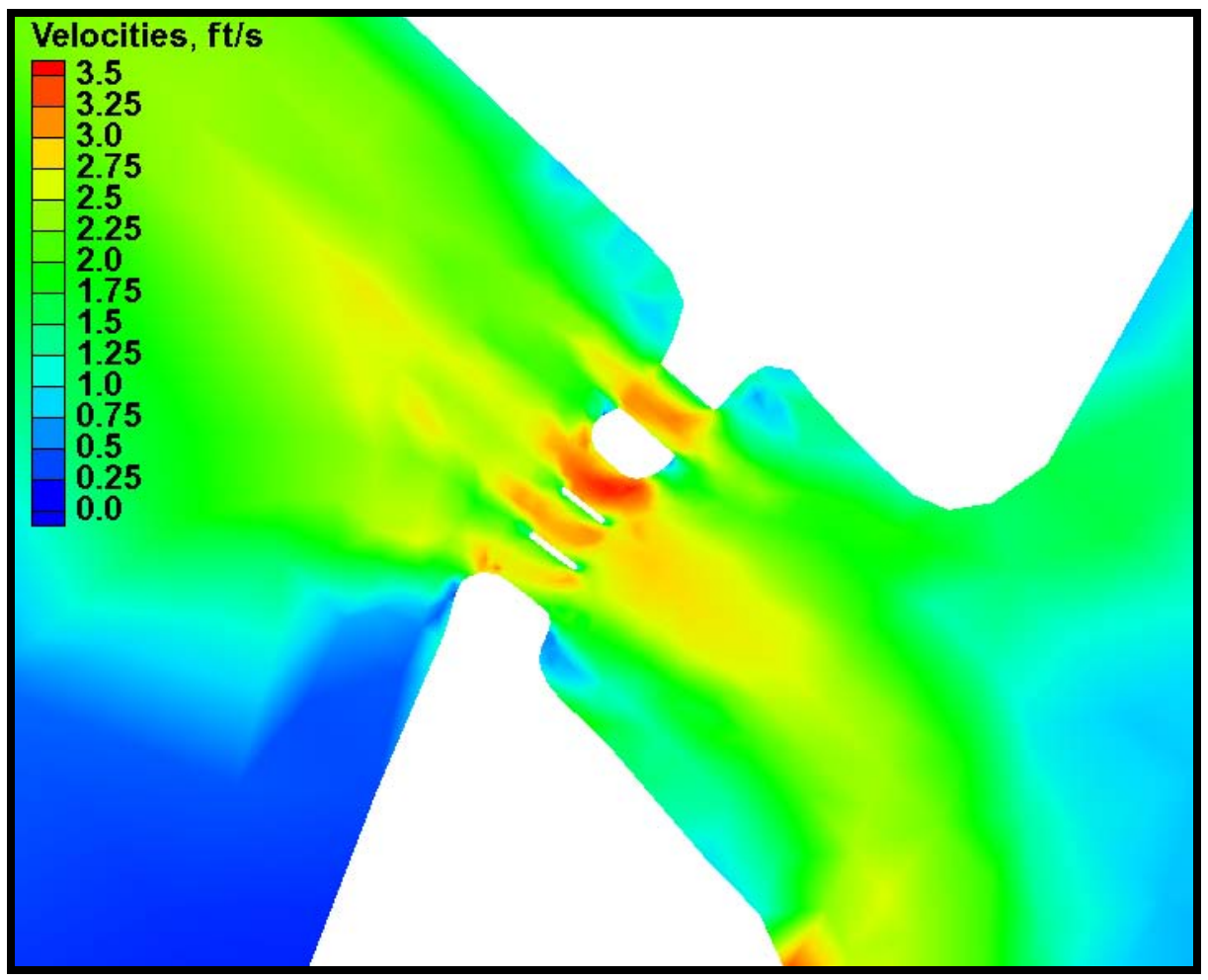

Figure 42. Maximum velocities for Alternative 5, without wind.

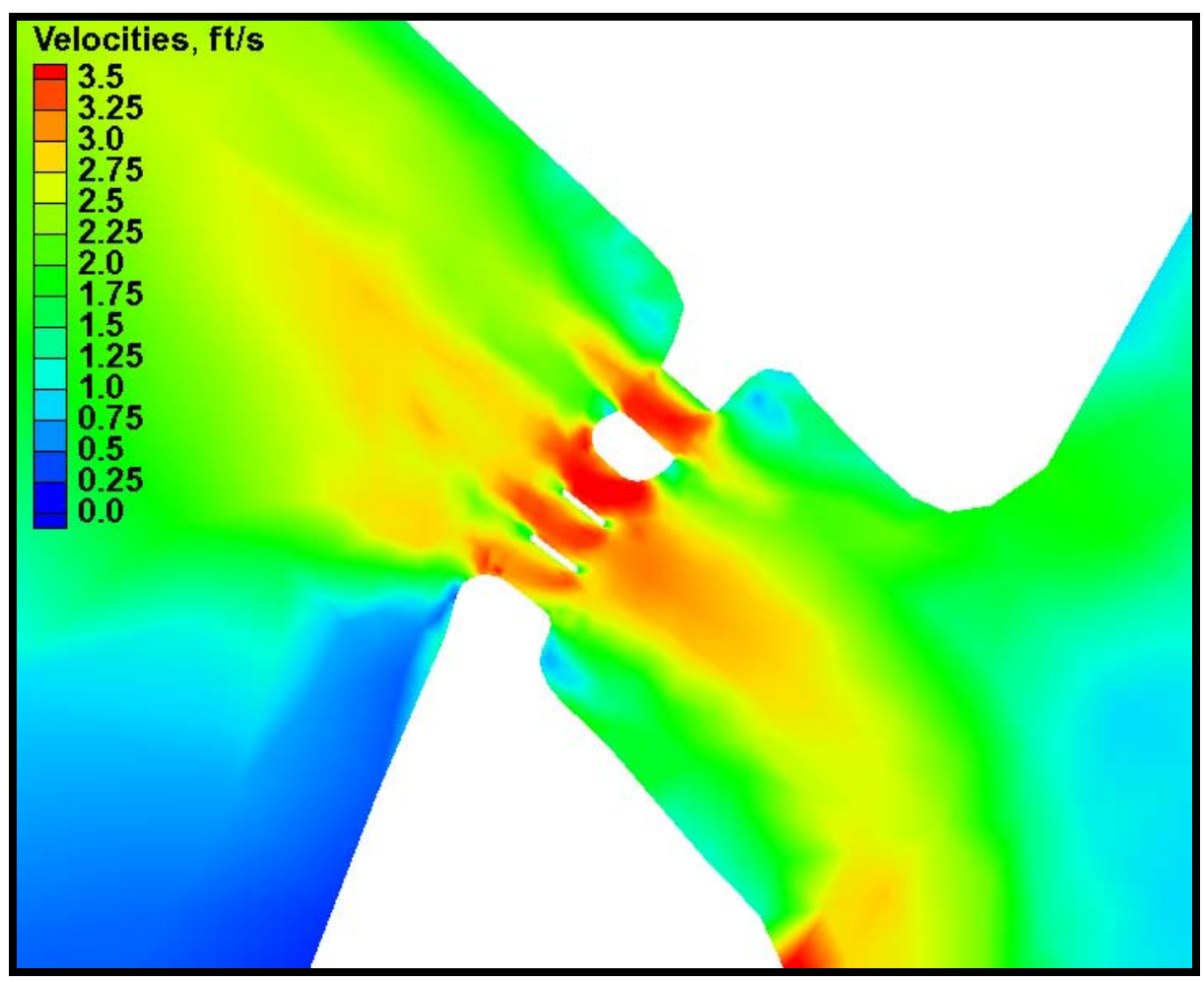

Figure 43. Maximum velocities for Alternative 5, with wind. 


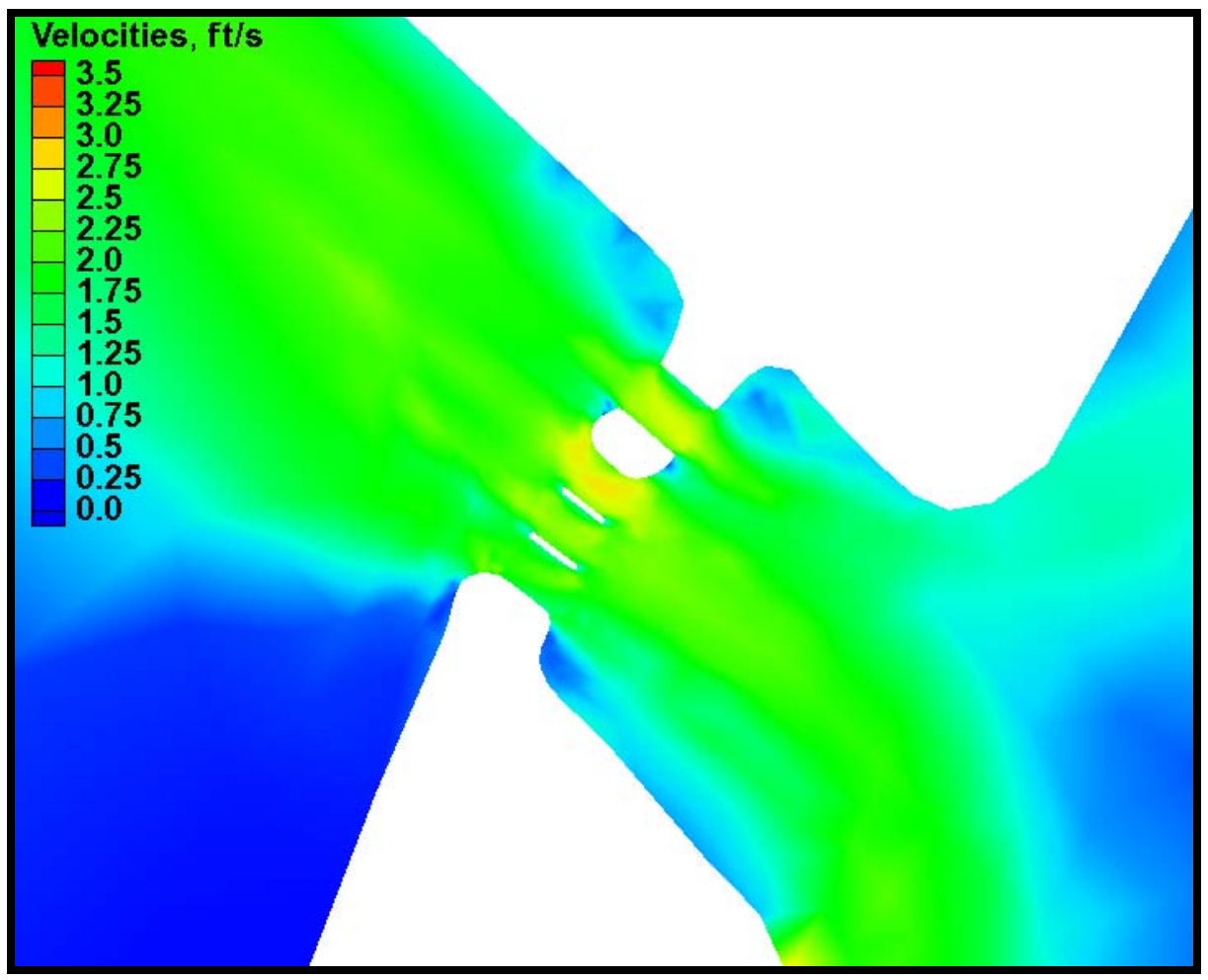

Figure $44.90^{\text {th }}$ percentile velocities for Alternative 5, without wind.

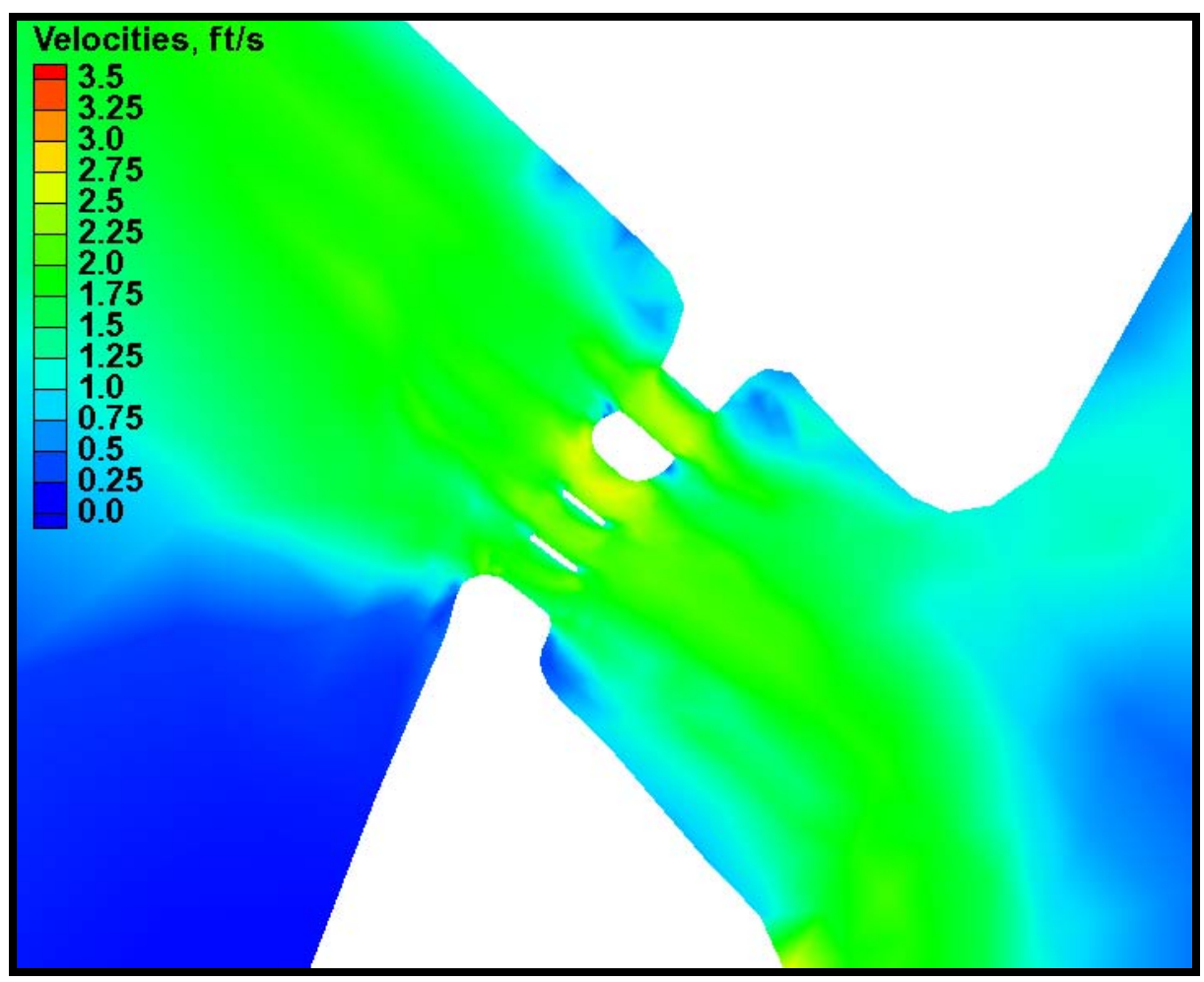

Figure $45.90^{\text {th }}$ percentile velocities for Alternative 5 , with wind. 


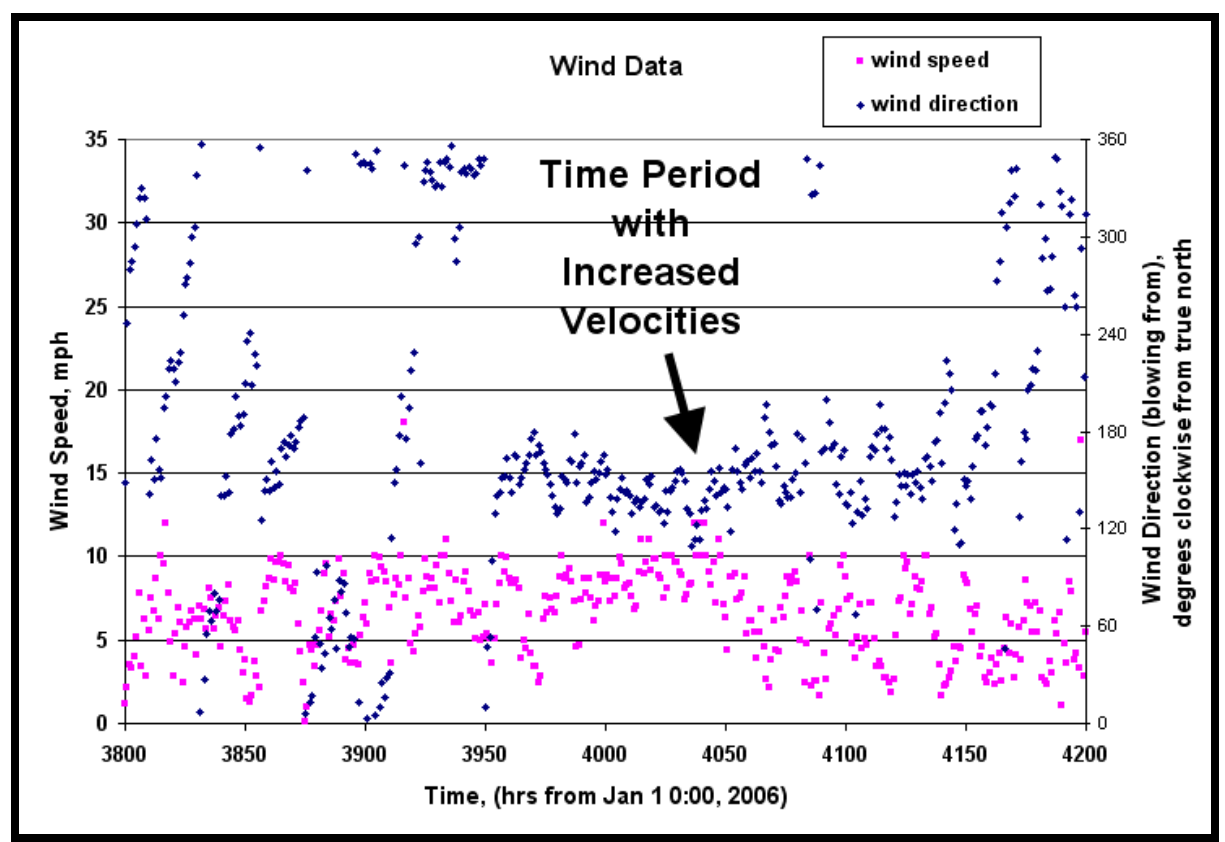

Figure 46 . Wind data during maximum velocity model results. 


\section{Conclusions}

Using the information developed in this study, New Orleans District determined that alternative 5 produced the best benefit/ cost ratio with favorable velocity results. Alternative 5 consists of a sail-through structure of $56 \mathrm{ft}$ in width and $10 \mathrm{ft}$ in depth, with three sluice gates each $46 \mathrm{ft}$ in width and $10 \mathrm{ft}$ in depth. This alternative is illustrated in Figure 47. Other alternatives produced better velocity results, but the improvement was deemed not worth the significant additional costs associated with those alternatives. It should be noted that these velocity results are highly dependent on the actual specifications of the structure design. As discussed and illustrated in Chapter 2, if the sail-through structure is more efficient than the one modeled, the velocities may be higher than those reported here for the same structure combination. Another important consideration is the effect of wind, which can be significant, but is not believed to impact the operation of the structure represented by alternative 5 in normal conditions. Significant wind events large enough to notably change the velocities are believed to be a rare occurrence.

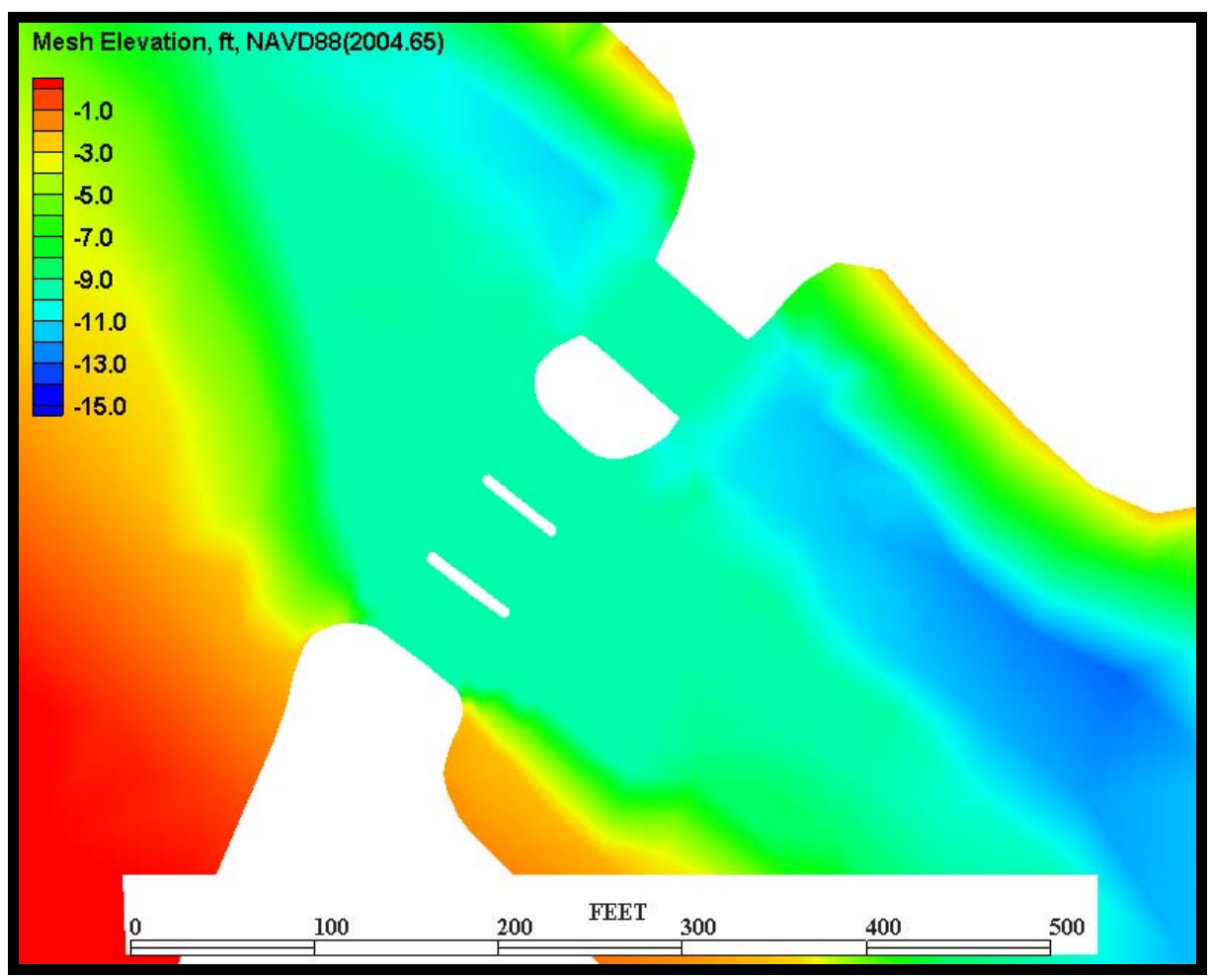

Figure 47. Alternative 5. 


\section{References}

Berger, R.C. and Lee, L.M. (2004) “Multidimensional Numerical Modeling of Surges Over Initially Dry Land", Coastal and Hydraulics Engineering Technical Report, ERDC/CHL TR-04-10. Vicksburg, MS: U.S. Army Engineering Research and Development Center.

Berger, R.C. and Stockstill, R.L. (1995). "Finite element model for high-velocity channels.” J ournal of Hydraulic Engineering ASCE, 121(10), 710- 716.

Berger, R.C. and Tate J.N. "Guidelines for Solving Two Dimensional Shallow Water Problems with the ADaptive Hydraulics (ADH) Modeling System", Engineering Research and Development Center, Vicksburg, MS. https://adh.usace.army.mil/manual_sw/adh_doc.html.

Brigham Young University, 2002, "SMS version 8.0 Reference Manual for the Surface Water Modeling System", Engineering Graphics Laboratory, Provo, Utah.

Donnell, B. P., Letter, J . V., and Teeter A. M. (1991). "The Atchafalaya River Delta, Report 11, Two-Dimensional Modeling", Hydraulics Laboratory Technical Report, HL82-15. Vicksburg, MS: U.S. Army Engineering Research and Development Center.

Flather, R. A. (1988). "A numerical model investigation of tides and diurnal-period continental shelf waves along Vancouver Island," J ournal of Physical Oceanography 18, 115-139.

LeProvost, C., and Poncet, A. (1987). "Finite Element Method for Spectral Modeling of Tides." Int. J . Num. Methods Eng., 12, 853-871. 


\section{Appendix: Description of the ADaptive Hydraulics (ADH) Model}

$\mathrm{ADH}$ is a state-of-the-art ADaptive Hydraulics Modeling system developed by the U.S. Army Engineer Research and Development Center - Coastal and Hydraulics Laboratory (ERDC-CHL). It is capable of simulating both saturated and unsaturated groundwater, overland flow, three-dimensional Navier-Stokes flow, and two- or three-dimensional shallow water problems with the current study utilizing the two-dimensional shallow water module. The 2D shallow-water equations used for this application are a result of the vertical integration of the equations of mass and momentum conservation for incompressible flow under the hydrostatic pressure assumption. Written in conservative form, the 2D shallow water equations are:

$$
\frac{\partial \mathbf{U}}{\partial t}+\frac{\partial \mathbf{F}}{\partial x}+\frac{\partial \mathbf{G}}{\partial y}+\mathbf{H}=0
$$

where

$$
\begin{gathered}
\mathbf{U}=\left\{\begin{array}{c}
h \\
u h \\
v h
\end{array}\right\} \\
\mathbf{F}=\left\{\begin{array}{c}
u h \\
\left.u^{2} h+\frac{1}{2} g h^{2}-h \frac{\sigma_{x x}}{\rho}\right\} \\
u v h-h \frac{\sigma_{y x}}{\rho}
\end{array}\right\} \\
\mathbf{G}=\left\{\begin{array}{c}
v h \\
u v h-h \frac{\sigma_{x y}}{\rho} \\
v^{2} h+\frac{1}{2} g h^{2}-h \frac{\sigma_{y y}}{\rho}
\end{array}\right\}
\end{gathered}
$$


and

$$
\mathbf{H}=\left\{\begin{array}{c}
0 \\
g h \frac{\partial z_{b}}{\partial x}+n^{2} g h \frac{u \sqrt{u^{2}+v^{2}}}{C_{o} h^{1 / 3}} \\
g h \frac{\partial z_{b}}{\partial y}+n^{2} g h \frac{v \sqrt{u^{2}+v^{2}}}{C_{o} h^{1 / 3}}
\end{array}\right\}
$$

where:

$$
\begin{array}{ll}
\rho & =\text { fluid density } \\
\mathrm{g} & =\text { gravitational acceleration } \\
\mathrm{Zb} & =\text { riverbed elevation } \\
\mathrm{n} & =\text { Manning's roughness coefficient } \\
\mathrm{h} & =\text { flow depth } \\
\mathrm{u} & =\mathrm{x} \text {-component of velocity } \\
\mathrm{v} & =\mathrm{y} \text {-component of velocity } \\
\mathrm{C}_{\mathrm{o}} & =\text { dimensional conversion coefficient (1 for SI units, } 1.486 \text { for U.S. } \\
& \quad \text { customary units) } \\
\sigma^{\prime} \mathrm{s} & =\text { the Reynolds stresses due to turbulence, where the first subscript } \\
& \quad \text { indicates the direction, and the second indicates the face on } \\
& \text { which the stress acts. }
\end{array}
$$

The Reynolds stresses are determined using the Boussinesq approach to the gradient in the mean currents:

$$
\begin{aligned}
& \sigma_{x x}=2 \rho v_{t} \frac{\partial u}{\partial x} \\
& \sigma_{y y}=2 \rho v_{t} \frac{\partial v}{\partial y}
\end{aligned}
$$

and

$$
\sigma_{x y}=\sigma_{y x}=2 \rho v_{t}\left(\frac{\partial u}{\partial y}+\frac{\partial v}{\partial x}\right)
$$

where $\mathrm{v}_{\mathrm{t}}=$ kinematic eddy viscosity (which varies spatially). 
The ADH shallow-water equations are placed in conservative form so that mass balance and the balance of momentum and pressure are identical across an interface. This is important in order to match the speed and height of a surge or hydraulic jump.

The equations are represented in a finite element approach. The quality of the numerical solution depends on the choice of the basis/trial function and the test function. The trial function determines how the variables are represented and the test function determines the manner in which the differential equation is enforced. In the Galerkin approach the test functions are chosen to be identical with the trial functions. When the flow is advection-dominated, the Galerkin approach produces oscillatory behavior. The Galerkin form of the test function cannot detect the presence of a node-tonode oscillation and so allows this spurious solution. The approach used in $\mathrm{ADH}$ is to enrich the standard Galerkin test function with an additional term that can detect and control this spurious solution.

This Petrov-Galerkin method used here is based on elemental constants for coefficients. This reduces the stabilization to the nonconservative form. This is not a problem for conservation since the stabilization is only applied within the elements and uses the Galerkin test function to enforce "flux" balance across element edges. For illustration, consider the shallowwater equations in nonconservative form

$$
\frac{\partial U}{\partial t}+A \frac{\partial U}{\partial x}+B \frac{\partial U}{\partial y}+H=0
$$

where $A=\frac{\partial F}{\partial U}$ and $B=\frac{\partial G}{\partial U}$. The trial functions (or interpolation/ basis functions) are the Lagrange polynomials. These are piecewise linear functions that are continuous across element boundaries. Spatial derivatives, however, are not continuous across these element edges. Each of the dependent and independent variables is interpolated via these trial functions. For example,

$$
\tilde{u}(x)=\sum_{j=1}^{N} \phi_{j}(x) u_{j}
$$


means that the approximate solution is made up of the sum of the products of the trial function for nodej and the nodal value at that location. The test function is chosen as:

$$
\phi_{i}^{*}=\phi_{i} I+\alpha\left(\frac{\partial \phi_{i}}{\partial x} A+\frac{\partial \phi_{i}}{\partial y} B\right)
$$

where,

$$
\alpha=0.5 l\left[\bar{v} \cdot \bar{v}+g h+\left(\frac{l}{\Delta t}\right)^{2}\right]^{-1 / 2}
$$

and

$$
\begin{aligned}
l & =\left(\Omega_{\mathrm{e}}\right)^{1 / 2}, \text { the square of the element area } \\
\bar{v} & =(\bar{u}, \bar{v}), \text { the element average velocity components } \\
\Delta t & =\text { time step size. }
\end{aligned}
$$

The finite element statement becomes:

$$
\begin{gathered}
\int_{\Omega}\left(\phi_{i} \frac{\partial U_{l}}{\partial t}-\frac{\partial \phi_{i}}{\partial x} F_{l}-\frac{\partial \phi_{i}}{\partial y} G_{l}+\phi_{i} H_{l}\right) d \Omega+ \\
\int_{\partial \Omega} \phi_{i}\left\{F_{l} n_{x}+G_{l} n_{y}\right\} d s+\sum_{e} \int_{\Omega_{e}} \alpha\left(\frac{\partial \phi_{i}}{\partial x} A_{l}+\frac{\partial \phi_{i}}{\partial y} B_{l}\right) \\
\left(\frac{\partial U_{l}}{\partial t}+A_{l} \frac{\partial U_{l}}{\partial x}+B_{l} \frac{\partial U_{l}}{\partial y}+H_{l}\right)=0
\end{gathered}
$$

where the subscript $l$ indicates the finite element approximation. The Petrov-Galerkin contributions are integrated over the interior of the elements, but not across element edges. This contribution stabilizes the Galerkin approach. This scheme utilizes a single scaling factor, $\alpha$. This is different from the scheme reported in Berger and Stockstill (1995). That scheme involved scaling each eigenvalue, but that method does not converge using the iterative solver in $\mathrm{ADH}$. Instead, a single value scaling (Equation 12) is used.

One of the major benefits of $\mathrm{ADH}$ is its ability to adapt the mesh in areas where additional resolution is needed to properly resolve the hydrodynam- 
ics. This process is done by normalizing the results so that an error quantity is determined for each element. If this error exceeds the tolerance set by the user, then the element is refined. ADH is also able to unrefined previously refined areas when the added resolution is no longer needed. $\mathrm{ADH}$ contains other essential features such as wetting and drying, completely coupled sediment and salt transport, and wind effects. A series of modularized libraries make it possible for $\mathrm{ADH}$ to include vessel movement, friction descriptions, as well as a host of other crucial features. ADH can run in parallel or on a single processor and runs on both Windows systems and UNIX based systems. 


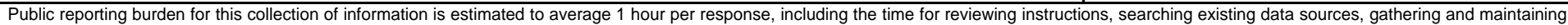

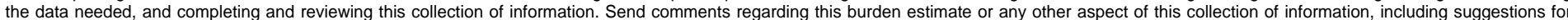

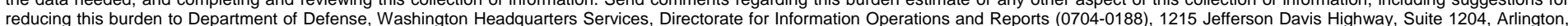

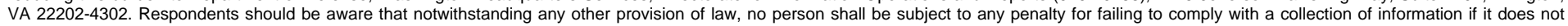
display a currently valid OMB control number. PLEASE DO NOT RETURN YOUR FORM TO THE ABOVE ADDRESS.
1. REPORT DATE (DD-MM-YYYY)
2. REPORT TYPE
3. DATES COVERED (From - To)

July 2009

4. TITLE AND SUBTITLE

Final

Bush Canal Floodgate Study

5a. CONTRACT NUMBER

5a. CONTRACT NUMBER

5b. GRANT NUMBER

5c. PROGRAM ELEMENT NUMBER

6. AUTHOR(S)

Tate O. McAlpin, Rutherford C. Berger, and Amena M. Henville

5d. PROJECT NUMBER

5e. TASK NUMBER

MIPR W42HEM60734548

5f. WORK UNIT NUMBER

7. PERFORMING ORGANIZATION NAME(S) AND ADDRESS(ES)

U.S. Army Engineer Research and Development Center

Coastal and Hydraulics Laboratory

8. PERFORMING ORGANIZATION REPORT NUMBER

3909 Halls Ferry Road

ERDC/CHL TR-09-9

Vicksburg, MS 39180

\section{SPONSORING I MONITORING AGENCY NAME(S) AND ADDRESS(ES)}

U.S. Army Engineer District New Orleans

7400 Leake Ave.

New Orleans, LA 70118-3651

10. SPONSOR/MONITOR'S ACRONYM(S)

MVN

11. SPONSOR/MONITOR'S REPORT NUMBER(S)

\section{DISTRIBUTION / AVAILABILITY STATEMENT}

Approved for public release; distribution is unlimited.

\section{SUPPLEMENTARY NOTES}

\section{ABSTRACT}

The ADaptive Hydraulics model, ADH, was used to investigate the circulation tendencies in and around Bush Canal by utilizing its two-dimensional shallow-water module. This study characterizes existing water levels and currents in the vicinity of Bush Canal and predicts any potential impacts that may result from the construction of a structure in Bush Canal near its junction with Bayou Terrebonne. Comparing model-generated currents and water-surface elevations between pre- and post-construction conditions provides insight into whether a particular alternative will adversely impact velocity conditions. ADH was used to develop time series of current fields for the base and plan conditions.

\section{SUBJECT TERMS}

ADaptive Hydaulics (ADH) model, Bush Canal, Bayou Terrebonne, Bayou Petit Caillou, Morganza to the Gulf of Mexico

\begin{tabular}{|c|c|c|}
\hline \multicolumn{3}{|c|}{ 16. SECURITY CLASSIFICATION OF: } \\
\hline a. REPORT & b. ABSTRACT & c. THIS PAGE \\
\hline Unclassified & Unclassified & Unclassified \\
\hline
\end{tabular}

17. LIMITATION
OF ABSTRACT

\section{NUMBER} OF PAGES

48

\section{9a. NAME OF RESPONSIBLE} PERSON

19b. TELEPHONE NUMBER (include area code) 